\title{
MONITORING AND DATA-LOGGING FOR STAND-ALONE AND GRID-TIED PHOTOVOLTAIC SYSTEMS
}

\author{
A Thesis \\ presented to \\ the Faculty of California Polytechnic State University, \\ San Luis Obispo
}

\author{
In Partial Fulfillment \\ of the Requirements for the Degree \\ Master of Science in Electrical Engineering
}

by

Nathan Hara

June 2013 
(C) 2013

Nathan Hara

ALL RIGHTS RESERVED

Page ii 


\section{COMMITTEE MEMBERSHIP}

TITLE: $\quad$ Monitoring and Data-Logging for Stand-Alone and GridTied Photovoltaic Systems

AUTHOR: $\quad$ Nathan Hara

DATE SUBMITTED: June 2013

COMMITTEE CHAIR: $\quad$ Dr. Dale Dolan, Assistant Professor Electrical Engineering Department

COMMITTEE MEMBER: Dr. James Harris, Professor

Electrical Engineering Department

COMMITTEE MEMBER: Dr. Taufik, Professor

Electrical Engineering Department 


\begin{abstract}
Monitoring and Data-Logging for Stand-Alone and Grid-Tied Photovoltaic Systems Nathan Hara

This thesis presents the topic of various monitoring and data-logging tools for stand-alone and grid-tied photovoltaic systems. The first part of this report describes the research, testing, and installation of a monitoring system for a stand-alone photovoltaic system created by students of California Polytechnic State University at San Luis Obispo for the 2005 Solar Decathlon. Analysis of the real-time data of the Solar Decathlon House resulted in the discovery of issues within the software of the monitoring system and within the battery bank of the photovoltaic system. The second part of this report gives a detailed description of possible monitoring systems for three different types of grid-tied photovoltaic systems that a possible upcoming project by Cal Poly students could use. System analysis, component analysis, and cost analysis are provided for each proposed grid-tied system. It is concluded that a monitoring system can be chosen only after the full design of the grid-tied system because of the various advantages and disadvantages of each type of photovoltaic system.
\end{abstract}




\section{ACKNOWLEDGEMENTS}

First off, I would like to thank my family for supporting through way too many years of school. I would also like to thank my friends for keeping me sane and giving me distractions for all these years. Thank you to Dr. Dolan for advising me throughout my thesis and to Dr. Harris and Dr. Taufik for agreeing to be on my thesis committee.

Finally, I would like to thank all of my teachers throughout the years. I may have learned more from some (Math and Engineering Teachers) and less from others (English and General Education Teachers), but I did at least learn a little from all of you. For that, I am extremely grateful. 


\section{TABLE OF CONTENTS}

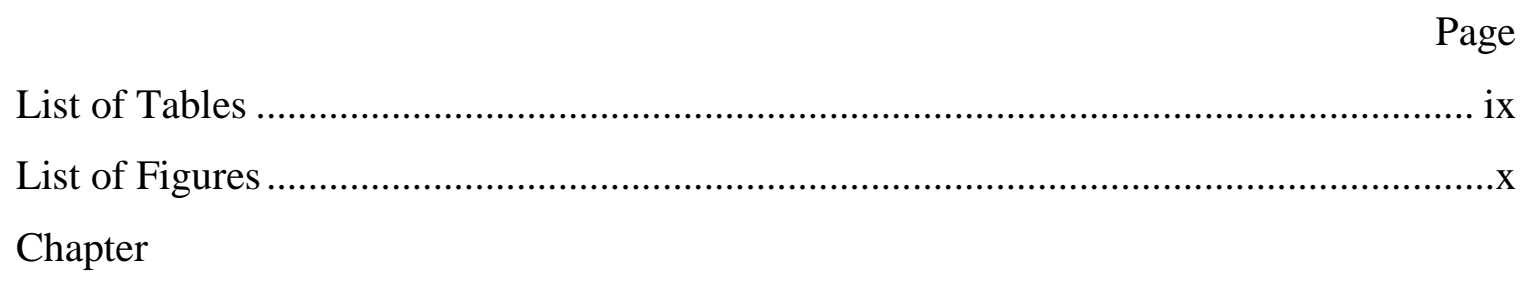

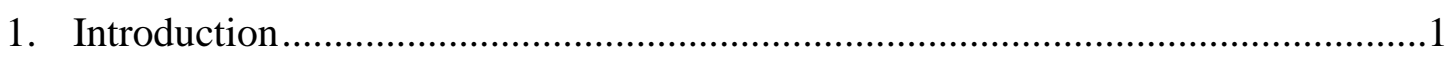

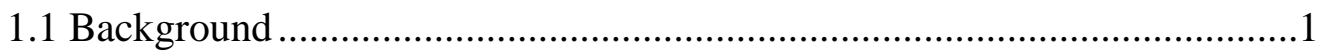

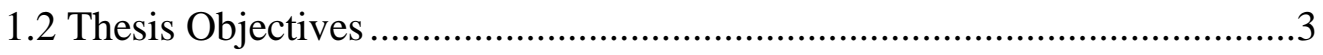

1.3 Document Overview ................................................................... 3

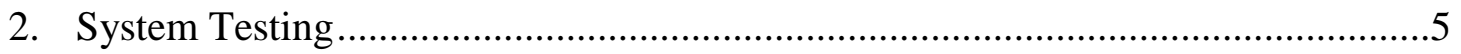

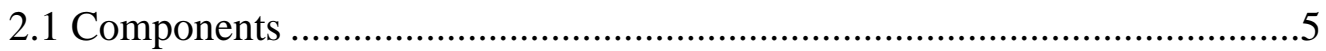

2.1.1 Photovoltaic Module ...................................................................5

2.1.2 OutBack MX-60 MPPT-CC ....................................................6

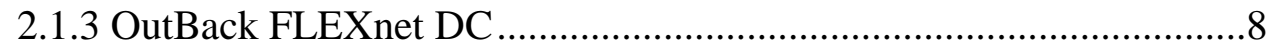

2.1.4 OutBack MATE2 ….................................................................8

2.1.5 OutBack HUB10 ...................................................................... 9

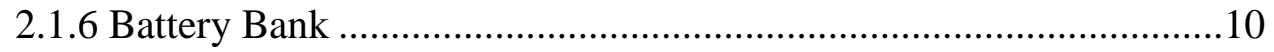

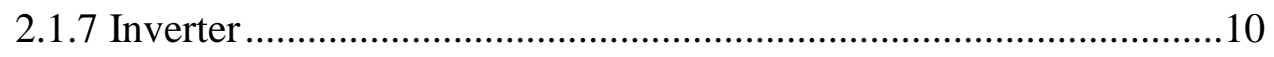

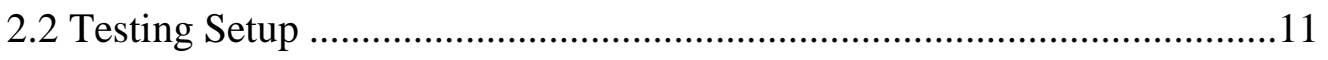

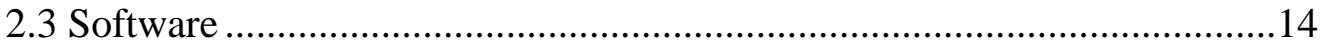

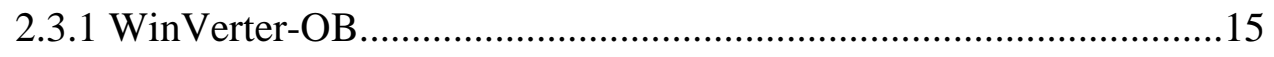

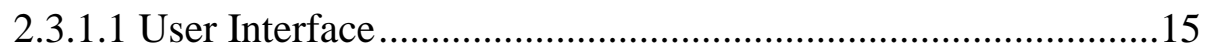

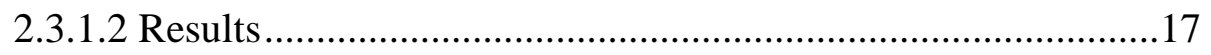

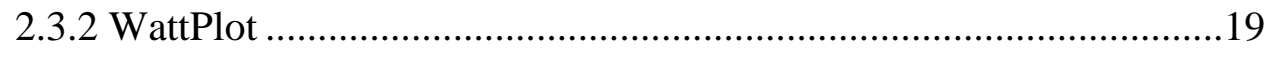

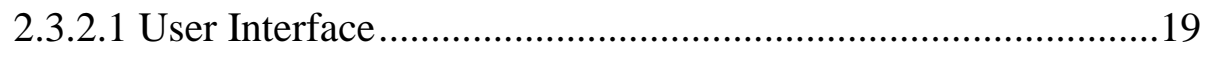

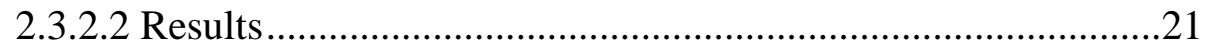

2.3.2.3 Extra Features ..............................................................25

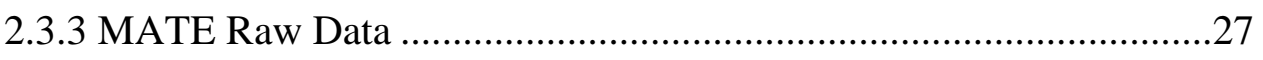

Page vi 


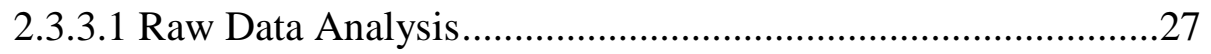

2.3.3.2 Excel Script and Results ....................................................33

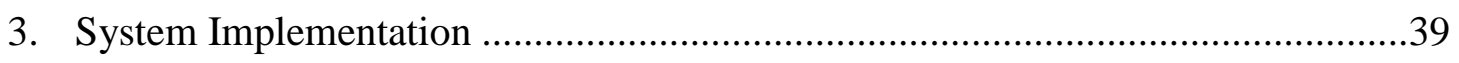

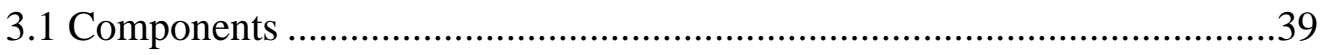

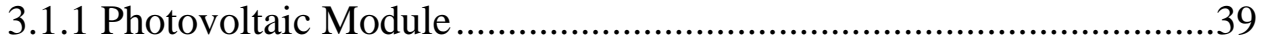

3.1.2 OutBack Power System Components ..........................................40

3.1.3 Battery Bank .......................................................................42

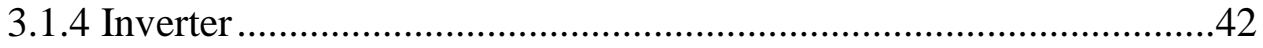

3.2 Solar Decathlon House Layout .......................................................43

3.3 Remote Monitoring Setup .............................................................46

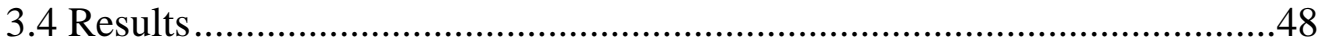

3.4.1 Results on Primary Computer .......................................................48

3.4.2 Results on Secondary Computer ...............................................52

3.4.3 Excel Results Using Logged Raw Data ......................................54

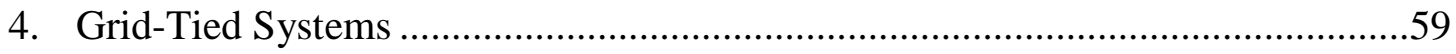

4.1 Battery Backed Grid-Tied System ................................................60

4.1.1 Component Analysis ............................................................61

4.1.2 Monitoring Analysis ..............................................................62

4.1.3 Cost Analysis ...................................................................63

4.2 Non-Battery Backed Grid-Tied System.............................................64

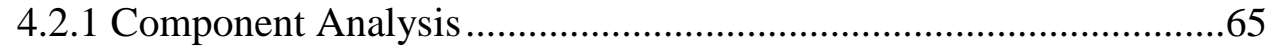

4.2.2 Monitoring Analysis ................................................................66

4.2.3 Cost Analysis .........................................................................68

4.3 Microinverter Based Grid-Tied System...............................................68

4.3.1 Component Analysis ............................................................. 70

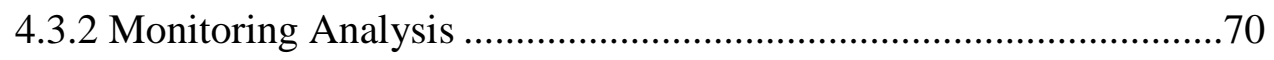

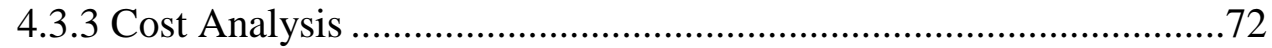

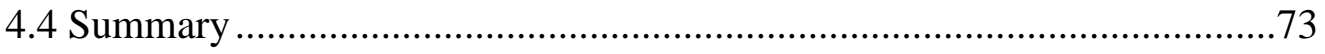

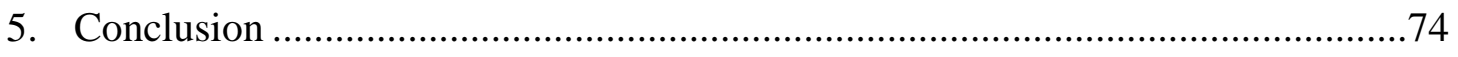

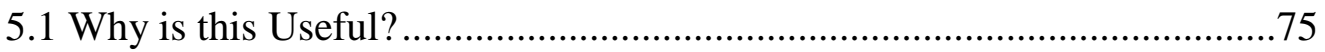




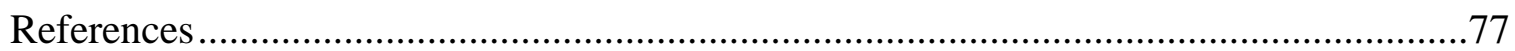

Appendix A: Solar Decathlon House Electrical Report Images .......................................79

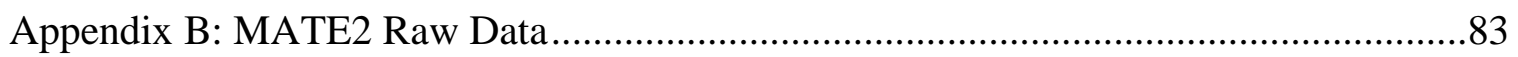

Appendix C: Excel Script for Test Setup .......................................................................85

Appendix D: Excel Script for Solar Decathlon House ………………………...............91

Appendix E: Download and Setup Instructions for WattPlot Monitor................................99 


\section{LIST OF TABLES}

Page

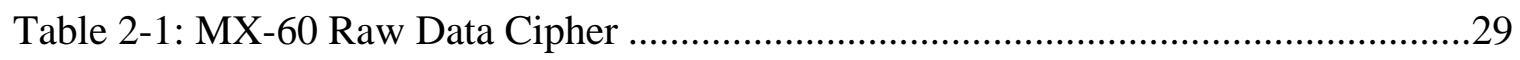

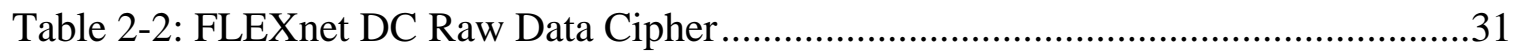

Table 2-3: Charge Controller \#1 Data for Test Setup from Excel Script .........................36

Table 2-4: FLEXnet DC \#1 Data for Test Setup from Excel Script ................................38

Table 3-1: Charge Controller \#1 Data for the Solar Decathlon House ..............................55

Table 3-2: Charge Controller \#2 Data for the Solar Decathlon House .............................56

Table 3-3: FLEXnet DC Data for the Solar Decathlon House .......................................57

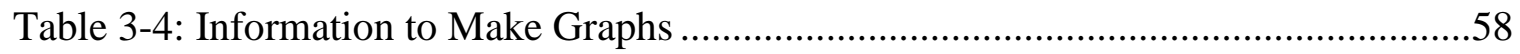

Table 4-1: Cost Analysis of Battery Back Grid-Tied System......................................63

Table 4-2: Cost Analysis for Non-Battery Backed Grid-Tied System ...........................68

Table 4-3: Cost Analysis for the Microinverter Based System ....................................72

Table B-1: MATE2 Raw Data from Test Setup ...................................................83

Table B-2: MATE2 Raw Data from Solar Decathlon House .........................................84 


\section{LIST OF FIGURES}

Page

Figure 1-1: Cal Poly's 2005 Solar Decathlon House .....................................................2

Figure 2-1: NXT-20e Solar Panel by Next Solar Systems ............................................6

Figure 2-2: Maximum Power Point Tracking on an I-V Curve ......................................

Figure 2-3: OutBack MX-60 MPPT-CC.................................................................

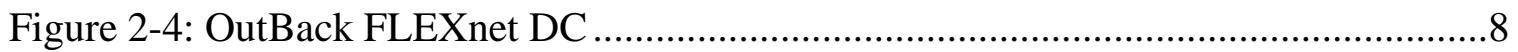

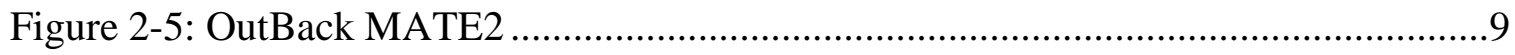

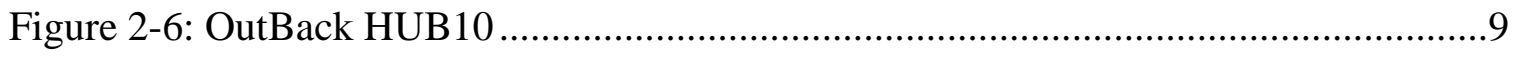

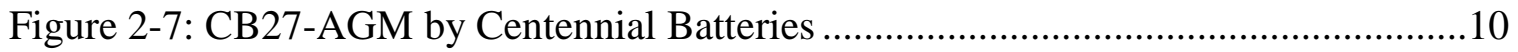

Figure 2-8: Samlex Pure Sine Wave Power Inverter ...............................................11

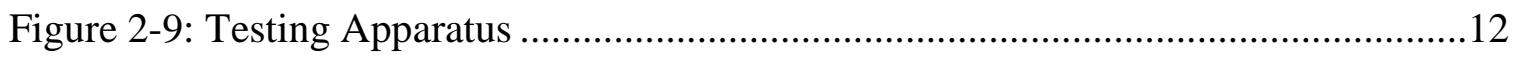

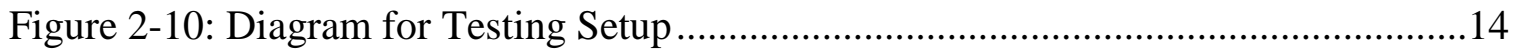

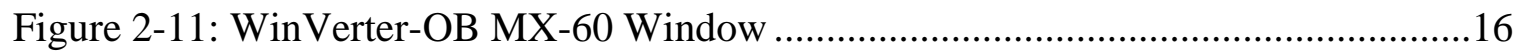

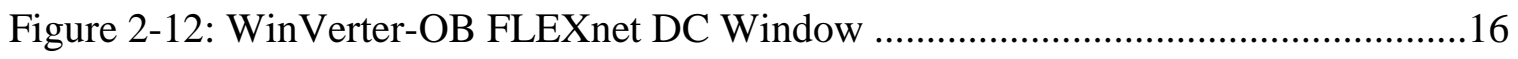

Figure 2-13: MX-60 MPPT-CC Data for System with 200W Load................................17

Figure 2-14: FLEXnet DC Data for System with 200W Load .....................................17

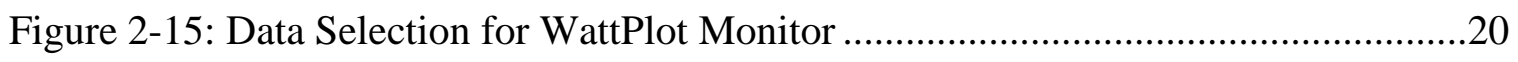

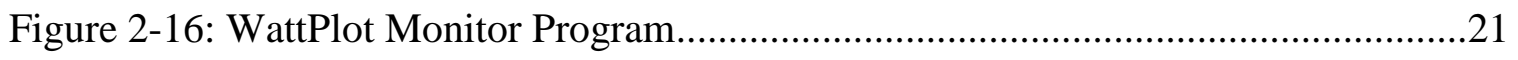

Figure 2-17: Real-Time Numeric Data from WattPlot Monitor....................................22

Figure 2-18: General Log Sub-Window from WattPlot Monitor ...................................23

Figure 2-19: Charge Controller Pen Plot for WattPlot Monitor ....................................23

Figure 2-20: FLEXnet DC Pen Plot for WattPlot Monitor............................................24

Figure 2-21: FLEXnet DC Accumulated Values for WattPlot Monitor..........................25

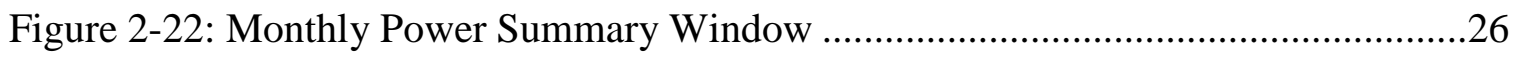

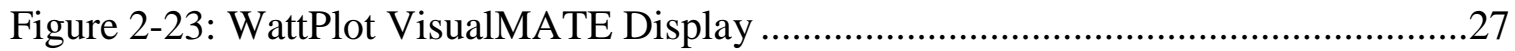

Figure 3-1: (a) BP 4175 Solar Panel (b) BP 4175 I-V Curves......................................40

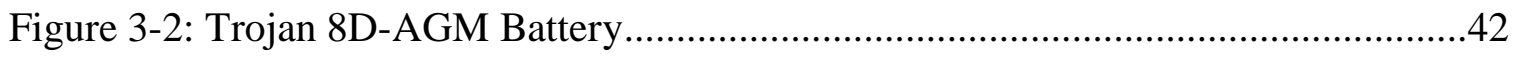




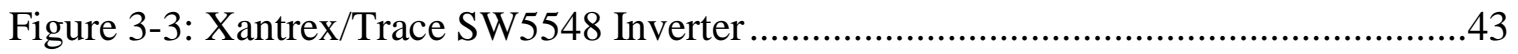

Figure 3-4: Component Layout of the Solar Decathlon House ......................................44

Figure 3-5: Battery Bank of the Solar Decathlon House ...............................................44

Figure 3-6: Complete Diagram for Solar Decathlon House ...........................................46

Figure 3-7: WattPlot as a TCP/IP Server Window ....................................................47

Figure 3-8: Real-Time Numeric Values from the MX-60's and FLEXnet DC ................50

Figure 3-9: Pen Plots for Both Charge Controllers.........................................................51

Figure 3-10: a) FLEXnet DC Numeric Results b) FLEXnet DC Pen Plot Results ...........52

Figure 3-11: a) Total Numeric Data, b) Both MX-60 Pen Plots, c) FLEXnet DC Numeric Results, d) FLEXnet DC Pen Plot......................................................53

Figure 4-1: Battery Backed Grid-Tied System .......................................................61

Figure 4-2: Non-Battery Backed Grid-Tied System .................................................64

Figure 4-3: System Overview for Sunny Portal...................................................67

Figure 4-4: Daily Energy and Power Overview for Sunny Portal ................................67

Figure 4-5: Microinverter Based Grid-Tied System Block Diagram .............................69

Figure 4-6: Enlighten's Overview Display ............................................................

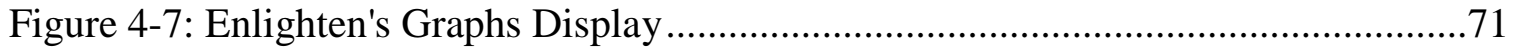

Figure 4-8: Enlighten's Environmental Benefits Display ..........................................72

Figure A-1: Photovoltaic System Block Diagram ..................................................

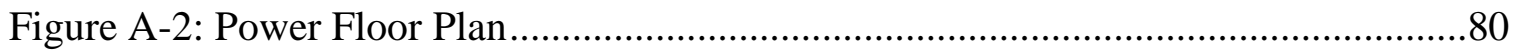

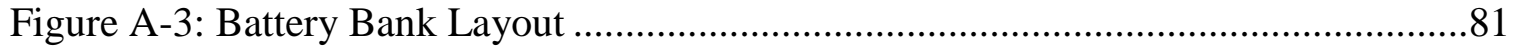

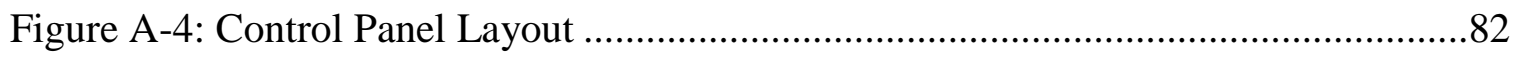




\section{Introduction}

\subsection{Background}

Within the past decade, there has been a boom in the renewable energies market and more specifically with photovoltaic energy. In even more recent years, there have been examples of the federal government giving incentives "that might reduce the cost of a PV system by 50\%" [1, p. 387] and state governments passing laws to increase renewable energy production. In 2008, former California Governor Schwarzenegger signed into law Executive Order \#S-14-08 which states: "That the following Renewable Portfolio Standard target is hereby established for California: All retail sellers of electricity shall serve 33 percent of their load with renewable energy by 2020" [2]. Because of incentives and laws such as these, a growing number of photovoltaic systems are being installed on both residential and industrial levels. Without a monitoring system, the owner cannot know how much energy is being stored into a battery bank from the solar panels for a stand-alone system or how much power is being given to or

taken from the grid for a grid-tied system. With the addition of a monitoring system, it is possible to know the power flow through the battery bank and its state of charge for a stand-alone system, or if it is a grid-tied system, the effects that all the grid-tied systems are having on the grid itself can be determined.

In 2005, an interdisciplinary group of Cal Poly students entered a competition sponsored by the Department of Energy called the Solar Decathlon. The main challenge was to build an energy-efficient, completely solar-powered home that would be featured 
in a "solar village" in the National Mall of Washington, D.C. The contestants, which consisted of seventeen other groups and universities, were scored on architecture, dwelling, documentation, communications, comfort zone, appliances, hot water, lighting, energy balance, and getting around. The final product of Cal Poly's entry can be seen in Figure 1-1. Appendix A shows the original electrical documentation created by $\mathrm{Cal}$ Poly's Solar Decathlon team [3].

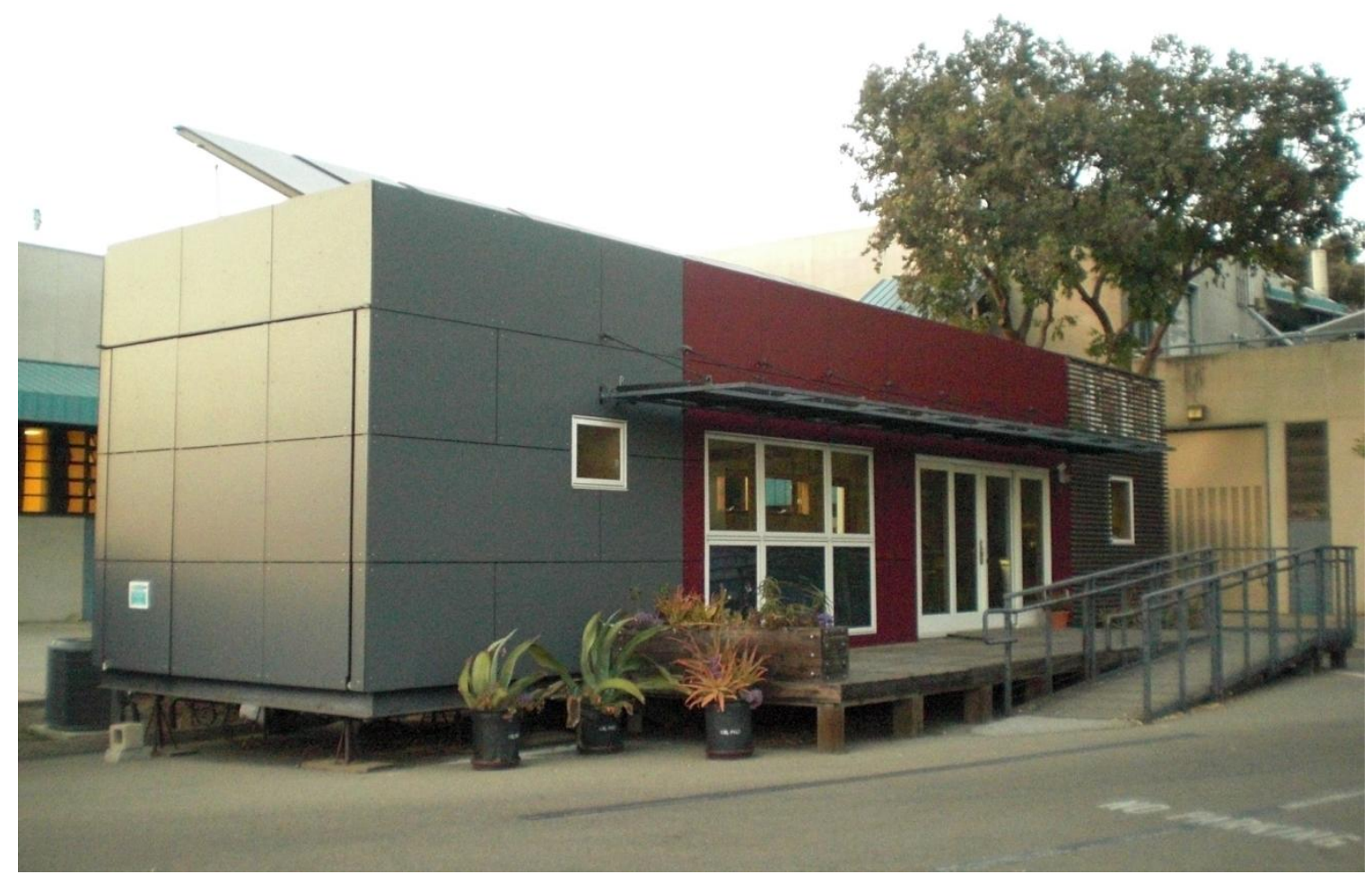

Figure 1-1: Cal Poly's 2005 Solar Decathlon House

When the competition finally concluded, Cal Poly's team did very well, placing third overall in the field of eighteen. The Cal Poly team also took first place in both appliances and lighting and second place in both architecture and dwelling. As of right now, Cal Poly's Solar Decathlon House sits in parking lot C7 on Cal Poly's campus. Its main loads are a charging station for electric vehicles, occasional club meetings, and 
tours of the Solar Decathlon House when appliances are turned on. Unfortunately, currently, there is no system in place to monitor the system as a whole.

\subsection{Thesis Objectives}

The main objective of this thesis is to inform the public about monitoring and data-logging stand-alone and grid-tied photovoltaic systems. To accomplish this, an indepth analysis of setting up a monitoring system for a stand-alone photovoltaic system and proposals of a monitoring system for a grid-tied photovoltaic system are provided. For the stand-alone system, three monitoring options are explored: two are commercially available programs and one is an Excel script that can be used to customize what data is displayed using the OutBack MATE2's raw data. For the grid-tied system, three gridtied systems are proposed with their own monitoring methods. By the end of this thesis, the reader should have adequate knowledge of how to monitor a photovoltaic system.

\subsection{Document Overview}

Chapter 2 discusses the testing setup that is being used to understand how the monitoring system works prior to installation at the main site, the Solar Decathlon House. It begins with a description of the components that are being used within the testing setup and what each component does. It then gives a description of how all of the connections are made on the testing setup.

The second half of Chapter 2 focuses on the monitoring software. It describes the user interface and results from two different, commercially-available programs that were tested: WinVerter-OB and WattPlot. Then, it describes the analysis and programming of 
an Excel script that utilizes the MATE's raw data to create a custom display to present the system's data.

Chapter 3 describes the process in installing the monitoring system into the Solar Decathlon House. It describes the different components used in the Solar Decathlon House as compared to the testing setup. Next, it discusses the results from the monitoring system utilizing WattPlot and the Excel script. Finally, it explains the set up using WattPlot in its remote monitoring configuration along with results from the remote monitoring data.

Chapter 4 addresses the design of a monitoring system for a grid-tied photovoltaic system. It discusses the difference between a stand-alone and grid-tied system. Finally, it evaluates three possible grid-tied systems through component analysis, monitoring analysis, and cost analysis.

Chapter 5 wraps up this thesis with a brief overview of the topics covered. It then gives reasons why these topics are currently important and applicable. Finally, it concludes with some improvements that can be made. 


\section{System Testing}

Before installing the monitoring system on the Solar Decathlon House, a test system was created to ensure full knowledge of how the monitoring system would function. The test setup consisted of a 200W solar panel, an OutBack MX-60 Maximum Power Point Tracking Charge Controller (MPPT-CC), an OutBack FLEXnet DC, an OutBack MATE2, an OutBack HUB10, a Samlex Power Inverter, and a single 12V battery. Once the test system was setup, three methods of system monitoring were incorporated through a computer and analyzed.

\subsection{Components}

Section 2.1 is a comprehensive list of the components used for the test setup. It also briefly discusses the function of each component.

\subsubsection{Photovoltaic Module}

The photovoltaic module or solar panel that is being utilized for the test setup is a NXT-20e solar panel with 60 solar cells from Next Solar Systems, as seen in Figure 2-1. Its nominal maximum power output is $200 \mathrm{~W}$ with an open circuit voltage of $36.2 \mathrm{~V}$ and short circuit current of 7.68A. Its nominal operating voltage and current are $28.9 \mathrm{~V}$ and 6.93A respectively [4]. It is being tapped off of a previous senior project which used the solar panel in a photovoltaic system tester. 

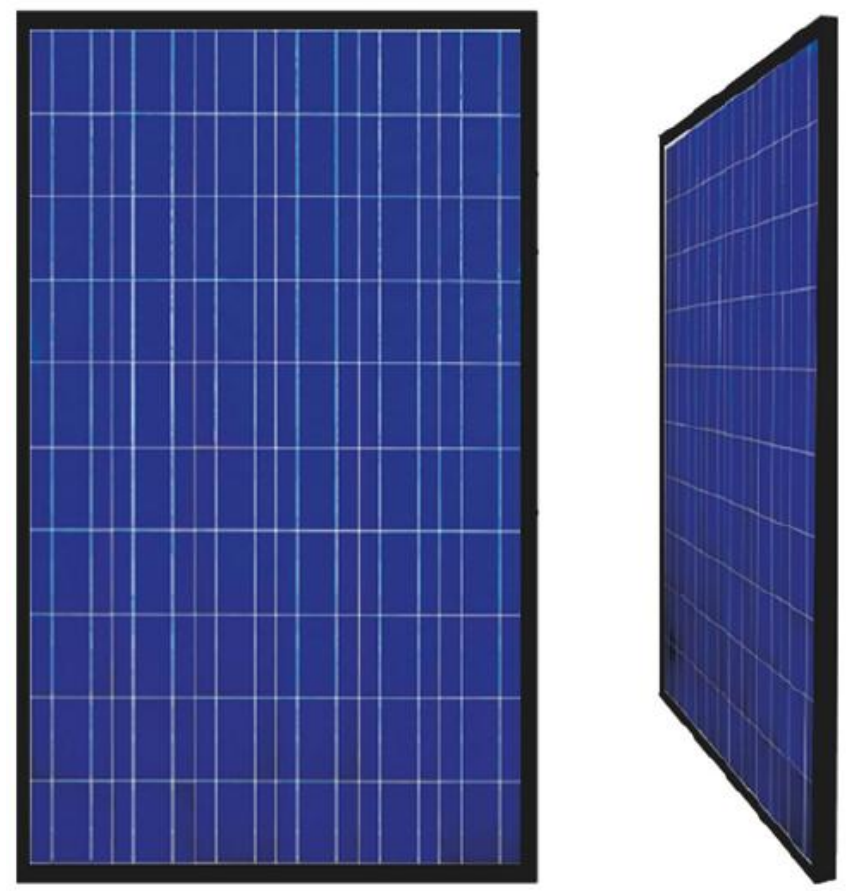

Figure 2-1: NXT-20e Solar Panel by Next Solar Systems [4]

\subsubsection{OutBack MX-60 MPPT-CC}

The purpose of a maximum power point tracker is to output the maximum amount of power from the photovoltaic array at all times. Throughout the day, there are variations in the voltage and current outputs of the photovoltaic array due to variations in the irradiance. This causes changes to the array's I-V curve. A maximum power point tracker utilizes the formula, power is equal to voltage times current:

$$
\mathrm{P}=\mathrm{IV}
$$

and finds the optimal voltage and current to output the maximum amount of power. Figure 2-2 shows an example of the change in output power in comparison to an I-V curve. 


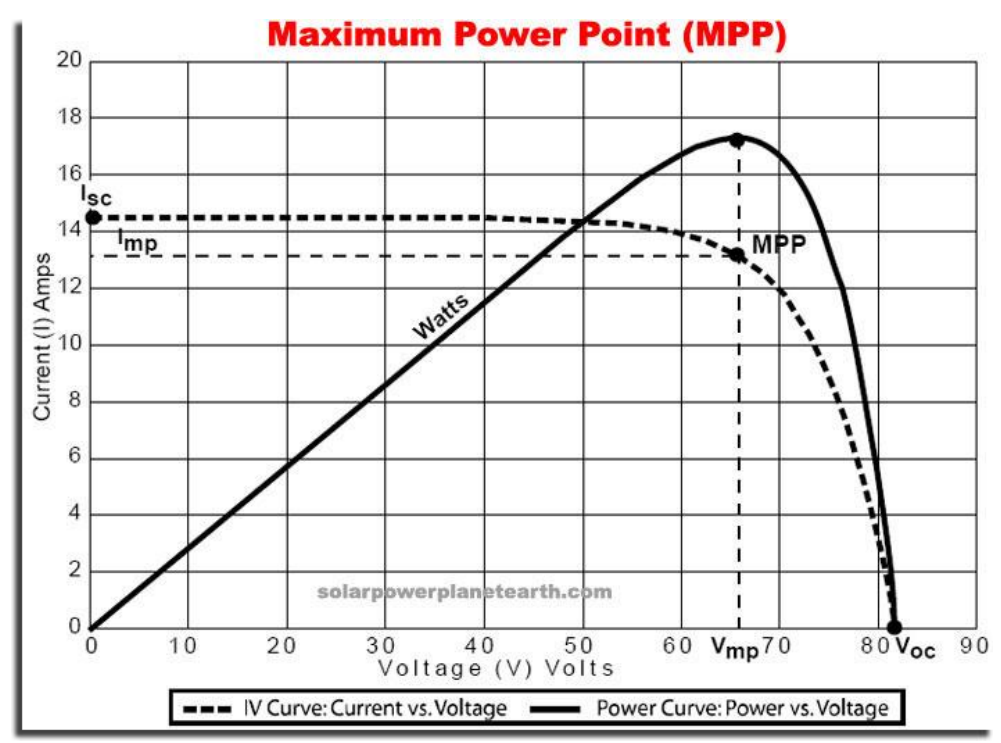

Figure 2-2: Maximum Power Point Tracking on an I-V Curve [5]

The maximum power point tracking charge controller used for the test setup is a MX-60 MPPT-CC, as seen in Figure 2-3. It is rated for up to an output of $60 \mathrm{~A}_{\mathrm{DC}}$ and is compatible with battery systems ranging from $12 \mathrm{~V}$ to $60 \mathrm{~V}$. The user is able to use a higher PV array voltage than battery bank voltage in order to ensure that the MX-60's voltage is above the battery voltage even when the PV array is not running at its optimal level [6].

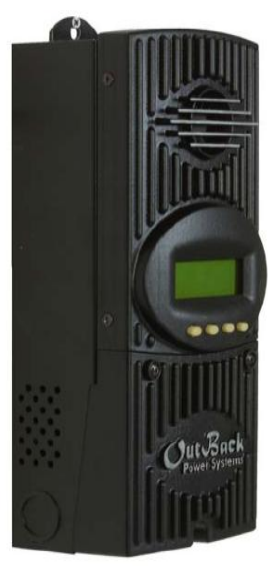

Figure 2-3: OutBack MX-60 MPPT-CC [6] 


\subsubsection{OutBack FLEXnet DC}

The FLEXnet DC, as shown in Figure 2-4, is a battery monitoring device. It is able to record and display current, power, and voltage for a battery bank through the OutBack MATE2, which allows for precise battery charging. It also has an LED array to display state of charge of the battery bank directly on the FLEXnet DC. The main function of the FLEXnet DC in this system will be to read the current through up to three 500A, $50 \mathrm{mV}$ shunts placed in various positions in the system. This data will show the amount of current and direction of the current through the shunt [7].

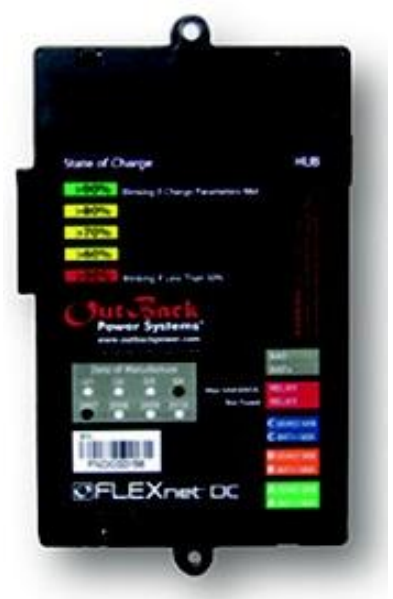

Figure 2-4: OutBack FLEXnet DC [8]

\subsubsection{OutBack MATE2}

The MATE2, as seen in Figure 2-5, can display the data sent from OutBack products used in a photovoltaic system. It can also be used to send commands to change the settings of the OutBack products connected to it. If it is used in coordination with the HUB10, it can "coordinate system operation, maximize performance, and prevent multiple products from conflicting" [9]. It is the main control for a photovoltaic system 
which utilizes OutBack products. Most importantly, it is the component that sends the data from the system to a computer [9].

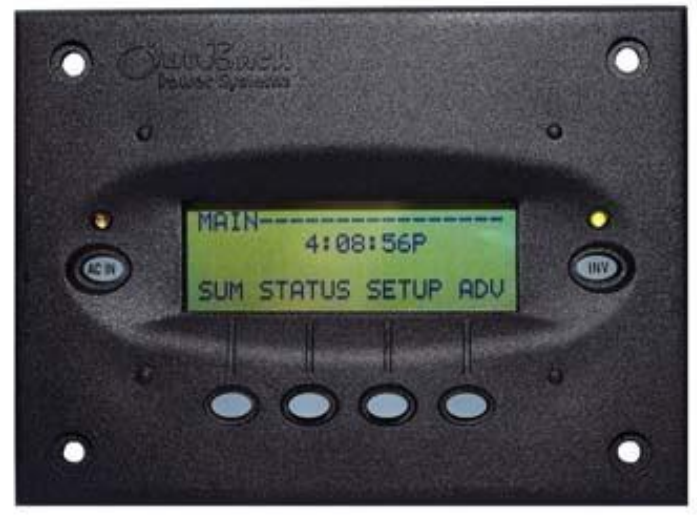

Figure 2-5: OutBack MATE2 [10]

\subsubsection{OutBack HUB10}

The HUB10, as seen in Figure 2-6, is a communications manager for OutBack products. It enables the communication lines from up to ten OutBack products to combine in a single point. It then sends the data from all of the devices to either one or two OutBack MATEs. Therefore, instead of have a single MATE for every OutBack device, the user can have one MATE for up to ten OutBack devices. There must be at least one OutBack inverter or maximum power point tracking charge controller connected to the HUB10 in order to power it [11].

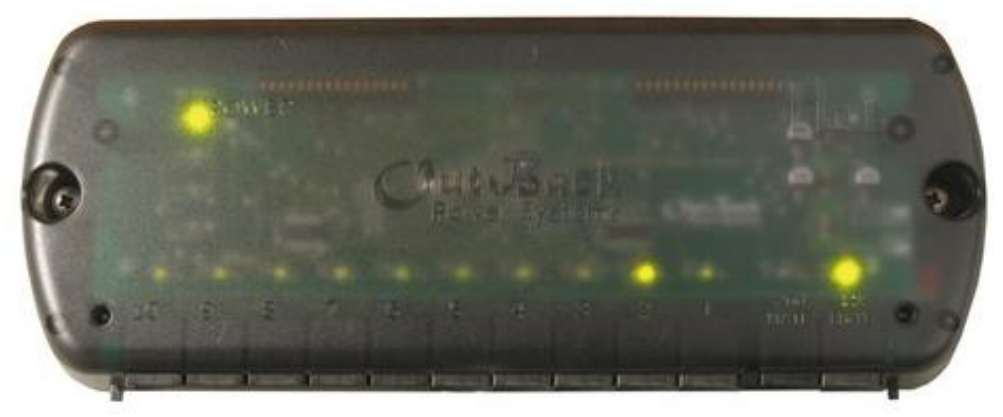

Figure 2-6: OutBack HUB10 [8]

Page 9 


\subsubsection{Battery Bank}

The battery bank used for the test setup is a single 12V CB27-AGM battery from Centennial Batteries, as seen in Figure 2-7. Its amp-hour capacity is $100 \mathrm{AH}$ at 20 hours. Its reserve capacity time at $25 \mathrm{~A}$ is 186 minutes, which means that the battery can be discharged for 186 minutes at a rate of $25 \mathrm{~A}$ and still has a voltage above $1.75 \mathrm{~V} /$ cell [12].

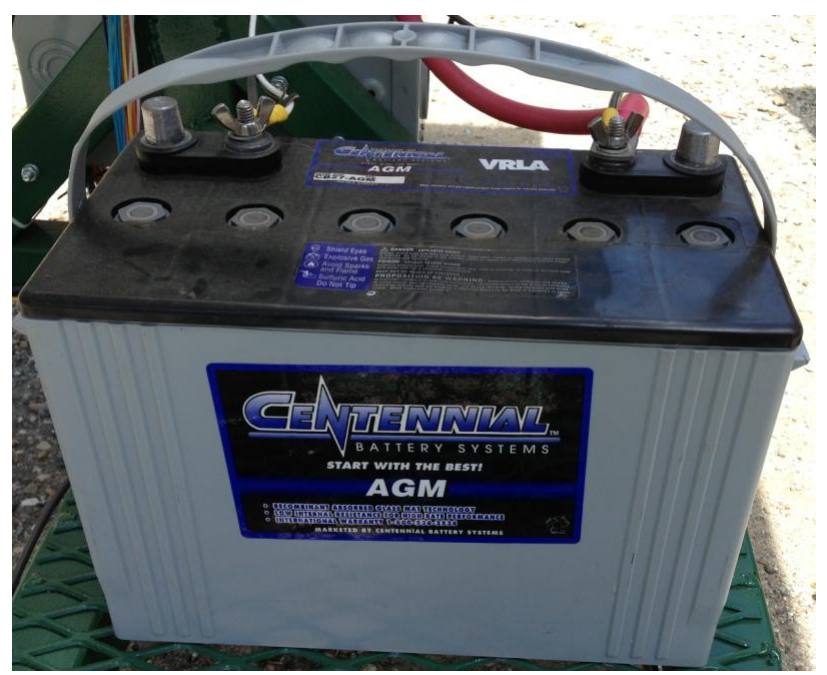

Figure 2-7: CB27-AGM by Centennial Batteries

\subsubsection{Inverter}

There are multiple types of inverters that output a variety of sinusoidal waveforms from simple square waves up to pure sine waves. Depending on the application, a consumer may not need to output a pure sine wave. However, when tying to the grid, there are certain standards and regulations that the consumer must meet and, therefore, must have a pure sine wave.

Although not connected to the grid, the inverter used for testing is the SSW-60012A Pure Sine Wave Power Inverter by Samlex Power, as seen in Figure 2-8. The first stage of the inverter is a DC-DC converter to boost the voltage from a low input voltage 
to $150 \mathrm{~V}_{\mathrm{DC}}$. The second stage is the inverter itself which converts the $150 \mathrm{~V}_{\mathrm{DC}}$ into a nominal $115 \mathrm{~V}_{\mathrm{RMS}}$ sine wave at $60 \mathrm{~Hz}$ with a continuous power rating of $600 \mathrm{~W}$ [13].

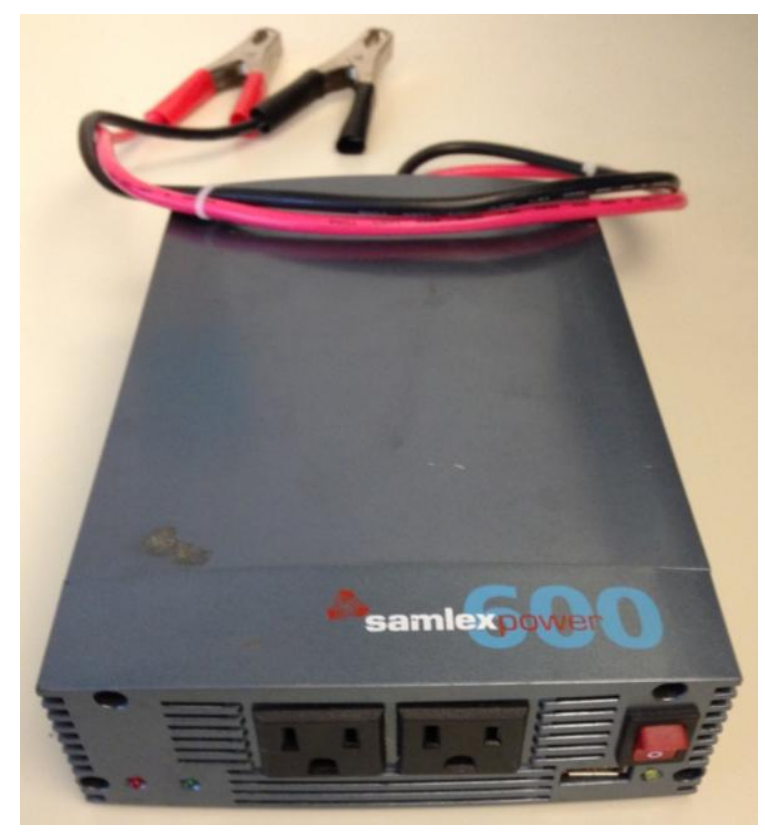

Figure 2-8: Samlex Pure Sine Wave Power Inverter

\subsection{Testing Setup}

Once all the components were acquired, the MX-60 MPPT-CC, FLEXnet DC, MATE2, and HUB10 were mounted on a stand for easy transportation and to keep all the components near each other. The test stand can be seen in Figure 2-9. 


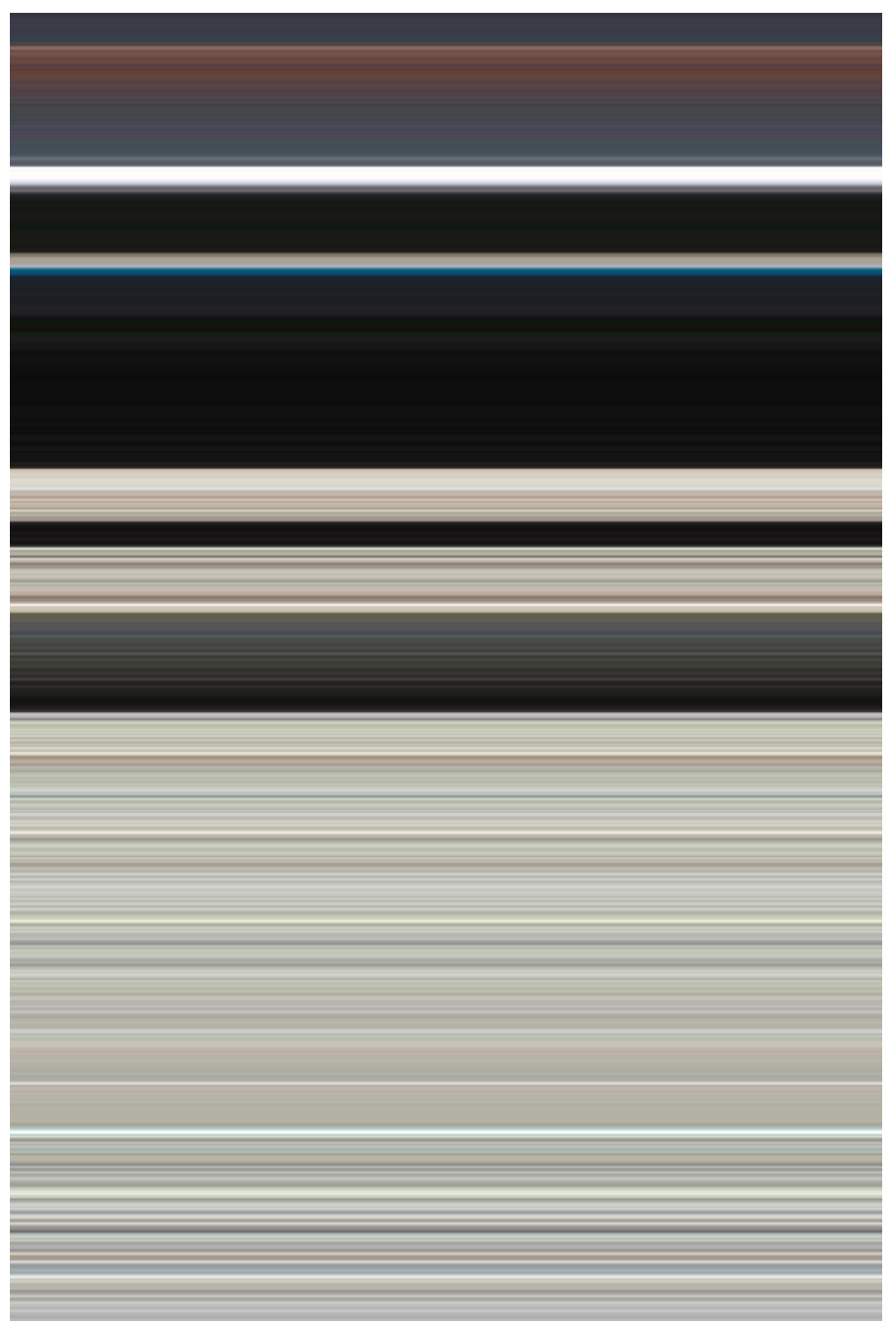

Figure 2-9: Testing Apparatus

The power connections were made following the red and black lines in the diagram in Figure 2-10. The solar panels are connected to the PV(+) and PV(-) of the MX-60 MPPT-CC. The Battery(+) and Battery(-) of the MX-60 MPPT-CC are then connected to the $12 \mathrm{~V}$ battery. Finally, the battery is then connected to the inverter which supplies two 100W light bulbs as a load for testing purposes.

The communication connections were made following the green lines in the diagram in Figure 2-10. Each of the communication lines utilizes CAT5e cables, which 
also bring power to the MATE2. First, the MX-60 MPPT-CC communication port is connected to port 1 of the HUB10. Then, the FLEXnet DC communication port is connected to port 2 of the HUB10. Finally, the MATE2 is connected to the $1^{\text {st }}$ MATE port of the HUB10 via its communication port. It is important to note that the Solar Decathlon House does not utilize an OutBack inverter because a Xantrex inverter was acquired for the system. Unfortunately, the Xantrex inverter is not compatible with the communication protocol of the HUB10 and MATE2. Therefore, the data from the Xantrex inverter cannot be extrapolated using the HUB10 and MATE2. Instead, a shunt is connected in series with the connection from the negative terminal of the battery to the corresponding negative terminal of the inverter used for testing. However, if an OutBack inverter is used in place of any other type of inverter, another CAT5e cable can be used to connect the communication port of the OutBack inverter to the HUB10. Protocol indicates that the OutBack inverter should be connected to port 1 of the HUB10, which would then move the MX-60 MPPT-CC communication line to port 2 and the FLEXnet DC communication line to port 3. 


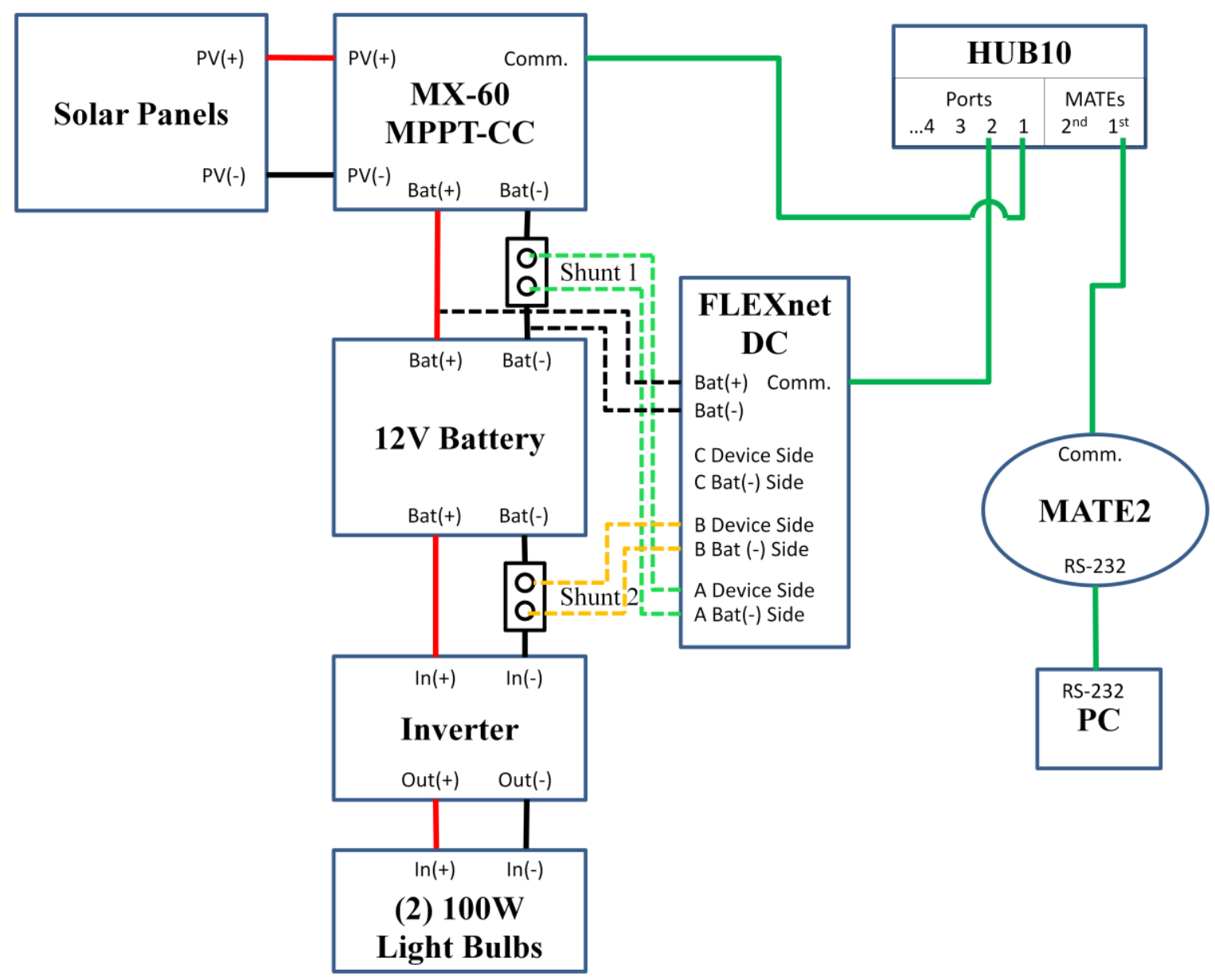

Figure 2-10: Diagram for Testing Setup

\subsection{Software}

Once the testing apparatus was complete and all components had power, a PC was connected to the MATE2 through a RS-232 cable. This allows the data that the MATE2 collects from all the components through the communication lines to be transferred to a PC. That data can then be analyzed through various methods. Three methods were analyzed for this project. Two of the methods are commercially available programs which are WinVerter-OB and WattPlot, and the third method is analyzing the raw data from the MATE2 through an Excel script. 


\subsubsection{WinVerter-OB}

The WinVerter-OB program was the first program that was tested to analyze and display the data received by the MATE2. An unlicensed version was given for free by RightHand Engineering, LLC, for this specific project which meant that the program would run in Evaluation Mode until a license is purchased. The unlicensed version of WinVerter-OB has many of the same features as a licensed version except that it can be used only to monitor one charge controller and one inverter and cannot log the data from the MATE2.

\subsubsection{User Interface}

The user interface for the WinVerter-OB is very straightforward. Once the program starts and the user gets past the opening window, multiple windows are then opened. Each new window corresponds with an OutBack component depending on what components the user has. Since the test setup only had one MX-60 MPPT-CC and one FLEXnet DC, two windows were opened and displayed the data from the MATE2 for each component in the appropriate window.

Figure 2-11 shows the window for the MX-60 MPPT-CC that WinVerter-OB displays. It displays the input voltage and current from the photovoltaic array and the output voltage and current from the charge controller going into the battery bank. It also calculates the corresponding power values utilizing Eq. 2-1. Finally, it shows the charging state of the charge controller and the state of the auxiliary power of the charge controller. For Figure 2-11, the charging state is floating and the auxiliary power is disabled for the charge controller. 


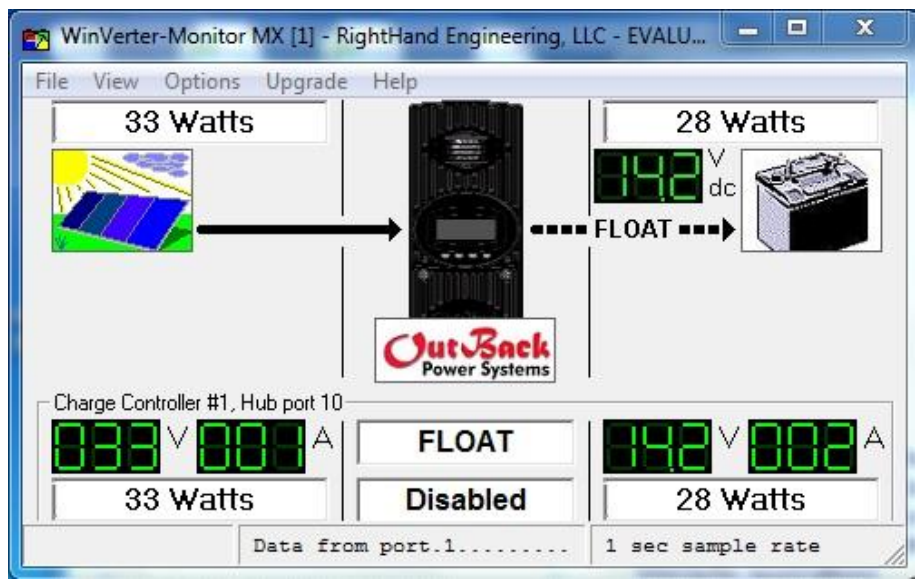

Figure 2-11: WinVerter-OB MX-60 Window

Figure 2-12 shows the window for the FLEXnet DC that WinVerter-OB displays. It shows the current voltage and the state of charge (SOC) of the battery bank. It is also able to display the temperature of the batteries, which is shown on the picture of the battery. However, the test setup did not have a temperature sensor, so the $28^{\circ} \mathrm{F}$ is the default temperature that it displays. It also shows the state of the relay control of the FLEXnet DC. Finally, it supposedly is able to show the shunt currents that are read by the FLEXnet DC. Unfortunately, after much debugging, the shunt currents could not be displayed. This could be due to the fact that WinVerter-OB was running in Evaluation Mode since it was unlicensed.

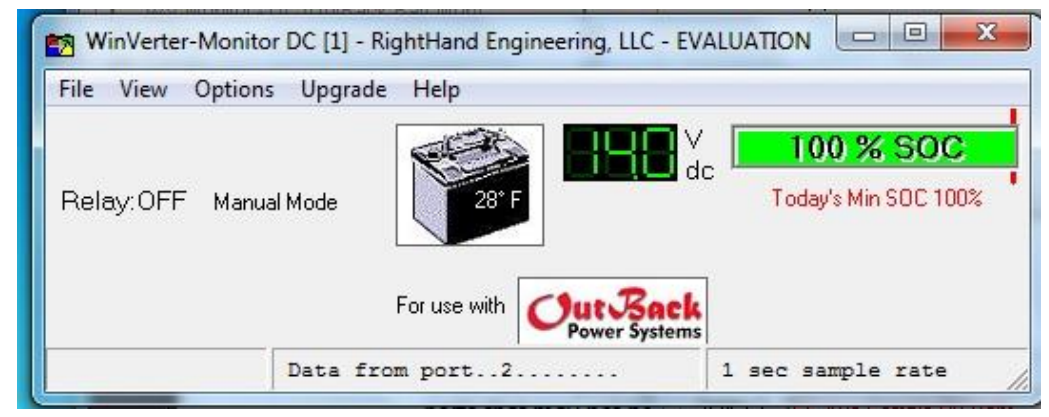

Figure 2-12: WinVerter-OB FLEXnet DC Window 


\subsubsection{Results}

Once it was confirmed that the program was working properly and reading data from the MATE2, two 100W light bulbs were connected to the inverter in order to simulate a load. Figure 2-13 and Figure 2-14 show the MX-60 and FLEXnet DC data for this system.

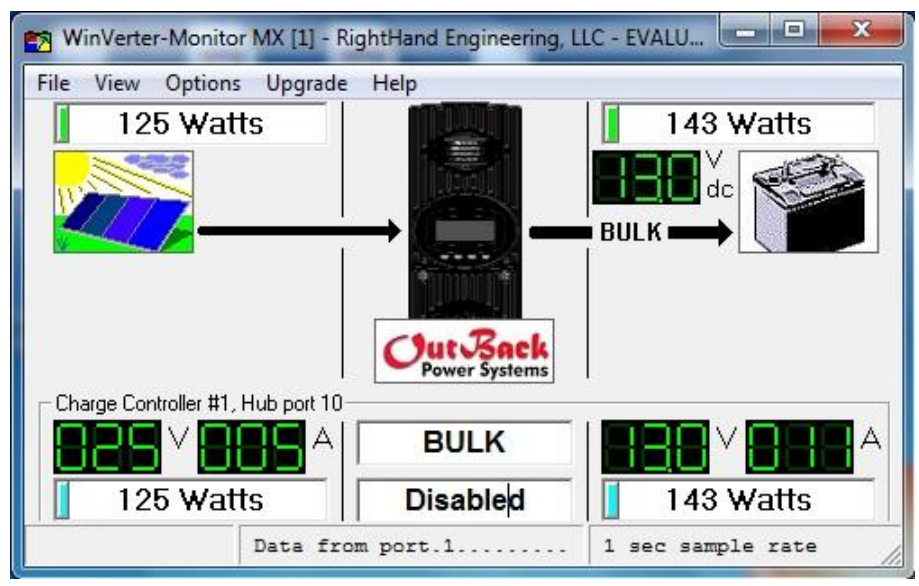

Figure 2-13: MX-60 MPPT-CC Data for System with 200W Load

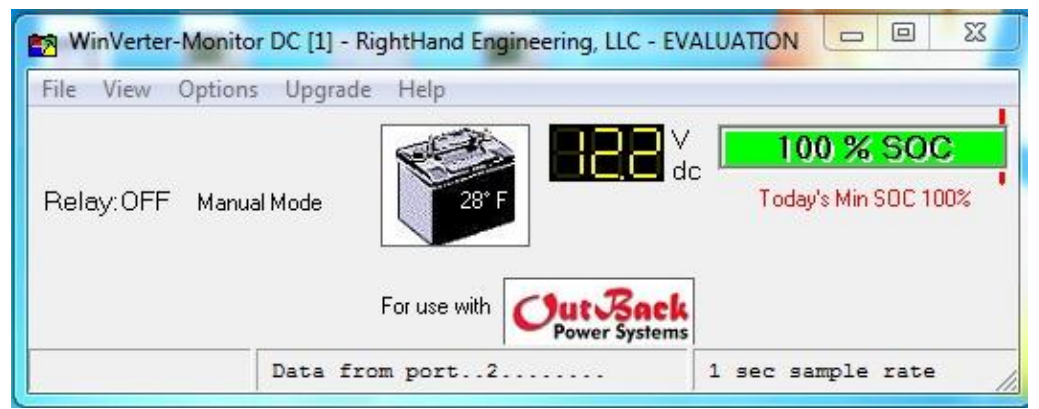

Figure 2-14: FLEXnet DC Data for System with 200W Load

From Figure 2-13, the voltage and current being displayed for the input from the solar panel are $25 \mathrm{~V}$ and $5 \mathrm{~A}$ respectively. This results in a power of $125 \mathrm{~W}$ from Eq. 2-1. For the output of the charge controller, the voltage and current are $13.0 \mathrm{~V}$ and $11 \mathrm{~A}$ respectively. This results in a power of $143 \mathrm{~W}$ from Eq. 2-1. This leads to the main issue 
with this program. From the two power values that are displayed, the output power is greater than the input power by $18 \mathrm{~W}$. This is impossible because a system cannot give out more power than what is put into the system, which would result in a system that is over $100 \%$ efficient. The cause of this issue stems from the significant figures of the voltage and current values that are displayed and rounding errors.

After reading the voltage and current values directly from the MX-60 MPPT-CC, it was noted that the input from the solar panels was $25 \mathrm{~V}$ and $5.9 \mathrm{~A}$, and the output of the charge controller was $13.0 \mathrm{~V}$ and 11.0A. When comparing the actual values to the displayed values, the only difference is the input current gets rounded down from 5.9A to 5A. This one rounding error caused the issue with having more output power than input power. When the actual power is calculated using Eq. 2-1, it is $147.5 \mathrm{~W}$. This result now makes the system possible again because the input power is now $147.5 \mathrm{~W}$ while the output power is $143 \mathrm{~W}$.

From analyzing Figure 2-14, it is evident that once the loads were added to the system, the voltage of the battery dropped. This is because the battery is now being discharged rather than only being charged when there was no load. Unfortunately, the shunt currents are not being displayed for possible reasons stated prior. Also, the default battery temperature is being displayed because there is no temperature sensor connected to the system. 


\subsubsection{WattPlot}

The WattPlot software was the second program that was tested to analyze and display the data received by the MATE2. A fully-functional, 15 day free trial of WattPlot was obtained to test the program in order to get a better idea of how the program works before making the decision whether or not to purchase a license for it.

\subsubsection{User Interface}

Upon initial startup for the WattPlot Monitor, a window, like the one in Figure 2-15, appears that has the user define from where the data source of the computer will be coming. The options are Serial, TCP/IP, Remote, and Captured Data. For the test setup, Serial was chosen because there was a direct serial connection from the MATE2 to the computer through a RS-232 cable. The TCP/IP option allows the user to "piggyback" on another computer that is connected serially to the MATE2. This gives the user the option to monitor a system without being at the system site. The TCP/IP option will be explored further in Section 3.3. The Remote option allows the user to read files that get sent from a computer connected directly to a system. While this is another option for remote monitoring like the TCP/IP option, the Remote option stores the data in files rather than being able to directly read the data from another computer. Finally, the Captured Data option allows users to review previously logged data. It runs through the data while acting like it is in real-time, even though it is logged data.

Also in this window, there is the option to select Capture Raw Data. This stores the raw data from the MATE2 into a folder on the computer. This option will be explored further in Section 2.3.3. There is also a button labeled "Connection Wizard..." 
This option helps the user to troubleshoot any connection issues that user may be having.

Finally, there is a button labeled "WattPlot as TCP Server..." If there will be a secondary computer piggybacking on the primary computer that is connected directly to the MATE2, this option will allow the user to decide what will be disabled, restricted, or open for the piggybacking computer. It also gives the computer's IP address, listening port, and a password option for the piggybacking computer. This option will be explored further in Section 3.3.

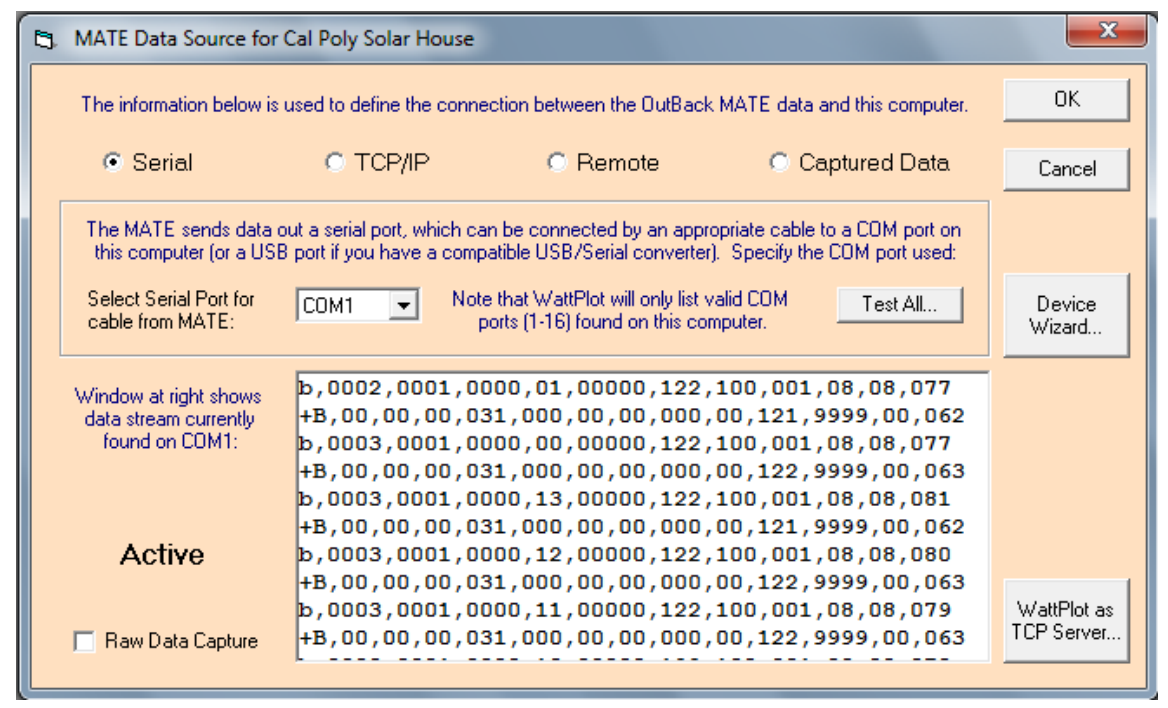

Figure 2-15: Data Selection for WattPlot Monitor

Once the data source has been chosen, the user can begin receiving data, and WattPlot Monitor will automatically open the correct windows corresponding to the devices that are connected to the MATE2. Figure 2-16 shows the display for WattPlot Monitor. Within the main window of WattPlot Monitor, real-time numerical data and plotted data can be viewed. At the top of the main window, the real-time numerical data is displayed for each device. Also, within the main window, more sub-windows are opened to display statuses and plots. 


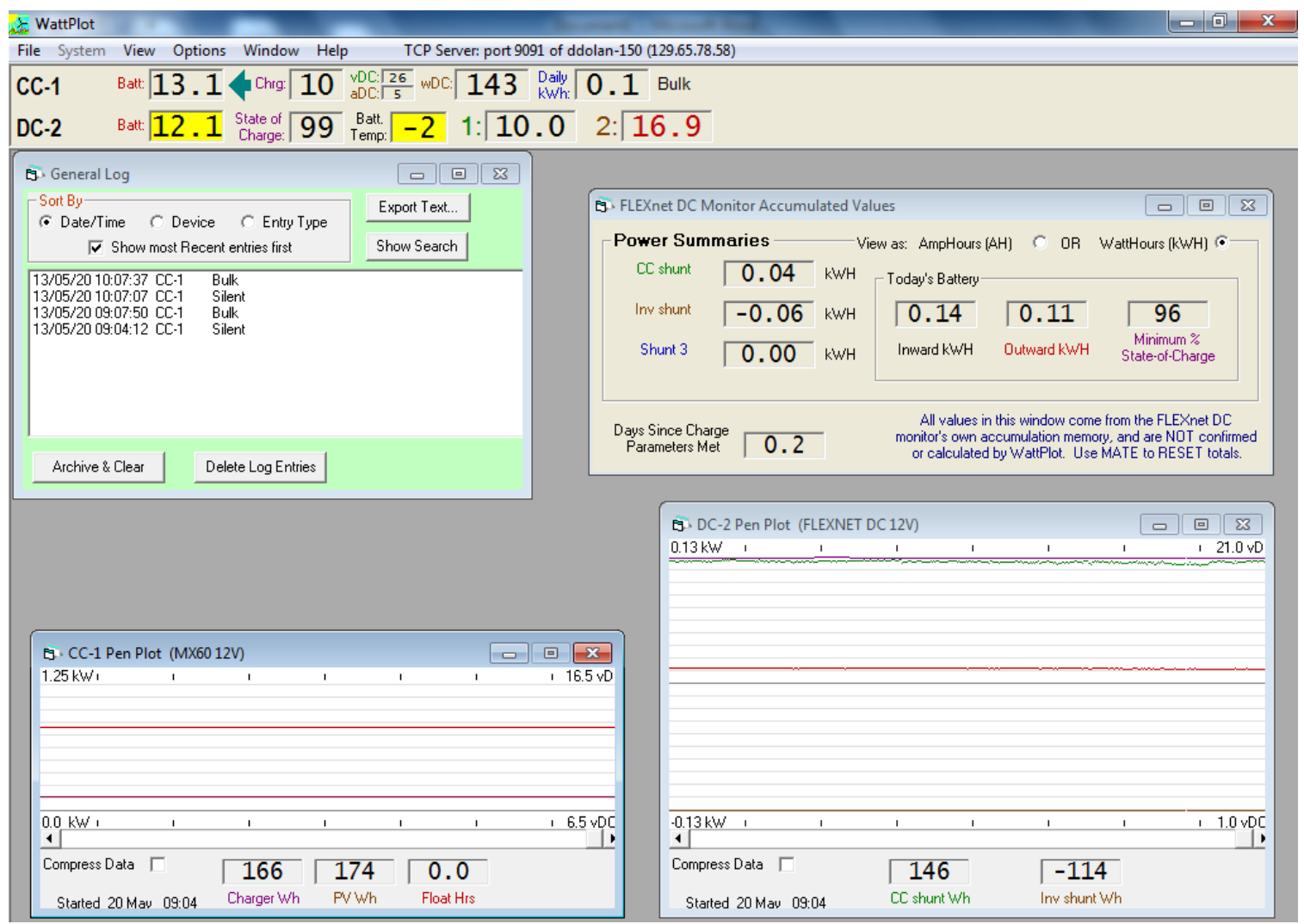

Figure 2-16: WattPlot Monitor Program

\subsubsection{Results}

For the test setup, since the MATE2 was receiving data from only one MX-60 MPPT-CC and one FLEXnet DC, the corresponding windows and values are displayed. Figure 2-17 shows the top of the main window for WattPlot Monitor. CC-1 corresponds with the MX-60. It shows the output voltage (13.1V), the output current (10A), the input voltage from the PV panels (26V), the input current from the PV panels (5A), the input power from the PV panels (143W) which is found using Eq. 2-1, the daily $\mathrm{kWh}$ $(0.1 \mathrm{kWh})$, and the mode of the charge controller (Bulk). Since WattPlot does not use the fractional values of the currents like WinVerter, there is a possibility of calculating more output power than input power. DC-2 corresponds with the FLEXnet DC. It shows the 
actual battery bank voltage $(12.1 \mathrm{~V})$, the state of charge in percentage $(99 \%)$, the battery temperature $\left(-2^{\circ} \mathrm{C}\right)$ which is its default temperature since no temperature sensors are hooked up to the system, and the current flowing through the shunts where black is positive and flowing to the battery bank and red is negative and flowing away from the battery bank (Shunt $1=10.0 \mathrm{~A}$; Shunt $2=-16.9 \mathrm{~A})$.

\begin{tabular}{|c|c|}
\hline ;- & $I 0$ aDC: \\
\hline & $\begin{array}{ll}\text { att } & -2\end{array}$ \\
\hline
\end{tabular}

Figure 2-17: Real-Time Numeric Data from WattPlot Monitor

Figure 2-18 shows the general log sub-window for WattPlot Monitor. The general log displays status changes, software activity, and various commands sent from WattPlot. From Figure 2-18, changes in the charge controller mode are shown with the date and time the changes happened. The user has the options of searching through the $\log$, sorting the log, and exporting the log. There is also an alert log and maintenance $\log$. The alert log displays warnings and errors in the communications with the inverter and MATE. The maintenance $\log$ records maintenance information for the system but is only available with the upgraded WattPlot PRO edition. Both of these logs can be displayed in sub-windows by changing their settings. However, since the test system does not have an OutBack inverter and WattPlot PRO was not purchased, the alert and maintenance logs were hidden. 


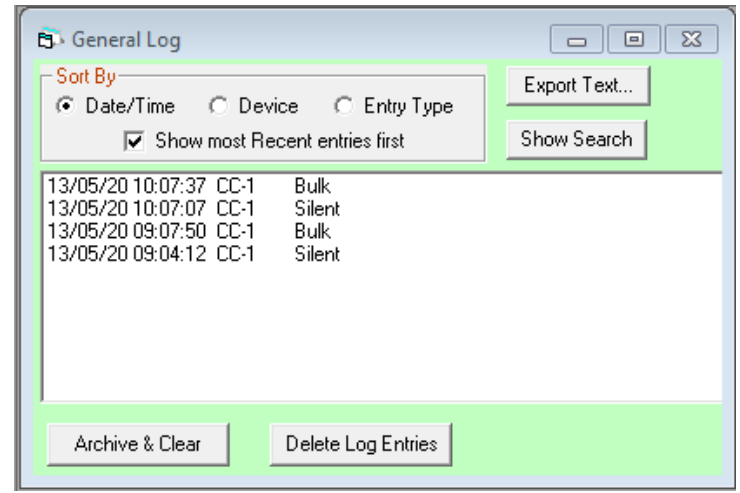

Figure 2-18: General Log Sub-Window from WattPlot Monitor

Figure 2-19 shows the charge controller pen plot sub-window for WattPlot

Monitor. It displays the output power of the charger in purple and the input power from the PV panels in brown using Eq. 2-1 to calculate the power. However, the brown trace is not visible within the plot. This is because the MX-60 tracks the input power from the PV panels and tries to output as much of that input power as possible. Since the input power at the time of the image was close to constant, the MX-60 was able to output nearly the identical amount of input power. It also displays the battery voltage in red. Finally, it displays the numeric values of the output watt-hours for the charge controller (166Wh), the input watt-hours for the charge controller from the PV panels (174Wh), and the number of hours the charge controller has been in its Float mode $(0.0 \mathrm{~h})$.

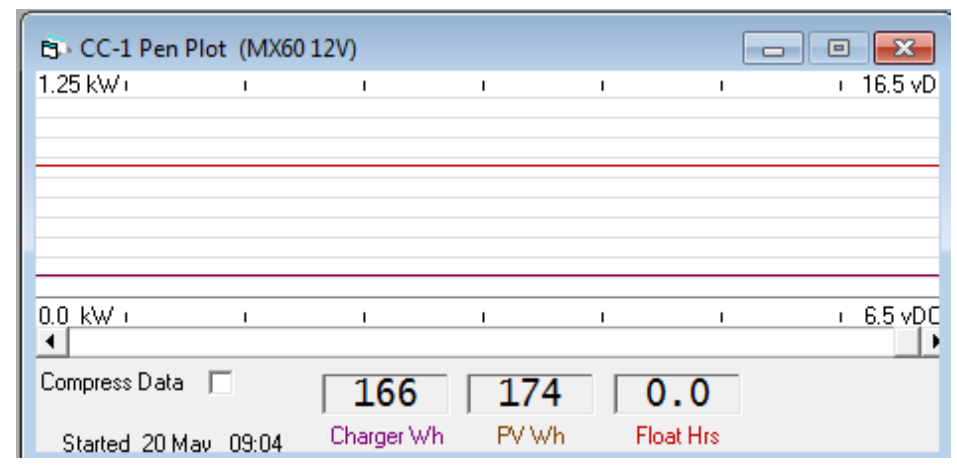

Figure 2-19: Charge Controller Pen Plot for WattPlot Monitor

Page 23 
Figure 2-20 shows the FLEXnet DC pen plot sub-window for WattPlot Monitor. It displays the state of charge in percentage in purple, the power through shunt 1 in green, the power through shunt 2 in brown, the power through shunt 3 in blue, and the battery voltage in red. Since only two shunts were connected to this system, the shunt 3 , blue line is not displayed. This sub-window also displays the numeric, watt-hour values through each shunt (Shunt $1=146 \mathrm{Wh}$; Shunt $2=-114 \mathrm{Wh}$ ).

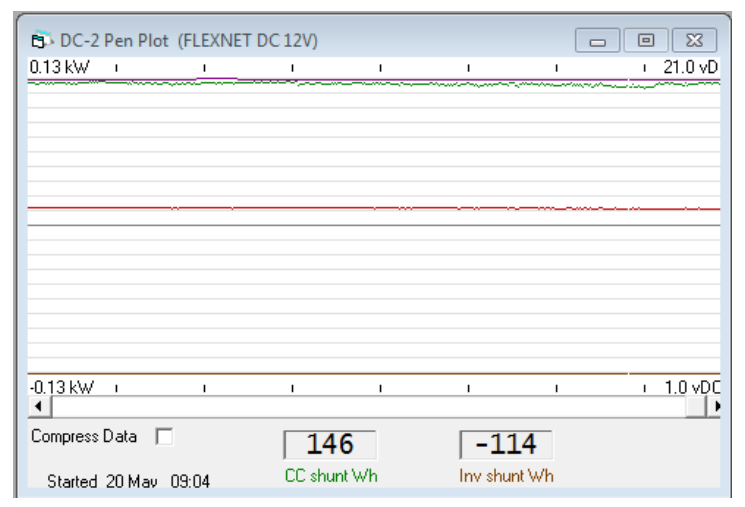

Figure 2-20: FLEXnet DC Pen Plot for WattPlot Monitor

Finally, Figure 2-21 shows the accumulated values for the FLEXnet DC. As stated within the sub-window, the values come from the FLEXnet DC memory and are not calculated by WattPlot. It gives the power summaries through each shunt in kilowatthour (Shunt $1=0.04 \mathrm{kWh}$; Shunt $2=-0.06 \mathrm{kWh}$; Shunt $3=0.00 \mathrm{kWh}$ ). It also gives the day's input and output power summary for the battery bank. The power being put into the battery bank is the Inward $\mathrm{kWh}(0.14 \mathrm{kWh})$, the power being taken out of the battery bank is the Outward kWh $(0.11 \mathrm{kWh})$, and the battery bank's state of charge is $96 \%$. Finally, depending on the charge parameters that are set in the MATE2, it displays the number of days since those parameters were met (0.2days). 


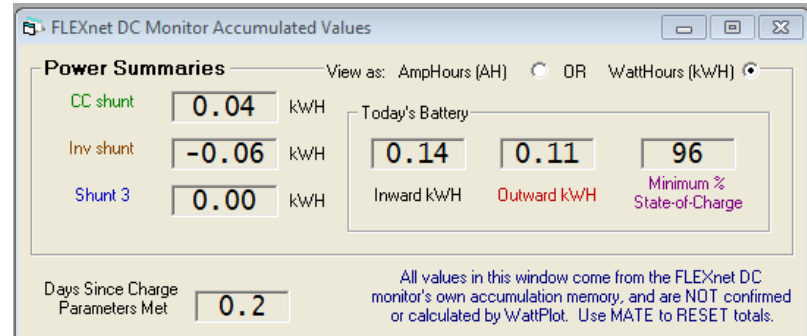

Figure 2-21: FLEXnet DC Accumulated Values for WattPlot Monitor

\subsubsection{Extra Features}

Along with the real-time data stream that the user can view through WattPlot Monitor, the user can also view a monthly power summary as graphs of all the logged data that was taken through the MATE2. Figure 2-22 shows the layout of the monthly power summary window for the MX-60 charge controller. Only April 9 and April 17 had any logged data because those were the only days in April that the testing setup was utilized with WattPlot running. The monthly power summary window is able to display two graphs, one bar graph and one line graph. The user is able to determine what data to display for each of the graphs. For both the bar graph and the line graph, the options are auxiliary hours, minimum and maximum battery voltage, charger $\mathrm{kWh}$, daily $\mathrm{kWh}$, the number of hours the charge controller is floating, maximum voltage of the PV arrays, and the PV kWh. There is also a monthly power summary window for the FLEXnet DC, which looks identical to that of Figure 2-22. However, the options for both the bar graph and the line graph for the FLEXnet DC are Shunt $1 \mathrm{kWh}$, Shunt $2 \mathrm{kWh}$, Shunt $3 \mathrm{kWh}$, minimum and maximum battery voltage, inward $\mathrm{AH}$, inward $\mathrm{kWh}$, minimum state of charge, outward AH, and outward kWh. 


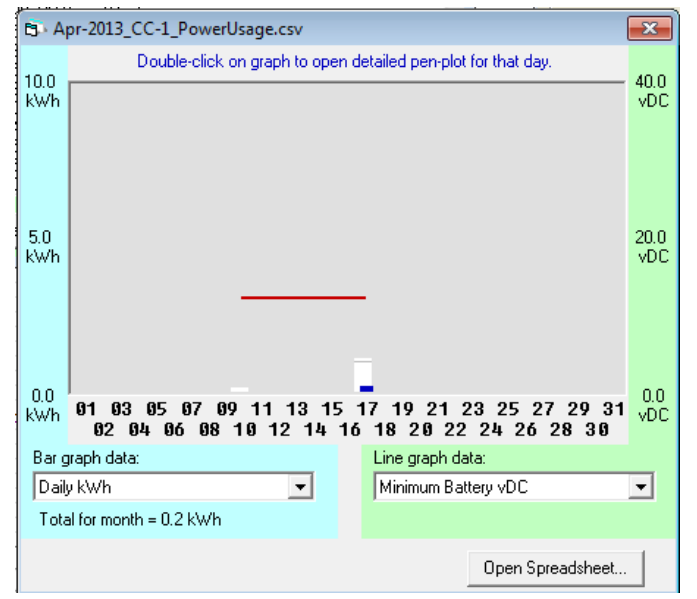

Figure 2-22: Monthly Power Summary Window

WattPlot also offers a couple of other extra features which are a free download of their VisualMATE, Test/Data Capture, and Remote software. Although the Test/Data Capture and Remote software was not analyzed because they were not necessary for the Solar Decathlon House system, the VisualMATE program was downloaded and analyzed. Figure 2-23 shows the display of VisualMATE. VisualMATE shows all the same data that WattPlot Monitor shows. However, it puts the data in a more colorful and user-friendly window. That is, VisualMATE separates the components of the entire system and shows how the power flows from one component to the next. In Figure 2-23, the user can clearly see that the panels are outputting $5.5 \mathrm{~A}$ and $24 \mathrm{~V}$ into the charge controller and so on. It is unusual that the fractional portions of the currents are being displayed for VisualMATE since they are not used in either WinVerter or WattPlot Monitor. VisualMATE also adapts to the components that are in the system. For instance, if there was an OutBack inverter within the system, there would be another box for the inverter data. The only issue that is evident is the spacing. In the yellow, DC Monitor box, the Net IN is $5 \mathrm{Ah}$ and $0.06 \mathrm{kWh}$. However, the Net IN states 50.06, when it 
should say "5 0.06 " with a space in between. Other than that one critique, the VisualMATE is a nice supplement to WattPlot Monitor.

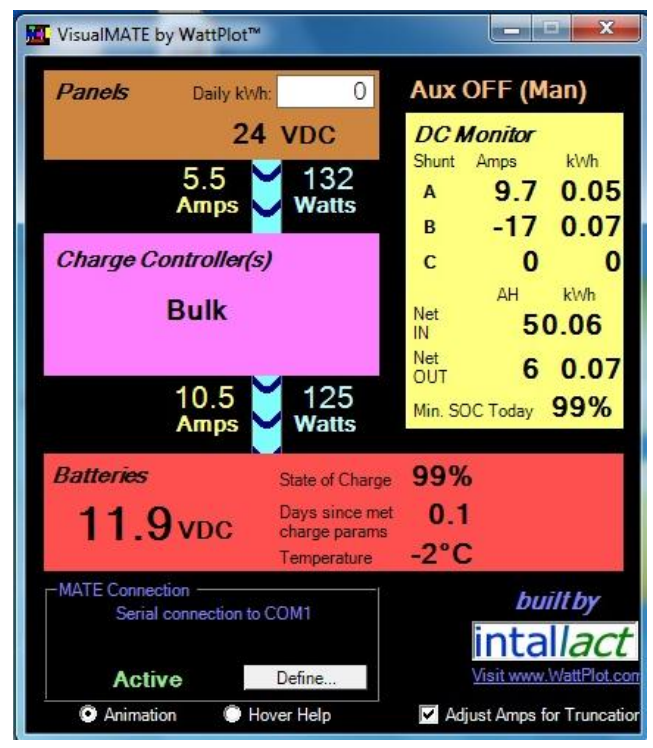

Figure 2-23: WattPlot VisualMATE Display

\subsubsection{MATE Raw Data}

A third option that was pursued was creating an Excel script for the raw data that the MATE2 outputs. This method enables the user to customize what data to display and how to display it. However, this method was not implemented for real-time data analysis, so it can only be used to analyze any data that has been stored in a folder on a computer.

\subsubsection{Raw Data Analysis}

Using the "Raw Data Capture" option of WattPlot Monitor in Figure 2-15, the raw data from the MATE2 is stored in a file within the program data folder. A sample of the raw data from the test setup can be seen in Table B-1. As is evident, only one column is being used to store this data. Every second, a new sample of data is stored within the 
file. Because it stores data every second, this means that the file can grow rather rapidly. In fact, the file size grows by about 3 kilobytes per minute [14]. Therefore, using this method for long periods of time could result in extremely large memory usage. As for the data itself, with the test setup, there are two main rows of data and a third row with a “ " which does not occur every second. It is important to note that the rows of " $\sim$ " are input by WattPlot and are not generated by the MATE2.

One of the rows of data begins with a "B" at the leftmost character and appears as: "B, $00,00,00,033,000,00,00,000,01,137,9999,00,072 . "$ This row of data is the raw data from the MX-60 MPPT-CC. Table 2-1 displays the function of each character within the raw data. Please note that the first and last characters are not visible because they are the ASCII characters to start a new line and a carriage return to end a line respectively. 
Table 2-1: MX-60 Raw Data Cipher [15]

\begin{tabular}{|c|c|}
\hline Character \# & Function of Character \\
\hline 1 & New Line character denoting the start of the status page \\
\hline 2 & MX/FM address \\
\hline 3 & A comma used as a data separator \\
\hline 4 & Unused \\
\hline 5 & Unused \\
\hline 6 & A comma used as a data separator \\
\hline 7 & Tens digit of Charger output current \\
\hline 8 & Ones digit of Charger output current \\
\hline 9 & A comma used as a data separator \\
\hline 10 & Tens digit of PV current \\
\hline 11 & Ones digit of PV current \\
\hline 12 & A comma used as a data separator \\
\hline 13 & Hundreds digit of the PV input voltage \\
\hline 14 & Tens digit of PV input voltage \\
\hline 15 & Ones digit of PV input voltage \\
\hline 16 & A comma used as a data separator \\
\hline 17 & Tens digit of Daily kWH \\
\hline 18 & Ones digit of Daily kWH \\
\hline 19 & Tenths digit of Daily kWH \\
\hline 20 & A comma used as a data separator \\
\hline 21 & Unused \\
\hline 22 & Tenths of amp Charger current (FM80 / FM60 only) \\
\hline 23 & A comma used as a data separator \\
\hline 24 & High byte of Aux mode \\
\hline 25 & Low byte of Aux mode \\
\hline 26 & A comma used as a data separator \\
\hline 27 & High byte of Error mode \\
\hline 28 & Middle byte of Error mode \\
\hline 29 & Low byte of Error mode \\
\hline 30 & A comma used as a data separator \\
\hline 31 & High byte of charger mode \\
\hline 32 & Low byte of charger mode \\
\hline 33 & A comma used as a data separator \\
\hline 34 & Tens digit of battery voltage \\
\hline 35 & Ones digit of battery voltage \\
\hline 36 & Tenths digit of battery voltage \\
\hline 37 & A comma used as a data separator \\
\hline
\end{tabular}




\begin{tabular}{|c|l|}
\hline Character \# & \multicolumn{1}{|c|}{ Function of Character } \\
\hline 38 & Thousands digit of daily AH \\
\hline 39 & Hundreds digit of daily AH \\
\hline 40 & Tens digit of daily AH \\
\hline 41 & Ones digit of daily AH \\
\hline 42 & A comma used as a data separator \\
\hline 43 & Unused \\
\hline 44 & Unused \\
\hline 45 & A comma used as a data separator \\
\hline 46 & Hundreds digit of Checksum \\
\hline 47 & Tens digit of Checksum \\
\hline 48 & Ones digit of Checksum \\
\hline 49 & Carriage return which denotes end of status page \\
\hline
\end{tabular}

The majority of the characters' functions are self-explanatory. However, there are a couple of sets of characters that need more in depth analysis. Character 22 is unused because an FM80 or FM60 is not used in the test setup. This is the reason why both WinVerter and WattPlot do not contain any fractional values of the output current since a MX-60 is being used. Characters 24 and 25 are the high byte and low byte of the auxiliary mode. The auxiliary mode changes the mode of the charge controller in order to change the output power depending on what the load is doing. It is able to divert power or stop power altogether if needed. Characters 27, 28, and 29 are the high, middle and low bytes of the error mode respectively. In order to utilize the error modes, more sensors need to be placed within the system to track changes in voltage, temperature, and more. Characters 31 and 32 are the high byte and low byte of the charge controller mode respectively. Possible modes of the charge controller are silent, float, bulk, absorb, and EQ. Characters 38-41 contain the amp-hour value of the charge controller. However, since this is an MX-60, these characters do not measure anything. Finally, characters 46- 
48 contain the "check sum" value of the entire string of data. The check sum value should be equal to all of the other digits together including the ASCII character number for the initial letter subtracted by 48 . For example, row 2 of Table B-1 would be calculated by:

$$
66-48+3+3+1+1+3+7+9+9+9+9=72
$$

The check sum value of the corresponding row is 72 . Therefore, the check sum value holds for this row of data.

The other row of data begins with a "b" at the leftmost character and appears as: "b,0002,0001,0000,09,00000,137,100,001,16,08,090." This row of data is the raw data from the FLEXnet DC. Table 2-2 displays the function of each character within the raw data of the FLEXnet DC. As with the MX-60 raw data, the first and last characters are not visible because they are the ASCII characters to start a new line and a carriage return to end a line respectively.

Table 2-2: FLEXnet DC Raw Data Cipher [15]

\begin{tabular}{|c|l|}
\hline Character \# & \multicolumn{1}{|c|}{ Function of Character } \\
\hline 1 & New Line character denoting the start of the status page \\
\hline 2 & FLEXnet DC address. \\
\hline 3 & A comma used as a data separator \\
\hline 4 & Hundreds digit of shunt 'A' current. \\
\hline 5 & Tens digit of shunt 'A' current. \\
\hline 6 & Ones digit of shunt 'A' current. \\
\hline 7 & Tenths digit of shunt 'A' current. \\
\hline 8 & A comma used as a data separator \\
\hline 9 & Hundreds digit of shunt 'B' current. \\
\hline 10 & Tens digit of shunt 'B' current. \\
\hline 11 & Ones digit of shunt 'B' current. \\
\hline 12 & Tenths digit of shunt 'B' current. \\
\hline 13 & A comma used as a data separator \\
\hline 14 & Hundreds digit of shunt 'C' current. \\
\hline
\end{tabular}




\begin{tabular}{|c|c|}
\hline Character \# & Function of Character \\
\hline 15 & Tens digit of shunt 'C' current. \\
\hline 16 & Ones digit of shunt ' $C$ ' current. \\
\hline 17 & Tenths digit of shunt ' $C$ ' current. \\
\hline 18 & A comma used as a data separator \\
\hline 19 & Tens digit of extra data identifier. \\
\hline 20 & Ones digit of extra data identifier. \\
\hline 21 & A comma used as a data separator \\
\hline 22 & Ten thousands digit of extra data. \\
\hline 23 & Thousands digit of extra data. \\
\hline 24 & Hundreds digit of extra data. \\
\hline 25 & Tens digit of extra data. \\
\hline 26 & Ones digit of extra data. \\
\hline 27 & A comma used as a data separator \\
\hline 28 & Tens digit of FLEXnet DC battery voltage. \\
\hline 29 & Ones digit of FLEXnet DC battery voltage. \\
\hline 30 & Tenths digit of FLEXnet DC battery voltage. \\
\hline 31 & A comma used as a data separator \\
\hline 32 & Hundreds digit of state of charge. \\
\hline 33 & Tens digit of state of charge. \\
\hline 34 & Ones digit of state of charge. \\
\hline 35 & A comma used as a data separator \\
\hline 36 & Shunt A enabled flag. \\
\hline 37 & Shunt B enabled flag. \\
\hline 38 & Shunt $\mathrm{C}$ enabled flag. \\
\hline 39 & A comma used as a data separator \\
\hline 40 & High byte of status flags. \\
\hline 41 & Low byte of status flags. \\
\hline 42 & A comma used as a data separator \\
\hline 43 & Tens digit of battery temperature. \\
\hline 44 & Ones digit of battery temperature. \\
\hline 45 & A comma used as a data separator \\
\hline 46 & Hundreds digit of Chksum. \\
\hline 47 & Tens digit of Chksum. \\
\hline 48 & Ones digit of Chksum. \\
\hline 49 & Carriage return which denotes end of status page \\
\hline
\end{tabular}


As with the data for the MX-60, there needs to be more explanation for a couple of sets of characters for the data of the FLEXnet DC. Characters 19 and 20 are the tens and ones digits of the extra data identifier. Depending on the value of these characters, the value of characters 22-26 will change. However, the extra data is not used within the script that was written for the test setup or Solar Decathlon House. Characters 36-38 are the enable flags for the shunts. A value of 0 corresponds to an enabled shunt, and a value of 1 corresponds to a disabled shunt. Also, character 36 corresponds to shunt A, character 37 corresponds to shunt $\mathrm{B}$, and character 38 corresponds to shunt $\mathrm{C}$. Characters 40 and 41 are the high byte and low byte of the status flag. If the charge parameters are met, add 1 to this value. If the relay is in automatic mode, add 2 to this value. If the relay is closed, add 4 to this value. If shunt $A$ is negative, add 8 to this value. If shunt $B$ is negative, add 16 to this value. If shunt $\mathrm{C}$ is negative, add 32 to this value. Finally, characters $46-48$ contain the "check sum" value of the entire string of data and is calculated using the same method as the MX-60 raw data string.

\subsubsection{Excel Script and Results}

The Excel script that was written to extract and organize the raw data from the MATE2 can be seen in Appendix C. There are four main parts to the script. First, it finds how many seconds of data is contained in the file. To do this, it looks for the amount of B's in the data. Since a new line of data is produced each second, this method will result in the total time the raw data capture was running.

Next, it creates an input box for the user to input the start time of the raw data capture. This part is not extremely important since data will continue to be logged no 
matter what time of day it is. However, it would not make sense if there is a lot of input power from the PV arrays in the middle of the night. Therefore, the closer the time that the user can enter compared to the actual start time, the more sense the data and graphs will make.

Then, the script creates headers and labels for the tables. For the test setup, a table for the MX-60 raw data and the FLEXnet DC raw data is made. However, when the system is moved to the Solar Decathlon House, a third table will be generated for the second MX-60 being utilized. Also during this step, the time is incremented and placed within the table depending on the time from the user input and the number of seconds counted in the first part.

Subsequently, the script performs its main function and sorts through the raw data. For the MX-60, it finds the PV voltage, PV current, charge controller voltage, and charge controller current and places their corresponding values in the correct column. It then enters the correct mode of the charge controller. To accomplish this, it finds the corresponding characters, and through a Case statement, it displays the mode of the charge controller in the correct column. Finally, it enters the daily kilowatt-hour value in the final column. For the FLEXnet DC, the first step is to convert the decimal values of the status flag characters to binary values. It then enters the values for shunt A, shunt B, and shunt $\mathrm{C}$ into their correct columns while checking bits 3,4 , and 5 of the binary status flag values in order to determine whether they are negative or not. Finally, it enters the battery voltage, battery state of charge, and battery temperature into their corresponding columns. 
Table 2-3 and Table 2-4 display the results of 30 seconds worth of raw data. Table 2-3 is the charge controller data output from the Excel script. One thing to note is that the PV voltage, PV current, and charge controller current do not have any decimal values. This can lead to errors within the data itself because it is essentially rounding all of these values down which is the reason for the errors within both WinVerter and WattPlot Monitor. For instance, at 12:00:01 AM, the input power from the PV panel is $0 \mathrm{~W}$ because the current is displayed to be $0 \mathrm{~A}$. However, the output power is $13.7 \mathrm{~W}$. This does not make sense since it is impossible to have more output power than input power. The only reasoning that this could happen is that the PV current is actually a value below 1A, but the raw data does not display tenths of an amp. This was the only major issue with the charge controller data and explains why the WinVerter software also had errors. 
Table 2-3: Charge Controller \#1 Data for Test Setup from Excel Script

\begin{tabular}{|c|c|c|c|c|c|c|}
\hline \multicolumn{7}{|c|}{ Charge Controller \#1 Data } \\
\hline Time & $\begin{array}{l}\text { PV Voltage } \\
\text { (V) }\end{array}$ & $\begin{array}{l}\text { PV Current } \\
\text { (A) }\end{array}$ & $\begin{array}{l}\text { CC Voltage } \\
\text { (V) }\end{array}$ & $\begin{array}{l}\text { CC Current } \\
\text { (A) }\end{array}$ & $\begin{array}{l}\text { CC } \\
\text { Mode }\end{array}$ & $\begin{array}{l}\text { Daily } \\
\mathrm{kWh}\end{array}$ \\
\hline 10:30:00 AM & 33 & 0 & 13.7 & 0 & Float & 0 \\
\hline 10:30:01 AM & 33 & 0 & 13.7 & 1 & Float & 0 \\
\hline 10:30:02 AM & 33 & 0 & 13.7 & 1 & Float & 0 \\
\hline 10:30:03 AM & 33 & 0 & 13.7 & 1 & Float & 0 \\
\hline 10:30:04 AM & 33 & 0 & 13.7 & 1 & Float & 0 \\
\hline 10:30:05 AM & 33 & 0 & 13.7 & 1 & Float & 0 \\
\hline 10:30:06 AM & 33 & 0 & 13.7 & 1 & Float & 0 \\
\hline 10:30:07 AM & 33 & 0 & 13.7 & 0 & Float & 0 \\
\hline 10:30:08 AM & 33 & 0 & 13.7 & 1 & Float & 0 \\
\hline 10:30:09 AM & 33 & 0 & 13.7 & 1 & Float & 0 \\
\hline 10:30:10 AM & 33 & 0 & 13.7 & 1 & Float & 0 \\
\hline 10:30:11 AM & 33 & 0 & 13.7 & 1 & Float & 0 \\
\hline $10: 30: 12$ AM & 33 & 0 & 13.7 & 1 & Float & 0 \\
\hline 10:30:13 AM & 33 & 0 & 13.7 & 1 & Float & 0 \\
\hline 10:30:14 AM & 33 & 0 & 13.7 & 1 & Float & 0 \\
\hline 10:30:15 AM & 33 & 0 & 13.7 & 1 & Float & 0 \\
\hline 10:30:16 AM & 33 & 0 & 13.7 & 1 & Float & 0 \\
\hline 10:30:17 AM & 33 & 0 & 13.7 & 1 & Float & 0 \\
\hline 10:30:18 AM & 33 & 0 & 13.7 & 1 & Float & 0 \\
\hline 10:30:19 AM & 33 & 0 & 13.7 & 1 & Float & 0 \\
\hline 10:30:20 AM & 33 & 0 & 13.7 & 1 & Float & 0 \\
\hline 10:30:21 AM & 33 & 0 & 13.7 & 1 & Float & 0 \\
\hline 10:30:22 AM & 33 & 0 & 13.7 & 1 & Float & 0 \\
\hline $10: 30: 23$ AM & 33 & 0 & 13.7 & 1 & Float & 0 \\
\hline 10:30:24 AM & 33 & 0 & 13.7 & 1 & Float & 0 \\
\hline $10: 30: 25$ AM & 33 & 0 & 13.7 & 1 & Float & 0 \\
\hline 10:30:26 AM & 33 & 0 & 13.7 & 1 & Float & 0 \\
\hline $10: 30: 27$ AM & 33 & 0 & 13.7 & 1 & Float & 0 \\
\hline 10:30:28 AM & 33 & 0 & 13.7 & 1 & Float & 0 \\
\hline 10:30:29 AM & 33 & 0 & 13.7 & 1 & Float & 0 \\
\hline
\end{tabular}


Table 2-4 is the FLEXnet DC data output from the Excel script. Each of the shunt currents along with the battery voltage seems to be good data since their values are accurate down to a tenth. For the test setup, the state of charge did not change much since there was almost always equivalent input power from the PV panel as there was output power. Therefore, the state of charge had a minimum value of $96 \%$ throughout all of the testing. Finally, the battery temperature stayed at a constant $-2^{\circ} \mathrm{C}$ throughout all of the testing, which is due to the fact that $-2^{\circ} \mathrm{C}$ is the default value because there was no temperature sensor within the test setup. However, this value was displayed because there is a temperature sensor in the Solar Decathlon House, so there will be temperature values when the Solar Decathlon House is evaluated. 
Table 2-4: FLEXnet DC \#1 Data for Test Setup from Excel Script

\begin{tabular}{|c|c|c|c|c|c|c|}
\hline \multicolumn{7}{|c|}{ FLEXnet DC \#1 Data } \\
\hline Time & $\begin{array}{l}\text { Shunt A } \\
\text { (A) }\end{array}$ & $\begin{array}{l}\text { Shunt B } \\
\text { (A) }\end{array}$ & $\begin{array}{l}\text { Shunt C } \\
\text { (A) }\end{array}$ & $\begin{array}{l}\text { Bat. Voltage } \\
\text { (V) }\end{array}$ & $\begin{array}{l}\text { State of Charge } \\
(\%)\end{array}$ & $\begin{array}{l}\text { Bat. Temp. } \\
\text { (C) }\end{array}$ \\
\hline 10:30:00 AM & 0.2 & -0.1 & 0 & 13.7 & 100 & -2 \\
\hline 10:30:01 AM & 0.1 & 0 & 0 & 13.7 & 100 & -2 \\
\hline 10:30:02 AM & 0.1 & 0 & 0 & 13.6 & 100 & -2 \\
\hline 10:30:03 AM & 0.4 & 0 & 0 & 13.7 & 100 & -2 \\
\hline 10:30:04 AM & 0.4 & 0 & 0 & 13.7 & 100 & -2 \\
\hline 10:30:05 AM & 0.4 & 0 & 0 & 13.7 & 100 & -2 \\
\hline 10:30:06 AM & 0.3 & 0 & 0 & 13.7 & 100 & -2 \\
\hline 10:30:07 AM & 0.2 & 0.1 & 0 & 13.7 & 100 & -2 \\
\hline 10:30:08 AM & 0 & 0 & 0 & 13.7 & 100 & -2 \\
\hline 10:30:09 AM & 0.3 & 0 & 0 & 13.7 & 100 & -2 \\
\hline 10:30:10 AM & 0.4 & 0 & 0 & 13.7 & 100 & -2 \\
\hline 10:30:11 AM & 0.3 & 0.1 & 0 & 13.7 & 100 & -2 \\
\hline 10:30:12 AM & 0.3 & 0.1 & 0 & 13.7 & 100 & -2 \\
\hline 10:30:13 AM & 0.1 & 0 & 0 & 13.7 & 100 & -2 \\
\hline 10:30:14 AM & 0.3 & 0 & 0 & 13.7 & 100 & -2 \\
\hline $10: 30: 15$ AM & 0.3 & 0 & 0 & 13.7 & 100 & -2 \\
\hline 10:30:16 AM & 0.3 & 0 & 0 & 13.7 & 100 & -2 \\
\hline 10:30:17 AM & 0.2 & 0 & 0 & 13.7 & 100 & -2 \\
\hline 10:30:18 AM & 0.1 & 0 & 0 & 13.7 & 100 & -2 \\
\hline 10:30:19 AM & 0.2 & 0.1 & 0 & 13.7 & 100 & -2 \\
\hline 10:30:20 AM & 0.4 & 0.1 & 0 & 13.7 & 100 & -2 \\
\hline 10:30:21 AM & 0.4 & 0.1 & 0 & 13.7 & 100 & -2 \\
\hline $10: 30: 22$ AM & 0.3 & 0.2 & 0 & 13.7 & 100 & -2 \\
\hline 10:30:23 AM & 0.2 & 0.2 & 0 & 13.7 & 100 & -2 \\
\hline 10:30:24 AM & 0.1 & 0.3 & 0 & 13.7 & 100 & -2 \\
\hline $10: 30: 25$ AM & 0.2 & 0.3 & 0 & 13.6 & 100 & -2 \\
\hline $10: 30: 26$ AM & 0.5 & 0.3 & 0 & 13.7 & 100 & -2 \\
\hline $10: 30: 27$ AM & 0.5 & 0.3 & 0 & 13.7 & 100 & -2 \\
\hline 10:30:28 AM & 0.4 & 0.2 & 0 & 13.7 & 100 & -2 \\
\hline 10:30:29 AM & 0.3 & 0.3 & 0 & 13.7 & 100 & -2 \\
\hline
\end{tabular}




\section{System Implementation}

After thoroughly testing the mock system as described in Chapter 2, the monitoring devices were installed within the actual system of the Solar Decathlon House. The WattPlot Monitor program from Section 2.3.2 was chosen as the monitoring software because of the number of functions and features that it offered. Although the testing system was very similar to the Solar Decathlon House, there were a few differences between the two systems.

\subsection{Components}

Section 3.1 lists the differences in the components between the test setup and the Solar Decathlon House. It also describes the specifications of each of the new components.

\subsubsection{Photovoltaic Module}

The Solar Decathlon House utilizes BP 4175 solar panels from BP Solar, as seen in Figure 3-1a. Each individual panel is rated for a nominal voltage of $24 \mathrm{~V}$ and a maximum power of $175 \mathrm{~W}$ with a voltage at maximum power of $35.7 \mathrm{~V}$ and a current at maximum power of 4.9A. Its short-circuit current is 5.4A, and its open-circuit voltage is 44.0V. Its I-V Curve for various temperatures can be seen in Figure 3-1b [16]. The Solar Decathlon House utilizes 24 of these panels, which are broken into two arrays. Each array has 2 panels per string with 6 strings in parallel. This results in a nominal voltage 
of $48 \mathrm{~V}$, a nominal current of $29.4 \mathrm{~A}$, an open-circuit voltage of $88 \mathrm{~V}$, and a short-circuit current of $32.4 \mathrm{~A}$ per array. The total peak power output from the arrays is $2.1 \mathrm{kWp}$.

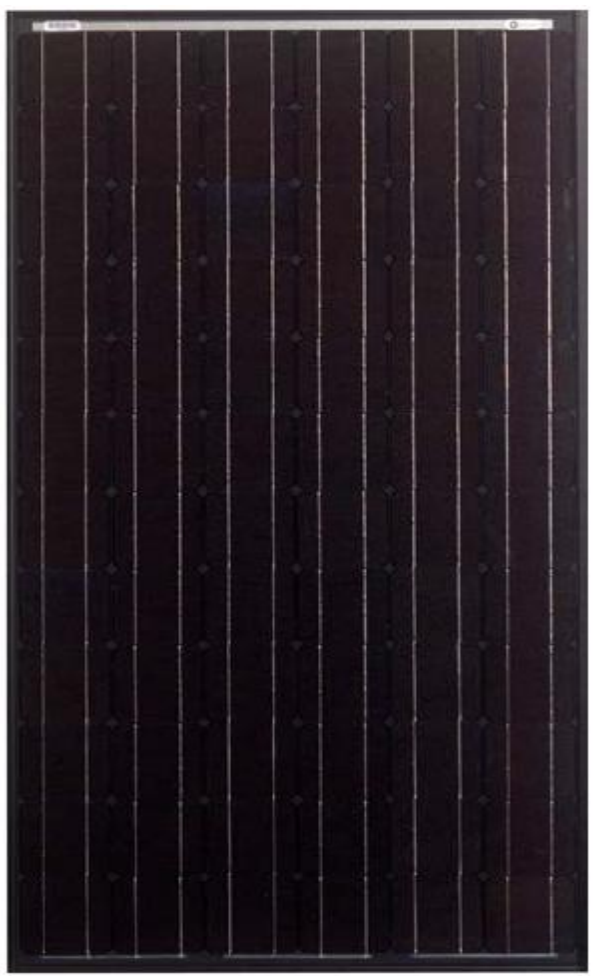

BP 4175 I-V Curves

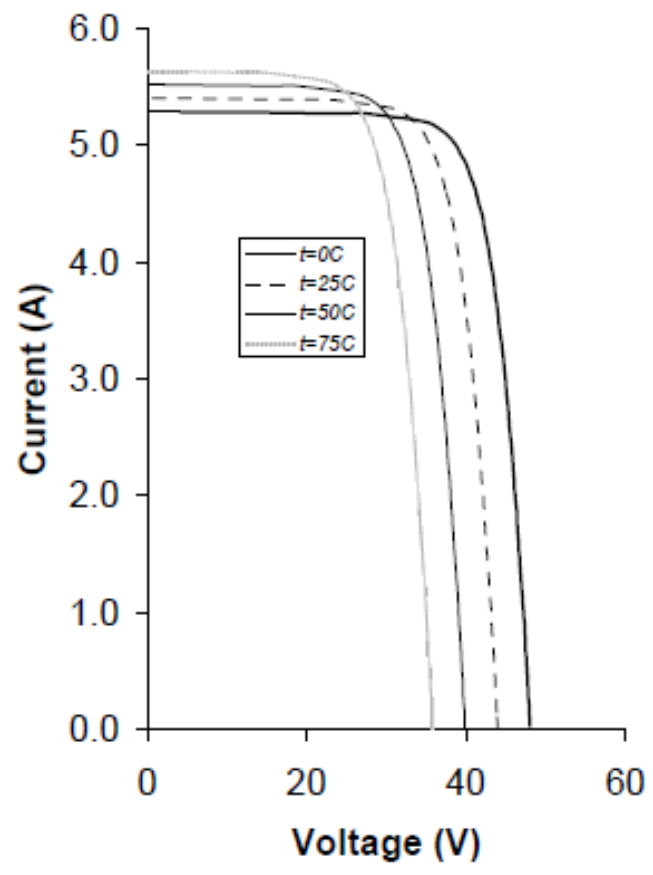

Figure 3-1: (a) BP 4175 Solar Panel (b) BP 4175 I-V Curves [16]

\subsubsection{OutBack Power Systems Components}

Currently, the Solar Decathlon House utilizes five OutBack Power Systems components which are important because WattPlot Monitor is only able to read data from OutBack components. Prior to the project, the Solar Decathlon House had two MX-60 charge controllers, one MATE, and one HUB4. The two MX-60 charge controllers were not changed during this project and are the reason why a MX-60 charge controller was used for the test setup. However, the key difference between the test setup and the Solar Decathlon House is that there are two MX-60 charge controllers in the house rather than just one in the test setup. This did not change anything with WattPlot since it 
automatically updates its user interface to display every OutBack component connected to the MATE2.

The MATE that was initially in the Solar Decathlon House is the previous version of the MATE2. Although the MATE could have been used to communicate with WattPlot Monitor, it was replaced by the MATE2. This is because the same MATE2 was used for testing and because the MATE2 is a newer version with updated software. If the MATE was used with the older software, WattPlot Monitor would have had to be reconfigured to account for the older version.

The HUB4 was also initially installed in the Solar Decathlon House. It is exactly the same as the HUB10 with the exception that it has four ports rather than ten ports along with the two MATE ports. Since the two MX-60 charge controllers and FLEXnet DC gets connected to the HUB, this means that only three ports are needed. However, if the exact same system is used except with two OutBack inverters instead of the Xantrex inverters, this would mean that the HUB4 would not be able to connect all of the OutBack components together because there would need to be five ports. With this in mind, the HUB4 was kept in the system to reduce installation time.

Finally, the FLEXnet DC was installed in the Solar Decathlon House. There was no previous FLEXnet DC, so a new mount had to be created in order to place it within the system. Also, three shunts were installed for the FLEXnet DC to monitor and measure the amount of current passing through them. Shunt 1 reads the current through two of the parallel strings of the battery bank, Shunt 2 read the current through three of the parallel strings of the battery bank, and Shunt 3 reads the total current entering or 
leaving the battery bank. These connections can be seen in the circuit diagram of Figure 3-6.

\subsubsection{Battery Bank}

The batteries being utilized for the Solar Decathlon House's battery bank are Trojan 8D-AGM batteries, as seen in Figure 3-2. The nominal voltage for each battery is $12 \mathrm{~V}$ and is rated for $230 \mathrm{Ah}$ at a 20 hour rate [17]. Within the battery bank itself, there are 24 total batteries which are configured in six parallel strings of four batteries each. This results in a nominal battery bank voltage of $48 \mathrm{~V}$.

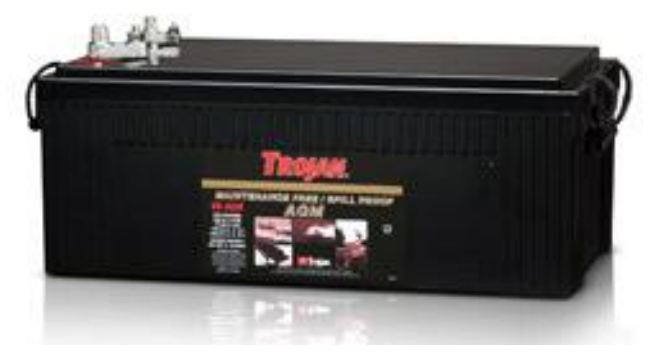

Figure 3-2: Trojan 8D-AGM Battery [17]

\subsubsection{Inverters}

The two inverters used in the Solar Decathlon House are Xantrex/Trace SW5548 Inverters, as seen in Figure 3-3. Each inverter is a pure sine wave inverter and is rated for a nominal input voltage of $48 \mathrm{~V}_{\mathrm{DC}}$ with a continuous $\mathrm{AC}$ power output of 5500VA. The output of each inverter is a $120 \mathrm{~V}_{\mathrm{AC}}$ sine wave at a frequency of $60 \mathrm{~Hz}$. Unfortunately, as stated before, the SW5548 inverter could not be used to communicate with the MATE2 because it is not an OutBack product. Therefore, the specific data off of the inverter could not be read [18]. 


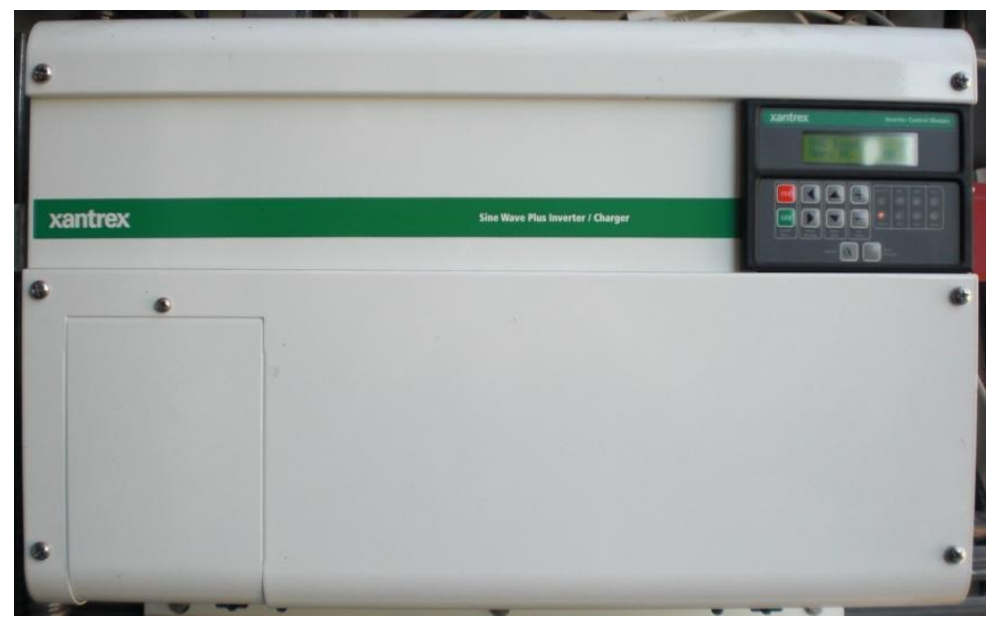

Figure 3-3: Xantrex/Trace SW5548 Inverter

\subsection{Solar Decathlon House Layout}

The electrical layout for the Solar Decathlon House can be seen in Figure A-1.

Figure 3-4 contains the layout of the components themselves within the Solar Decathlon House. Figure 3-5 displays half of the battery bank. There are two more shelves of six batteries each for the battery bank. 


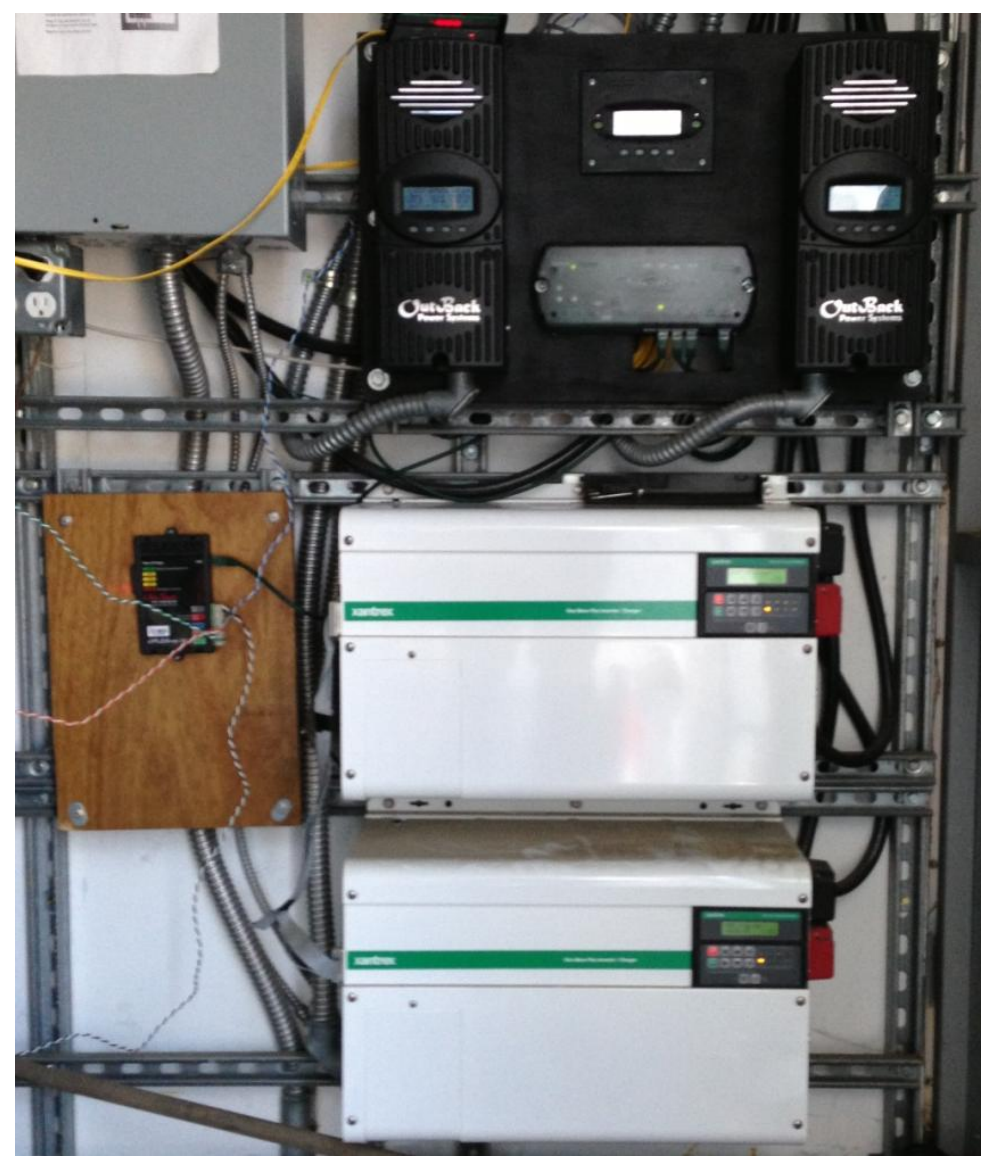

Figure 3-4: Component Layout of the Solar Decathlon House

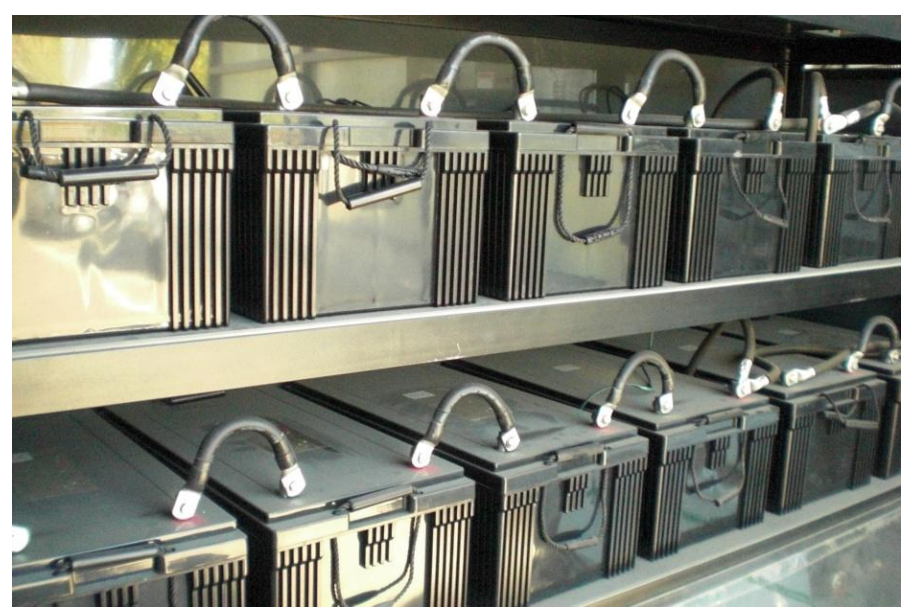

Figure 3-5: Battery Bank of the Solar Decathlon House 
As with the diagram for the test setup, the power connections were made following the red and black lines in the diagram in Figure 3-6. There are two photovoltaic arrays that feed into the $\mathrm{PV}(+)$ and $\mathrm{PV}(-)$ of two separate MX-60 MPPTCC. The Battery(+) and Battery(-) of both MX-60 MPPT-CCs are then connected to a breaker. The breaker is connected to the battery bank, which consists of six parallel strings of four batteries in series. Finally, the battery is connected to a breaker which supplies two Xantrex inverters which supply the load through a 120V/240V, 200A panel.

The communication connections were made following the green lines in the diagram in Figure 3-6. As with the test setup, each of the communication lines utilizes CAT5e cables, which also bring power to the MATE2. First, one of the MX-60 MPPTCC communication ports is connected to port 1 of the HUB4. The second MX-60 MPPT-CC is connected to port 2 of the HUB4 through its communication port. Then, the FLEXnet DC communication port is connected to port 3 of the HUB4. The FLEXnet DC measures the current through each of the shunts. As stated before, Shunt 1 measures the current through two parallel strings of the battery bank, Shunt 2 measures the current through three parallel strings of the battery bank, and Shunt 3 measures the total current entering or leaving the battery bank. Then, the MATE2 is connected to the $1^{\text {st }}$ MATE port of the HUB4 via its communication port. Finally, the MATE2 is connected to a computer through an RS-232 serial cable. 


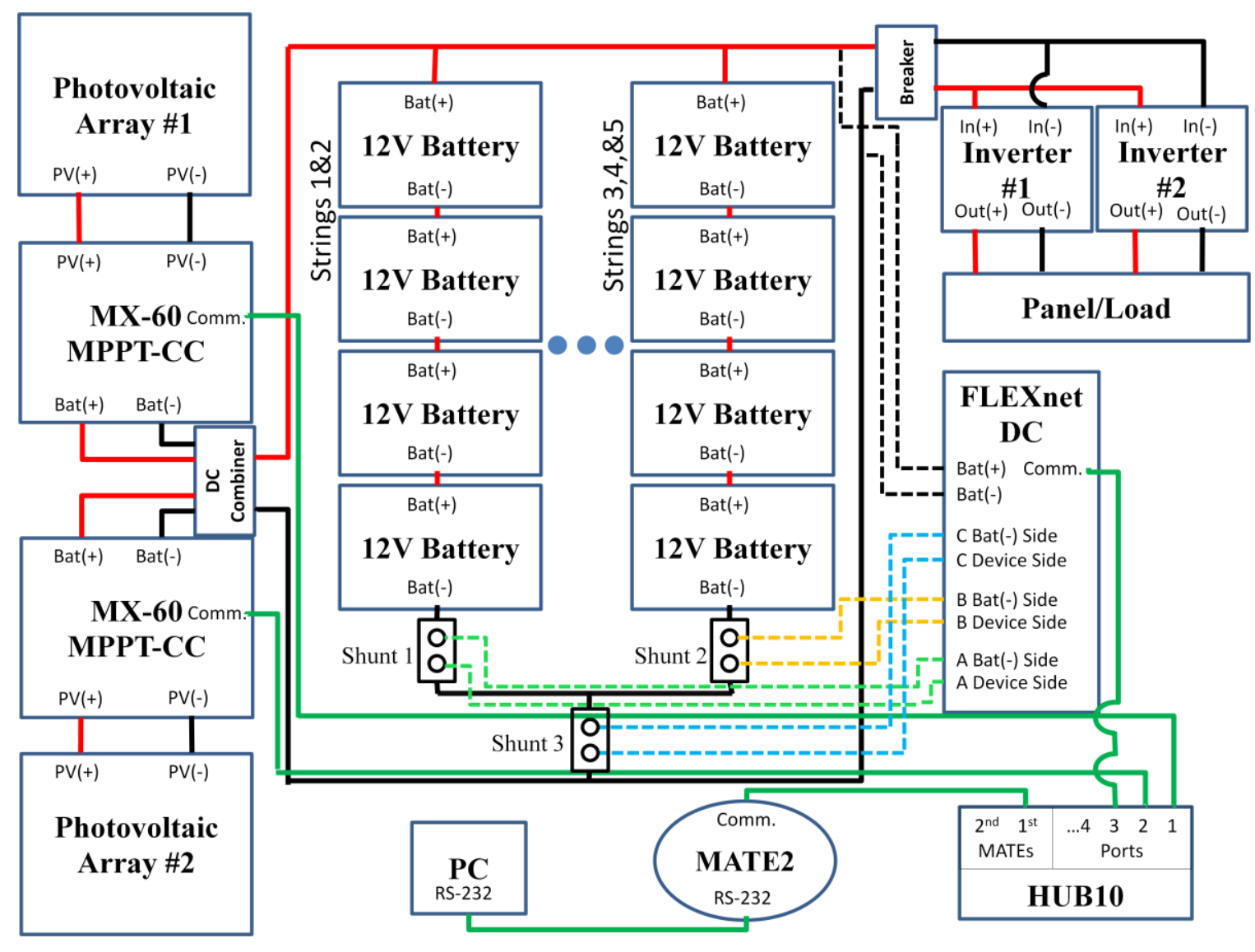

Figure 3-6: Complete Diagram for Solar Decathlon House

\subsection{Remote Monitoring Setup}

In order to setup remote monitoring, the first thing that needs to be done is setting up the computer that is connected directly to the MATE2 (the primary computer) to transmit data. To do this, the user must click on the "WattPlot as TCP Server..." button in Figure 2-15 of Section 2.3.2.1. Figure 3-7 shows the "WattPlot as a TCP/IP Server" option window. Initially, the "Allow Connection?" and "Allow MATE Commands?" are set to disabled. The user has the option to set them to open access or restricted access which would require a password. Once the access level is selected, the user is able to see their IP address, edit their listening port, and edit their password. Finally, the user needs 
to click on the "Save TCP Server Settings" button, and the set up for the primary computer is finished.

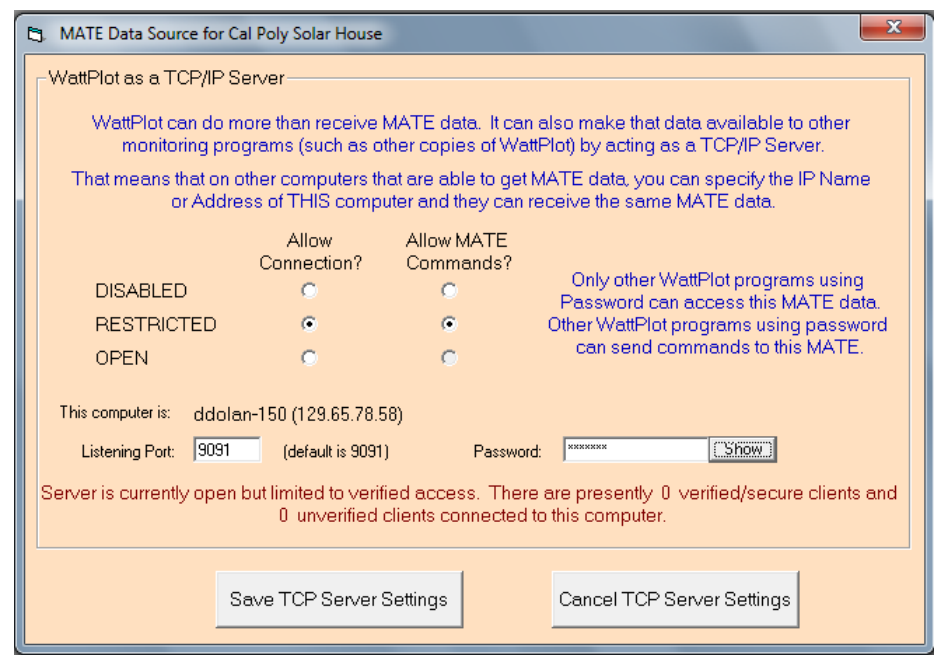

Figure 3-7: WattPlot as a TCP/IP Server Window

For the secondary computer, a comprehensive set of instructions to download and setup a free viewer version of WattPlot Monitor is given in Appendix E. Once these instructions have been followed, the secondary computer will display a replica of the primary computer's WattPlot Monitor. Please note that the secondary computer must be using Cal Poly's wireless internet connection because data cannot be sent through Cal Poly's firewall without the proper permissions.

While researching and setting up the remote monitoring, a few issues arose. First of all, any computer connected to Cal Poly's wireless internet must have the correct certificates to $\log$ on. If the user is receiving a certificate error, he or she needs to visit Cal Poly Mustang Wireless' troubleshooting webpage. Another issue that occurred is dropped connections. One possible cause of this is a weak signal. Therefore, a larger antenna was placed at the Solar Decathlon House for better connection. Another possible 
cause is a saturated access point. There is no solution for this that the user can try because this is caused by a chance occurrence that many people will log into Cal Poly's wireless internet at the same access point that the secondary computer is using. Finally, the last issue that occurred is the primary computer getting disconnected from the internet. This is due to the fact that Cal Poly protocol does not allow for a computer to stay connected to the internet wirelessly after a certain amount of time. To solve this, an IP address was requested and reserved in order to keep the same IP address and not be kicked off the wireless after a certain amount of time.

\subsection{Results}

The following data was taken while an electric vehicle was charging using the power supplied by the Solar Decathlon House.

\subsubsection{Results on Primary Computer}

After setting up the system and software as described in the previous sections of this chapter, WattPlot Monitor was run to display the real-time data of the Solar Decathlon House on the primary computer. For an explanation of the user interface, see Section 2.3.2.2 to understand what each value means, what the colors of the pen plots mean, and other meanings of the various feature of WattPlot Monitor. Otherwise, the following will be an analysis of the data from the Solar Decathlon House.

Figure 3-8 displays the real-time numeric values of the Solar Decathlon House. The first significant difference from the test setup to the Solar Decathlon House is the addition of the CC-2 row of data. This is caused by the second MX-60 within the system while the test setup only had one. The next major difference compared to the test setup 
deals with the much larger values of all the data. This is due to the fact that the Solar Decathlon House has 24 total panels with 24 batteries compared to just a single solar panel with a single battery in the test setup. As is evident, the power is up into the kilowatts with the input power from the PV array for CC-1 at $1.26 \mathrm{~kW}$ and the output power from the charger controller for CC-1 at approximately $1.21 \mathrm{~kW}$ using Eq. $2-1$. The significant figures issue that was occurring in the test setup is no longer a major issue since a few tenths of either voltage or current does not have a large affect on the power data in the order of kilowatts. Along with the larger power values, the battery temperature in the DC-1 row of data is now measuring the temperature of one of the 24 batteries in the battery bank. It is no longer displaying the default value of $-2^{\circ} \mathrm{C}$ but rather it is displaying $22^{\circ} \mathrm{C}$ which is equivalent to $71.6^{\circ} \mathrm{F}$.

One issue that was observed is that the state of charge was fluctuating more rapidly than would be expected. Looking deeper into the problem, there are only two methods that could be used in this setup to calculate the state of charge: the voltage method or the current integration method (a.k.a.: coulomb counting). The voltage method utilizes the voltage of the battery bank along with the discharge curve of the specific battery. However, since the type of battery was never specified with the software, it is impossible to get an accurate state of charge with this method. The second method, and slightly more realistic method, is the coulomb counting method. This method integrates the total current entering or leaving the battery bank which essentially results in counting the amount of coulombs entering or leaving the battery bank. However, although there was no issue with the test setup since one shunt measured input current from the MX-60 and the other shunt measured output current to the inverter, the 
Solar Decathlon House shunts do not add up to the total current entering or leaving the battery bank. Therefore, the state of charge value may not be very accurate. This would be very difficult to fix because the entire battery bank layout would need to be changed.

One significant discovery that was made using the real-time numeric values has to do with the current through each string of the battery bank. In an ideal system, an equivalent amount of current should be running through each parallel string of the battery bank. However, by inspecting the DC-1 row of data and the currents through shunts 1,2 , and 3 , this is not the case. As stated before, shunt 1 displays the current through two strings of the battery bank, shunt 2 displays the current through three other strings of the battery bank, and shunt 3 displays the total current entering or leaving the battery bank. Therefore, of the shunt 1 strings, each string has: $\frac{-2 A}{2 \text { strings }}=-1 \frac{A}{\text { string }}$ flowing through them, and of the shunt 2 strings, each string has $\frac{-20 \mathrm{~A}}{3 \text { strings }}=-6.67 \frac{\mathrm{A}}{\text { string }}$ flowing through them. This leaves $-21.9 A-(-20 A)-(-2 A)=+0.1 A$ flowing through the last string that is not being measured. It is clear through this analysis that the current through each string is not even close. This led to the hypothesis that the batteries became unbalanced overtime, and a quick voltage check of each of the batteries resulted in finding three undervoltaged batteries. To resolve this problem, those three batteries need to be replaced or be recharged to about the same voltage as the rest of the batteries if they are not damaged.

$\begin{array}{lll}\text { CC-1 } & \text { Batt: }[50.4\end{array}$

Figure 3-8: Real-Time Numeric Values from the MX-60's and FLEXnet DC 
Figure 3-9 displays the pen plots for both of the MX-60's. As stated before, the red line of the plot is the battery voltage. Since the nominal voltage of the battery bank is $48 \mathrm{~V}$, the voltage displayed is around $50 \mathrm{~V}$ since the battery bank is charging. The other two lines of the plot display the input and output power of the charge controllers. These two lines are a good representation of the maximum power point tracking aspect of the charge controllers. As the input power changes, the output power tries to follow the change in order to keep the maximum power at the output as possible.

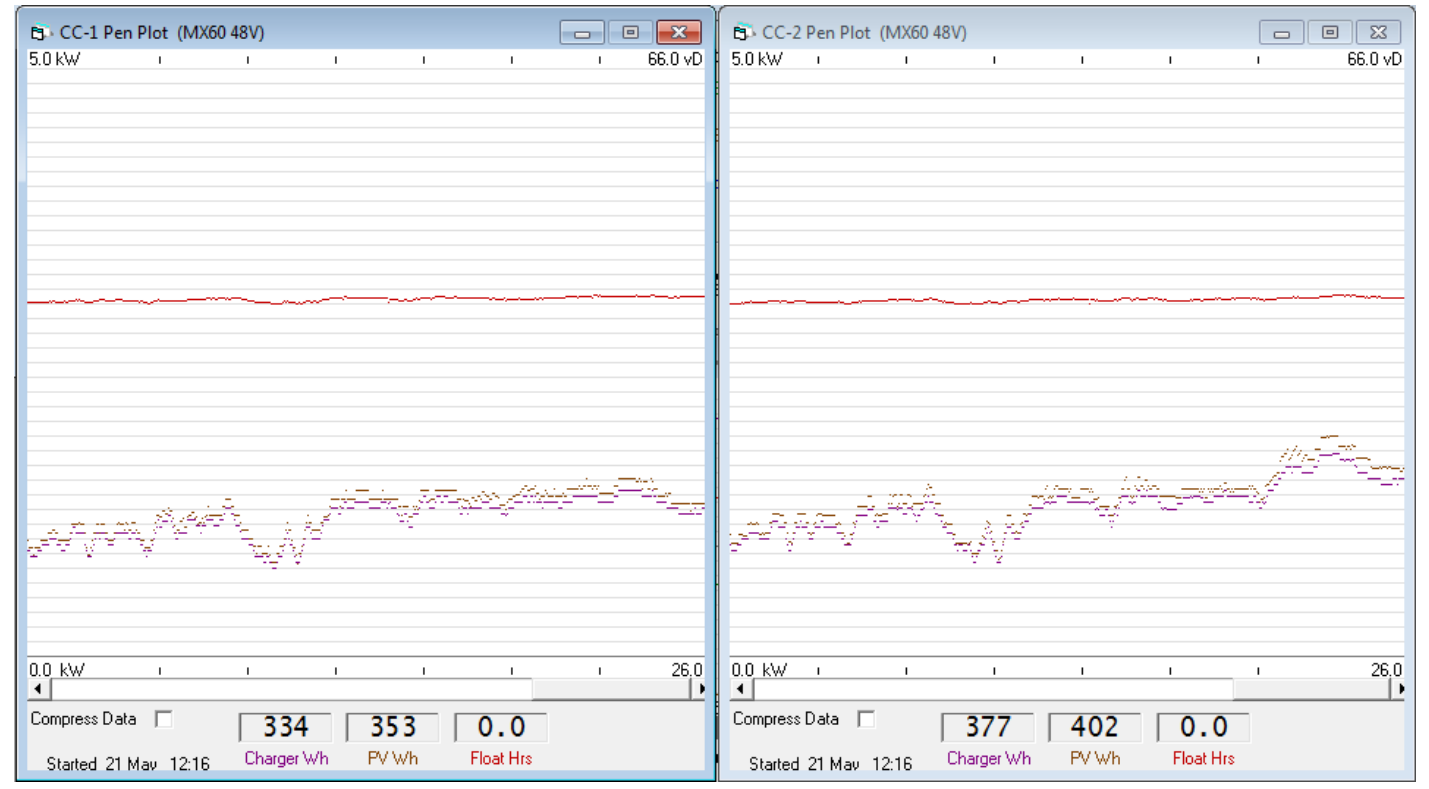

Figure 3-9: Pen Plots for Both Charge Controllers

Finally, the numeric and pen plot results of the FLEXnet DC can be seen in Figure 3-10. As stated before, this data was taken while an electric vehicle was charging using the power provided by the Solar Decathlon House. Therefore, there is no Inward $\mathrm{kWh}$ data because all of the power from the battery bank was leaving to supply such a large load, and not a significant amount of power was supplied to the battery by this time 
to add to the Inward kWh data. Other than that, there are no new issues found using the data from the FLEXnet DC, and the data from the FLEXnet DC seems to be consistent with the overall data of the system.

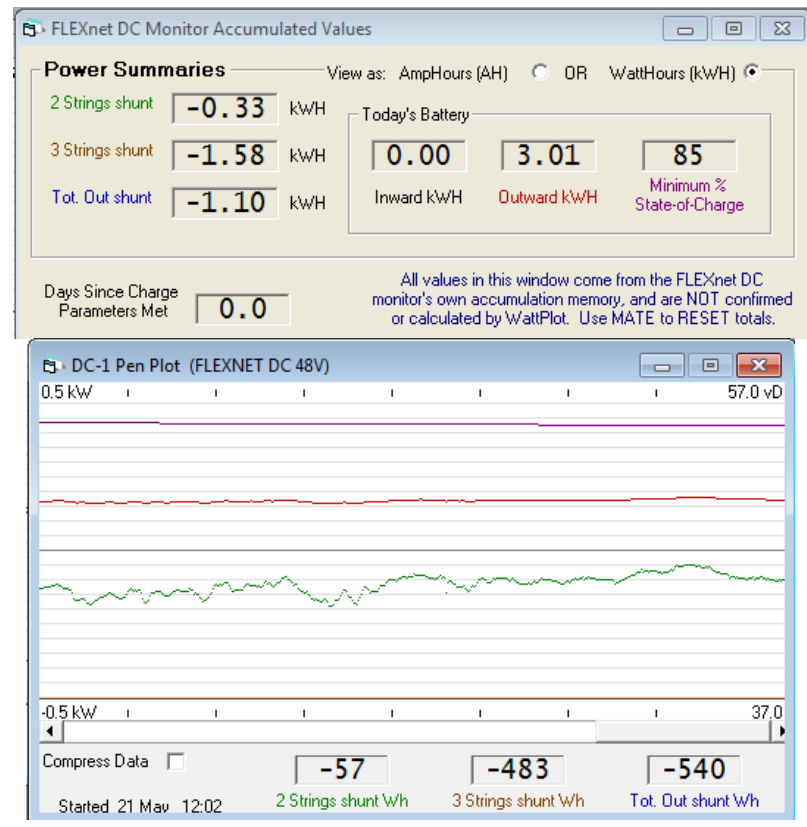

Figure 3-10: a) FLEXnet DC Numeric Results b) FLEXnet DC Pen Plot Results

\subsubsection{Results on Secondary Computer}

After setting up the WattPlot Monitor free viewer version on a secondary computer as stated in Appendix E, the secondary computer was used to monitor the Solar Decathlon House. The following data, in Figure 3-11, was taken approximately 30 minutes after the data in Section 3.4.1 was taken. As with the primary computer data, there are no new issues discovered with the secondary data. However, as mentioned previously, all the additive data for the secondary computer are not accurate. For instance, in the CC-1 pen plot in Figure 3-11b, it states that the charger has supplied 164Wh, but in Figure 3-9, the charger has supplied 334Wh of power which was 30 
minutes prior. This is due to the fact that the secondary computer does not log data.

Therefore, every time the secondary computer's monitoring is reset, all the summed data gets restarted at zero. The only way to solve this issue would be to purchase a license for WattPlot on the secondary computer, which would allow logged data on that computer.

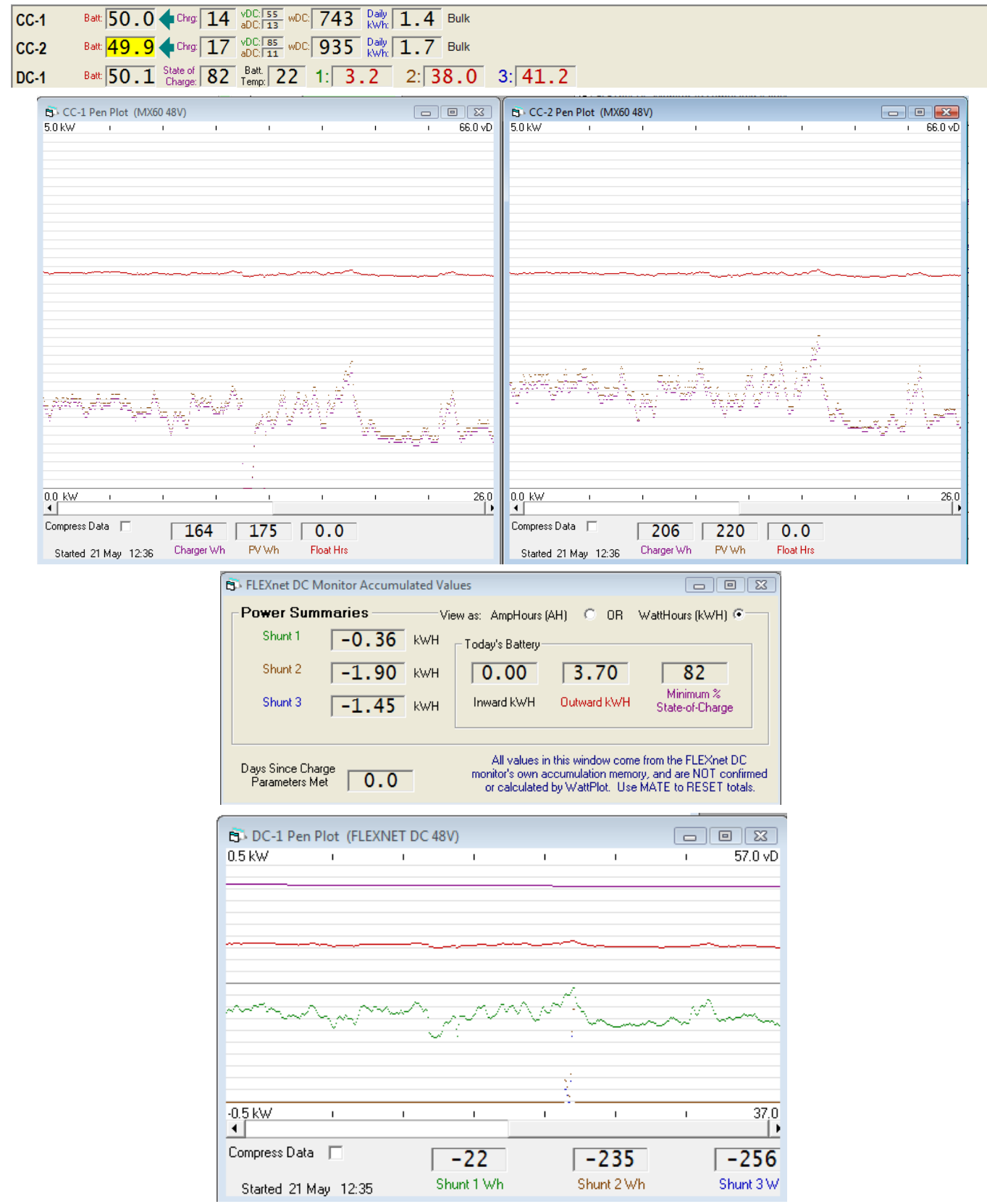

Figure 3-11: a) Total Numeric Data, b) Both MX-60 Pen Plots, c) FLEXnet DC Numeric Results, d) FLEXnet DC Pen Plot

Page 53 


\subsubsection{Excel Results using Logged Raw Data}

Once analysis of the WattPlot Monitor results was completed, the raw data from the MATE2 was captured and analyzed. Table B-2 contains the raw data from the Solar Decathlon House. The only difference compared to the test setup is that there is an extra row of data for the second charge controller that begins with "C". Also, the FLEXnet DC data begins with "c" rather than "b" as it did in the test setup. The exact same Excel script as the test setup was used except for a few changes. The largest change was the addition of the second charge controller code, but that was just copied from the first charge controller code with just the counting variables changed. Also, some counting variables and comments were changed in order to make the script flow better overall. As with the test setup, 30 seconds of raw data was run through the script and analyzed. Since the Solar Decathlon House system is larger than the test setup, the data being analyzed is much more active and varies a lot more than the test setup. Table 3-1 and Table 3-2 contain the results for the two charge controllers, and Table 3-3 contains the results for the FLEXnet DC. 
Table 3-1: Charge Controller \#1 Data for the Solar Decathlon House

\begin{tabular}{|c|c|c|c|c|c|c|}
\hline \multicolumn{7}{|c|}{ Charge Controller \#1 Data } \\
\hline Time & $\begin{array}{l}\text { PV Voltage } \\
\text { (V) }\end{array}$ & $\begin{array}{l}\text { PV Current } \\
\text { (A) }\end{array}$ & $\begin{array}{l}\text { CC Voltage } \\
(\mathrm{V})\end{array}$ & $\begin{array}{l}\text { CC Current } \\
\text { (A) }\end{array}$ & $\begin{array}{l}\text { CC } \\
\text { Mode } \\
\end{array}$ & $\begin{array}{l}\text { Daily } \\
\mathrm{kWh}\end{array}$ \\
\hline 11:45:00 AM & 56 & 24 & 50.5 & 25 & Bulk & 0.7 \\
\hline 11:45:01 AM & 56 & 23 & 50.4 & 24 & Bulk & 0.7 \\
\hline 11:45:02 AM & 56 & 23 & 50.4 & 24 & Bulk & 0.7 \\
\hline 11:45:03 AM & 56 & 22 & 50.5 & 23 & Bulk & 0.7 \\
\hline 11:45:04 AM & 56 & 22 & 50.5 & 23 & Bulk & 0.7 \\
\hline 11:45:05 AM & 57 & 22 & 50.4 & 23 & Bulk & 0.7 \\
\hline 11:45:06 AM & 57 & 22 & 50.4 & 23 & Bulk & 0.7 \\
\hline 11:45:07 AM & 57 & 21 & 50.4 & 23 & Bulk & 0.7 \\
\hline 11:45:08 AM & 58 & 21 & 50.4 & 23 & Bulk & 0.7 \\
\hline 11:45:09 AM & 58 & 21 & 50.4 & 23 & Bulk & 0.7 \\
\hline 11:45:10 AM & 59 & 20 & 50.4 & 22 & Bulk & 0.7 \\
\hline 11:45:11 AM & 59 & 21 & 50.3 & 23 & Bulk & 0.7 \\
\hline 11:45:12 AM & 59 & 21 & 50.4 & 24 & Bulk & 0.7 \\
\hline 11:45:13 AM & 60 & 23 & 50.5 & 26 & Bulk & 0.7 \\
\hline 11:45:14 AM & 60 & 24 & 50.5 & 27 & Bulk & 0.7 \\
\hline 11:45:15 AM & 61 & 25 & 50.6 & 29 & Bulk & 0.7 \\
\hline 11:45:16 AM & 61 & 26 & 50.6 & 29 & Bulk & 0.7 \\
\hline 11:45:17 AM & 62 & 26 & 50.6 & 29 & Bulk & 0.7 \\
\hline 11:45:18 AM & 62 & 25 & 50.6 & 29 & Bulk & 0.7 \\
\hline 11:45:19 AM & 63 & 25 & 50.6 & 29 & Bulk & 0.7 \\
\hline 11:45:20 AM & 63 & 24 & 50.6 & 28 & Bulk & 0.7 \\
\hline 11:45:21 AM & 64 & 24 & 50.7 & 28 & Bulk & 0.7 \\
\hline 11:45:22 AM & 63 & 23 & 50.6 & 27 & Bulk & 0.7 \\
\hline $11: 45: 23$ AM & 62 & 23 & 50.6 & 27 & Bulk & 0.7 \\
\hline 11:45:24 AM & 61 & 23 & 50.6 & 27 & Bulk & 0.7 \\
\hline $11: 45: 25$ AM & 61 & 24 & 50.6 & 27 & Bulk & 0.7 \\
\hline 11:45:26 AM & 61 & 24 & 50.6 & 27 & Bulk & 0.7 \\
\hline 11:45:27 AM & 61 & 24 & 50.6 & 28 & Bulk & 0.7 \\
\hline $11: 45: 28$ AM & 61 & 24 & 50.6 & 28 & Bulk & 0.7 \\
\hline 11:45:29 AM & 61 & 24 & 50.6 & 28 & Bulk & 0.7 \\
\hline
\end{tabular}


Table 3-2: Charge Controller \#2 Data for the Solar Decathlon House

\begin{tabular}{|c|c|c|c|c|c|c|}
\hline \multicolumn{7}{|c|}{ Charge Controller \#2 Data } \\
\hline Time & $\begin{array}{l}\text { PV Voltage } \\
\text { (V) }\end{array}$ & $\begin{array}{l}\text { PV Current } \\
\text { (A) }\end{array}$ & $\begin{array}{l}\text { CC Voltage } \\
(\mathrm{V})\end{array}$ & $\begin{array}{l}\text { CC Current } \\
\text { (A) }\end{array}$ & $\begin{array}{l}\text { CC } \\
\text { Mode } \\
\end{array}$ & $\begin{array}{l}\text { Daily } \\
\mathrm{kWh}\end{array}$ \\
\hline 11:45:00 AM & 83 & 19 & 50.4 & 29 & Bulk & 0.9 \\
\hline 11:45:01 AM & 84 & 18 & 50.4 & 29 & Bulk & 0.9 \\
\hline 11:45:02 AM & 83 & 18 & 50.4 & 29 & Bulk & 0.9 \\
\hline 11:45:03 AM & 84 & 18 & 50.4 & 28 & Bulk & 0.9 \\
\hline 11:45:04 AM & 84 & 18 & 50.4 & 28 & Bulk & 0.9 \\
\hline 11:45:05 AM & 84 & 18 & 50.4 & 28 & Bulk & 0.9 \\
\hline 11:45:06 AM & 84 & 18 & 50.4 & 27 & Bulk & 0.9 \\
\hline 11:45:07 AM & 83 & 17 & 50.4 & 27 & Bulk & 0.9 \\
\hline 11:45:08 AM & 84 & 17 & 50.4 & 27 & Bulk & 0.9 \\
\hline 11:45:09 AM & 83 & 17 & 50.4 & 26 & Bulk & 0.9 \\
\hline 11:45:10 AM & 84 & 17 & 50.4 & 26 & Bulk & 0.9 \\
\hline 11:45:11 AM & 84 & 17 & 50.4 & 27 & Bulk & 0.9 \\
\hline 11:45:12 AM & 84 & 18 & 50.5 & 28 & Bulk & 0.9 \\
\hline 11:45:13 AM & 85 & 19 & 50.5 & 30 & Bulk & 0.9 \\
\hline 11:45:14 AM & 84 & 20 & 50.6 & 32 & Bulk & 0.9 \\
\hline 11:45:15 AM & 84 & 21 & 50.6 & 33 & Bulk & 0.9 \\
\hline 11:45:16 AM & 84 & 22 & 50.6 & 33 & Bulk & 0.9 \\
\hline 11:45:17 AM & 84 & 22 & 50.6 & 33 & Bulk & 0.9 \\
\hline 11:45:18 AM & 84 & 21 & 50.6 & 33 & Bulk & 0.9 \\
\hline 11:45:19 AM & 84 & 21 & 50.6 & 32 & Bulk & 0.9 \\
\hline $11: 45: 20 \mathrm{AM}$ & 84 & 21 & 50.6 & 32 & Bulk & 0.9 \\
\hline 11:45:21 AM & 84 & 20 & 50.5 & 31 & Bulk & 0.9 \\
\hline 11:45:22 AM & 85 & 20 & 50.6 & 31 & Bulk & 0.9 \\
\hline 11:45:23 AM & 85 & 19 & 50.6 & 30 & Bulk & 0.9 \\
\hline 11:45:24 AM & 85 & 20 & 50.6 & 31 & Bulk & 0.9 \\
\hline $11: 45: 25$ AM & 85 & 20 & 50.6 & 31 & Bulk & 0.9 \\
\hline $11: 45: 26$ AM & 85 & 20 & 50.6 & 31 & Bulk & 0.9 \\
\hline $11: 45: 27 \mathrm{AM}$ & 85 & 20 & 50.6 & 32 & Bulk & 0.9 \\
\hline $11: 45: 28$ AM & 85 & 20 & 50.6 & 32 & Bulk & 0.9 \\
\hline 11:45:29 AM & 85 & 20 & 50.6 & 32 & Bulk & 0.9 \\
\hline
\end{tabular}


Table 3-3: FLEXnet DC Data for the Solar Decathlon House

\begin{tabular}{|c|c|c|c|c|c|c|}
\hline \multicolumn{7}{|c|}{ FLEXnet DC \#1 Data } \\
\hline Time & $\begin{array}{l}\text { Shunt A } \\
\text { (A) }\end{array}$ & $\begin{array}{l}\text { Shunt B } \\
\text { (A) }\end{array}$ & $\begin{array}{l}\text { Shunt C } \\
\text { (A) }\end{array}$ & $\begin{array}{l}\text { Bat. Voltage } \\
\text { (V) }\end{array}$ & $\begin{array}{l}\text { State of Charge } \\
(\%)\end{array}$ & $\begin{array}{l}\text { Bat. Temp. } \\
\text { (C) }\end{array}$ \\
\hline 11:45:00 AM & -2.2 & -15.2 & -17.3 & 50.5 & 90 & 22 \\
\hline 11:45:01 AM & -2.6 & -16.9 & -19.5 & 50.5 & 90 & 22 \\
\hline 11:45:02 AM & -2.7 & -17.2 & -19.8 & 50.5 & 90 & 22 \\
\hline 11:45:03 AM & -2.8 & -17.6 & -20.2 & 50.5 & 90 & 22 \\
\hline 11:45:04 AM & -2.8 & -17.6 & -20.2 & 50.5 & 90 & 22 \\
\hline 11:45:05 AM & -3 & -18.5 & -21.4 & 50.5 & 90 & 22 \\
\hline 11:45:06 AM & -3 & -18.7 & -21.6 & 50.5 & 90 & 22 \\
\hline 11:45:07 AM & -3.1 & -19.1 & -22.1 & 50.5 & 90 & 22 \\
\hline 11:45:08 AM & -3.2 & -19.8 & -22.8 & 50.5 & 90 & 22 \\
\hline 11:45:09 AM & -3.4 & -20.2 & -23.5 & 50.5 & 90 & 22 \\
\hline 11:45:10 AM & -3.4 & -20.6 & -23.9 & 50.5 & 90 & 22 \\
\hline 11:45:11 AM & -3.3 & -20.5 & -23.8 & 50.5 & 90 & 22 \\
\hline $11: 45: 12$ AM & -3.1 & -19.6 & -22.7 & 50.5 & 90 & 22 \\
\hline 11:45:13 AM & -2.5 & -16.9 & -19.2 & 50.5 & 90 & 22 \\
\hline 11:45:14 AM & -1.7 & -13.7 & -15.3 & 50.5 & 90 & 22 \\
\hline $11: 45: 15$ AM & -1.2 & -11.3 & -12.4 & 50.6 & 90 & 22 \\
\hline 11:45:16 AM & -0.8 & -9.5 & -10.2 & 50.6 & 90 & 22 \\
\hline 11:45:17 AM & -0.7 & -8.9 & -9.3 & 50.6 & 90 & 22 \\
\hline 11:45:18 AM & -0.7 & -8.9 & -9.6 & 50.6 & 90 & 22 \\
\hline 11:45:19 AM & -1 & -9.7 & -10.4 & 50.6 & 90 & 22 \\
\hline 11:45:20 AM & -1.1 & -10.4 & -11.3 & 50.6 & 90 & 22 \\
\hline 11:45:21 AM & -1.3 & -11.1 & -12.2 & 50.6 & 90 & 22 \\
\hline 11:45:22 AM & -1.5 & -12.1 & -13.5 & 50.6 & 90 & 22 \\
\hline 11:45:23 AM & -1.8 & -13.1 & -14.7 & 50.6 & 90 & 22 \\
\hline 11:45:24 AM & -2 & -13.8 & -15.6 & 50.6 & 90 & 22 \\
\hline 11:45:25 AM & -1.8 & -13.2 & -14.9 & 50.6 & 90 & 22 \\
\hline 11:45:26 AM & -1.7 & -12.8 & -14.4 & 50.6 & 90 & 22 \\
\hline $11: 45: 27$ AM & -1.6 & -12.2 & -13.6 & 50.6 & 90 & 22 \\
\hline 11:45:28 AM & -1.5 & -11.9 & -13.3 & 50.6 & 90 & 22 \\
\hline $11: 45: 29$ AM & -1.4 & -11.6 & -12.8 & 50.6 & 90 & 22 \\
\hline
\end{tabular}


All of the results from running the raw data through the Excel script were as expected. No new problems were found. However, the effects from the problem with the unbalanced batteries in the battery bank can be seen in each second of data from the FLEXnet DC. Overall, all of the data seems accurate except for the state of charge which was discussed before.

Finally, a small chart for important information for making graphs was added, which can be seen in Table 3-4. After trying to program the Excel script to add charts, it was concluded that it would be much easier for the user to manually enter the data that the user wants to appear in a graph. However, it is possible to have thousands of lines of data. Therefore, the chart for important information gives the first and last row of data in and instructions on how to use this data. All the user has to do is choose a specific column of data for the $\mathrm{x}$-axis and $\mathrm{y}$-axis and enter the first to last row of that column in the graph option of Excel.

Table 3-4: Information to Make Graphs

\begin{tabular}{|l|c|}
\hline \multicolumn{2}{|c|}{ Information for Graphs } \\
\hline First Row of Data & Last Row of Data \\
\hline 3 & 32 \\
\hline \multicolumn{2}{|c|}{ Instructions: 1)Insert New Graph } \\
2)Use column of Time Values as X \\
Values starting from 'First Row of \\
Data' to 'Last Row of Data' \\
3)Select any other column for Y \\
Values starting from 'First Row of \\
Data' to 'Last Row of Data' \\
\hline
\end{tabular}




\section{Grid-Tied Systems}

The Solar Decathlon House discussed in Chapter 3 is a stand-alone system and was created for the 2005 Solar Decathlon. In the next couple of years, there is a possibility that another group of Cal Poly students will enter the Solar Decathlon competition once again; however, their entry will most likely be a grid-tied, photovoltaic system. For the Solar Decathlon competition, the competition's organizers provide "an electric power grid that provides AC power to and accepts $\mathrm{AC}$ power from the houses" [19]. Therefore, although the grid-tied system will be tied to a grid, it will not be tied to the utility grid.

Depending on the layout, a grid-tied system may be a bit more complicated to monitor because there could be less components to read data from the panels to inverters. While there are many differences between stand-alone and grid-tied photovoltaic systems, one of the biggest advantages is that it usually uses fewer components although this is not always the case. Since the system is connected to the grid, it is no longer a necessity to store energy within a battery bank for times when the photovoltaic panels are not producing. However, there are some grid-tied systems that use a battery bank as a backup just in case there is a power outage on the grid although not having a battery bank results in much less cost. One disadvantage to a grid-tied system is that the output of the inverter must be synchronized to the grid, which means the inverter cannot be a low quality modified sine wave inverters. Because the utility grid supplies such vast amounts 
of people, much stricter regulations must be met in order to connect to the grid and buy and sell power to the utility. According to Photovoltaic Systems Engineering by Roger Messenger and Jerry Ventre, “In 2000, IEEE adopted Standard 929-2000. Any PV system meeting the performance criteria of IEEE Standard 929, using power conditioning

units/inverters listed under UL 1741 and installed in accordance with the current National Electrical Code, automatically met all established technical performance criteria" [20]. Since then, IEEE has made some changes to their standards which are reproduced in IEEE 1547-2003. Therefore, just to tie a system to the grid, that system needs to be in accordance with three different criteria created by IEEE.

In this chapter, three different grid-tied systems will be proposed: a battery backed grid-tied system, a non-battery backed grid tied system, and a grid-tied system with microinverters. For each system, a components, monitoring, and cost analysis will be performed. In the end, there should be a greater understanding of each system while comparing its components and costs.

\subsection{Battery Backed Grid-Tied System}

The battery backed grid-tied system is nearly identical to the Solar Decathlon House's stand-alone system with the exception that it will be connected to the grid. Figure 4-1 shows the block diagram of the proposed battery backed system. One thing to note is that it is an identical system as the stand-alone system in Figure 3-6 of Chapter 3 except with the output of the inverters going to the grid as well as the house. Since the two systems are nearly identical, the analysis of the battery backed grid-tied system was done assuming the same battery bank as the Solar Decathlon House. 


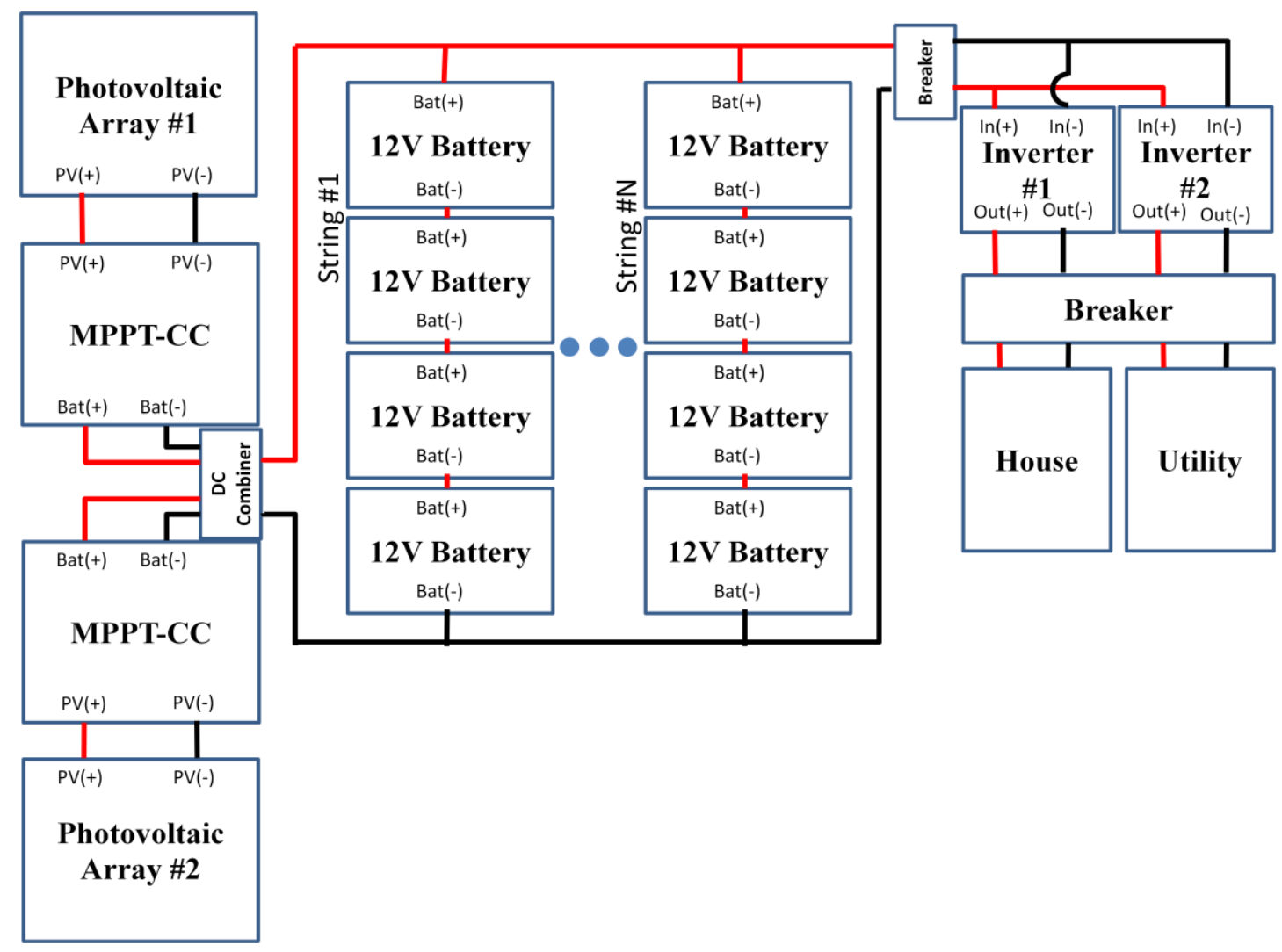

Figure 4-1: Battery Backed Grid-Tied System

\subsubsection{Component Analysis}

Since this system is extremely identical to the Solar Decathlon House's system, OutBack Power Systems components were chosen to be utilized for this system. After researching through the OutBack Power Systems components, the OutBack FLEXpower TWO (FP2-29) is being proposed for this system. The FP2-29 is a kit containing the majority of the components needed to run a $7.2 \mathrm{~kW}$ grid-tied photovoltaic system. It comes with two GTFX3648 inverter/chargers, a MATE2, a HUB10, pre-wired AC and DC boxes, two 175ADC breakers, and a few other minor things. Unfortunately, a separate purchase of a charge controller and FLEXnet DC will need to occur because these components do not come in the FP2-29 kit. 
The GTFX3648 inverter/charger is an inverter specifically designed to connect to the grid. It utilizes a $48 \mathrm{~V}$ input voltage and has a continuous power rating of 3600VA [21]. OutBack Power Systems recommends using the FLEXmax 80 maximum power point tracking charge controller. The FLEXmax 80 is identical to the MX-60 analyzed in the previous chapters except with a maximum output current of $80 \mathrm{~A}$ rather than $60 \mathrm{~A}$. The MATE2, HUB10, and FLEXnet DC were analyzed as part of the systems for the test setup and the Solar Decathlon House. Finally, the batteries being proposed for this system are the same batteries as the Solar Decathlon House. Analysis of the Trojan 8DAGM can be found in Section 3.1.3.

\subsubsection{Monitoring Analysis}

Another advantage of having this system as similar to the Solar Decathlon House as possible is the fact that the same monitoring programs can be used. Since WattPlot Monitor is compatible with OutBack Power System components, it can be used in the same manner as the Solar Decathlon House. The only changes made to the software would be during setup in which the user would have to add two FX inverters to be monitored and also specify that the system is grid-tied. One change to the hardware must be done as well. The Solar Decathlon House has the MX-60 charge controllers connected to port 1 and port 2 of the HUB4 in the system. However, since two more devices are being added which makes five devices in total (the two inverters, the two charge controllers, and the FLEXnet DC), a HUB10 needs to be used and the inverters need to be connected to port 1 and port 2 while shifting down the charge controllers and FLEXnet DC down to the next available ports. 
The Excel script for the MATE raw data created in Chapters 2 and 3 would also work for the most part. Since no functionality was written into the script to analyze data from the inverters, a small addition to the script would need to be added to extract and sort the raw data. The user would need to analyze the inverter raw data using the "MATE Serial Communications Manual" [15] in order to understand the raw data. Other than that, all of the counters and user inputs should remain the same for the Excel script.

\subsubsection{Cost Analysis}

Table 4-1 contains a list of equipment and costs of the proposed battery backed grid-tied system. Since the objective is to obtain a system as similar to the Solar Decathlon House, the exact same number of batteries was assumed.

Table 4-1: Cost Analysis of Battery Back Grid-Tied System

\begin{tabular}{|c|c|c|c|}
\hline Component & Quantity & Price/unit & Subtotal \\
\hline FLEXpower TWO (FP2-29) & 1 & $\$ 5,100.00$ & $\$ 5,100.00$ \\
\hline FLEXmax 80 & 2 & $\$ 578.25$ & $\$ 1,156.50$ \\
\hline FLEXnet DC & 1 & $\$ 275.00$ & $\$ 275.00$ \\
\hline Trojan 8D-AGM Batteries & 24 & $\$ 564.84$ & $\$ 13,556.16$ \\
\hline \multicolumn{2}{|r}{} & Total & $\$ 20,087.66$ \\
\hline
\end{tabular}

As is evident from the Table 4-1, the batteries are by far the most expensive portion of the system. Without the batteries, the system as a whole would have cost less than $\$ 7,000$. 


\subsection{Non-Battery Backed Grid-Tied System}

The non-battery backed grid-tied system is a common type of system for those who do not want to increase their costs by buying a battery bank. Figure 4-2 contains the block diagram for the proposed system. As with the name of this system, there is no battery bank to store energy within this system. Another thing that this system does not contain is maximum power point tracking charge controllers. The main purpose of charge controllers is to charge the batteries at the fastest but safest rate possible or to disconnect the batteries if they have a dangerously low state of charge. Since there are no batteries in this system, the charge controllers are no longer a necessity. This means that whenever the PV array is not producing enough power for the house, the grid will compensate for the lack of power, and if the $\mathrm{PV}$ array is producing more power than the house requires, then the extra power will be put onto the grid.

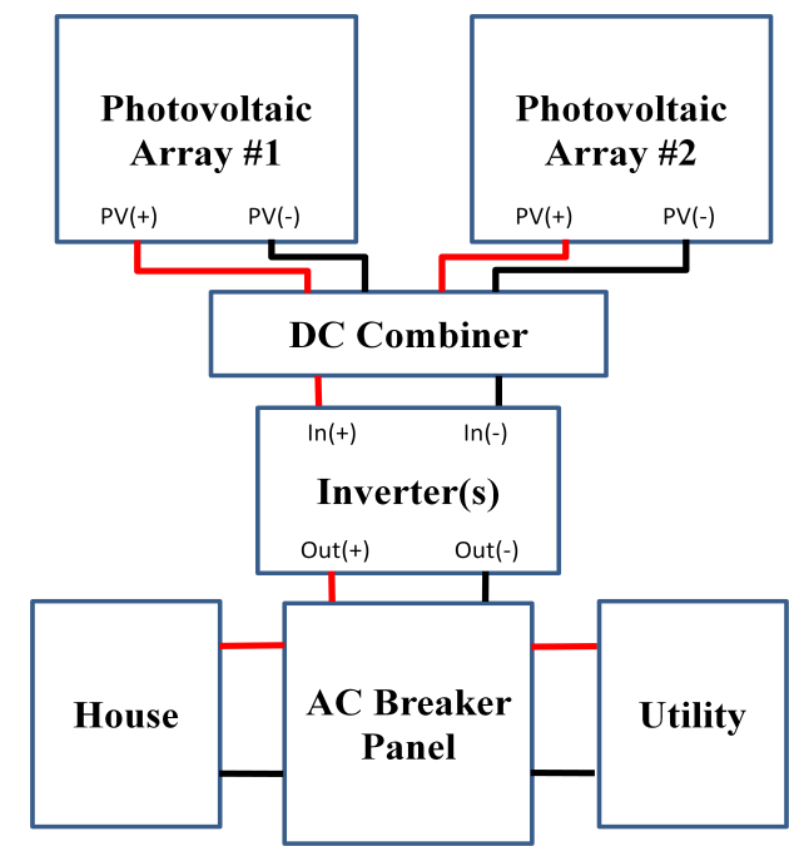

Figure 4-2: Non-Battery Backed Grid-Tied System 


\subsubsection{Component Analysis}

While talking with Bernie Boglioli, a Hawai`i sales and technical support manager, he mentioned that OutBack inverters would not work on this system because of the fact that it does not contain a battery bank. He mentioned that not all inverters are built the same because some inverters need to be connected to a battery bank in order to operate and others needed to be connected to the grid in order to operate. If either type of inverter is not connected to what they are designed to be connected to, they may simply just not turn on, which is a designed safety feature. For instance, if there is a power outage and a grid-tied inverter does not sense the grid anymore, it is better for it to be off so that it is not supplying power to the grid in the case that workers are repairing a part of the grid. It would be very unsafe for utility workers to believe they are working on a part of the grid with no power, when in fact, they are getting power from somewhere other than the utility's generators [22].

With this in mind, Mr. Boglioli suggested the SMA Sunny Boy series. After researching the SMA Sunny Boy series, a SMA Sunny Boy 5000-US was chosen for this system. The Sunny Boy 5000-US is rated for a maximum rated PV power of $6.25 \mathrm{~kW}$ with a maximum DC voltage of $600 \mathrm{~V}$. Its nominal DC voltage is $310 \mathrm{~V}$ with a maximum input current $21 \mathrm{~A}$ per string. The Sunny Boy $5000-\mathrm{US}$ is able to output $208 \mathrm{~V}_{\mathrm{AC}}$, $240 \mathrm{~V}_{\mathrm{AC}}$, or $277 \mathrm{~V}_{\mathrm{AC}}$ with a nominal frequency of $60 \mathrm{~Hz}$ which ranges between $59.3 \mathrm{~Hz}$ to $60.5 \mathrm{~Hz}$. Its maximum AC apparent power is 5000VA and has an efficiency of approximately $96.8 \%$ [23]. Because of the simplicity of this system, the Sunny Boy is the only new component needed. 


\subsubsection{Monitoring Analysis}

SMA conveniently produces monitoring tools for their components. The monitoring device chosen for this system is the SMA Sunny WebBox. Like the OutBack MATE2, the Sunny WebBox can be used to control the system or to log data from the system components. The Sunny WebBox can be connected directly to the Sunny Boy 5000-US via an Ethernet connection or RS485 communication bus. Then, the Sunny WebBox is connected directly to the computer via a Cat5 Ethernet connection. Once the physical connections are made, the computer may transmit the data once the static network settings are input into the computer program. There is also a method to obtain the raw data from the Sunny WebBox, which could possibly be used for creating a program like the Excel script for the Solar Decathlon House. For more information or

more detailed directions, the "Sunny WebBox User Manual" has a lot of information regarding setup and monitoring [24].

Once the Sunny WebBox has been setup, SMA offers an online tool to view the systems data called Sunny Portal. Sunny Portal offers graphs of the monthly yield in kilowatt-hour and an hourly yield in both kilowatt and kilowatt-hour. There are also daily energy and power overviews that can be generated. There is also a functionality to make this data available to the public. By visiting www.sunnyportal.com, there are public systems that can be viewed. Figure 4-3 and Figure 4-4 contain images of a system in San Luis Obispo, CA, directly from the Sunny Portal website [25]. 


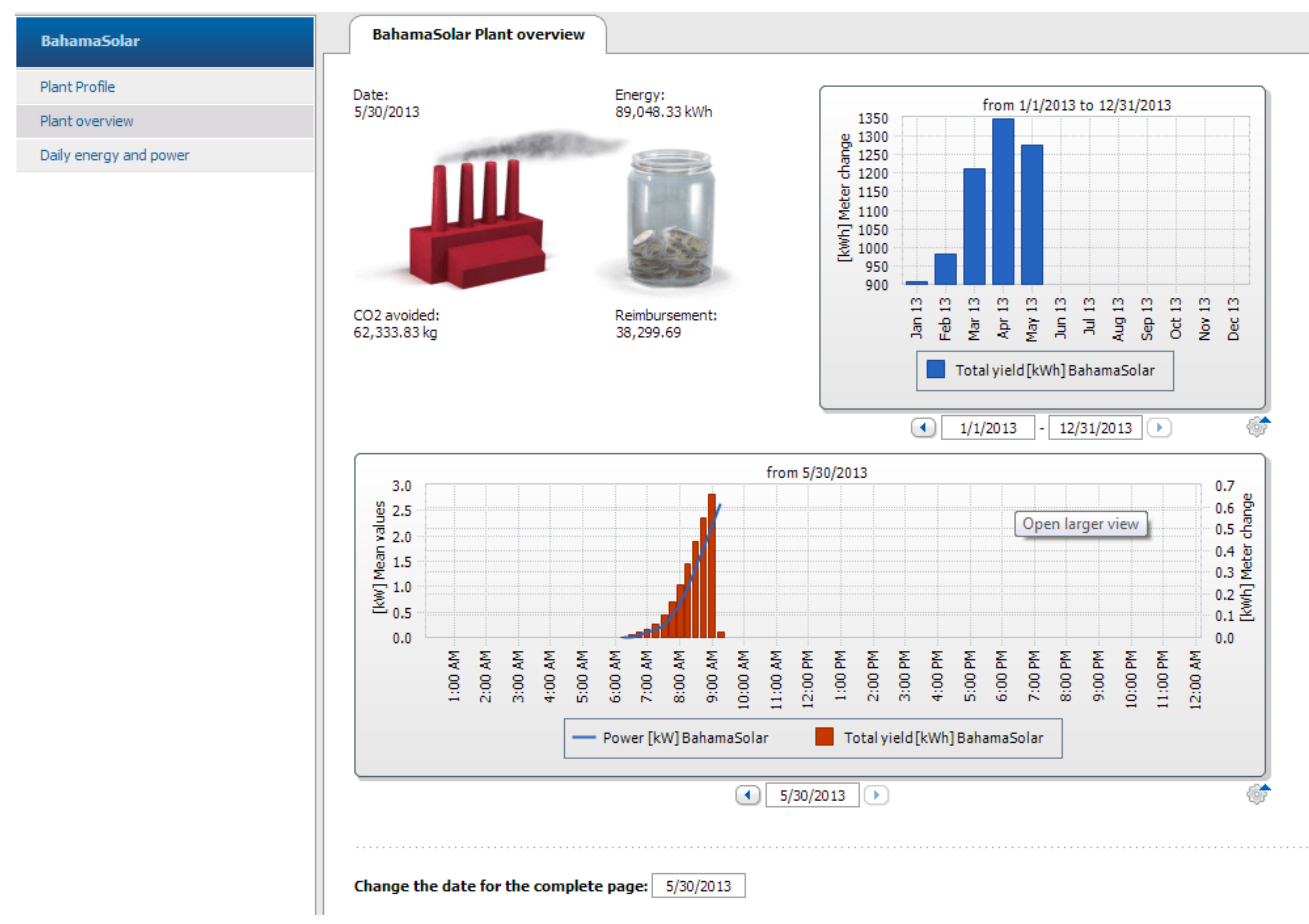

Figure 4-3: System Overview for Sunny Portal

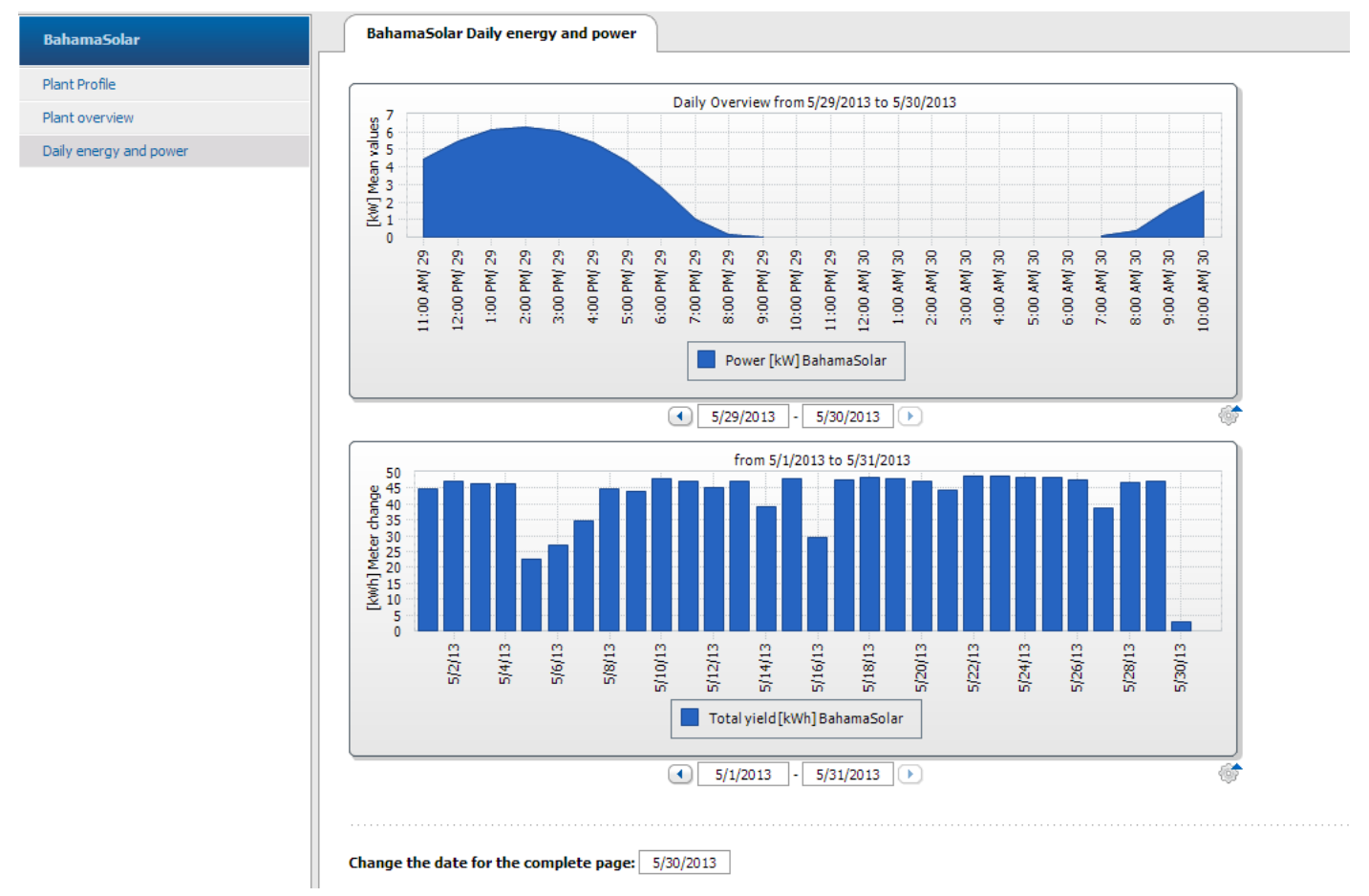

Figure 4-4: Daily Energy and Power Overview for Sunny Portal 


\subsubsection{Cost Analysis}

Table 4-2 contains the cost analysis of the non-battery backed grid-tied system. Besides the PV panels which is not included in any of the cost analysis, the Sunny Boy 5000-US is the only major component to purchase for system functionality. However, the Sunny WebBox also adds a bit more to the price.

Table 4-2: Cost Analysis for Non-Battery Backed Grid-Tied System

\begin{tabular}{|c|c|c|c|}
\hline Component & Quantity & Price/unit & Subtotal \\
\hline SMA Sunny Boy 5000-US & 1 & $\$ 1,578.95$ & $\$ 1,578.95$ \\
\hline Sunny WebBox & 1 & $\$ 620.00$ & $\$ 620.00$ \\
\hline \multicolumn{2}{|r|}{} & Total & $\$ 2,198.95$ \\
\cline { 3 - 4 }
\end{tabular}

As is evident from the cost analysis table, this system is just a fraction of the battery backed grid-tied system. This is largely due to the fact that there is not a battery bank in this system.

\subsection{Microinverter Based Grid-Tied System}

The final proposed system is a grid-tied system that utilizes one microinverter for each photovoltaic panel rather than one centralized inverter for the entire photovoltaic array. The microinverters are typically rated for much lower power than a single inverter since it is only inverting the DC power from one panel. One advantage to this method is that the overall efficiency of the photovoltaic array could potentially be greater. This is because by converting each panel to AC power, array mismatch would be negated, and if there is shading on a panel, it would not hurt the output from an entire array. Also, the microinverters are generally smaller physically and cheaper per unit. However, depending on how many panels the system contains, the price could end up being more 
because there would need to be a microinverter per panel. On the other hand, the main disadvantage of the microinverter system is that the microinverters are usually connected directly to the panel and housed along the support frame of the panels. This means that the microinverters are in a much higher temperature environment than standard inverter which could cause the electronics to fail at a higher rate. It also means that if there is a failure, the microinverters would be harder to reach in order to perform maintenance [20]. All in all, as with any system, a lot of research should go into the design of a system in order to ensure that microinverters are the best choice for that system.

Figure 4-5 shows a basic block diagram of a microinverter based grid-tied system. As with the non-battery backed grid-tied system, there is only one major component besides the photovoltaic panels which is the microinverters. However, unlike the previous system, there are multiple microinverters which are individually connected to a panel directly. The microinverter outputs are then combined and sent to either the house or the grid.

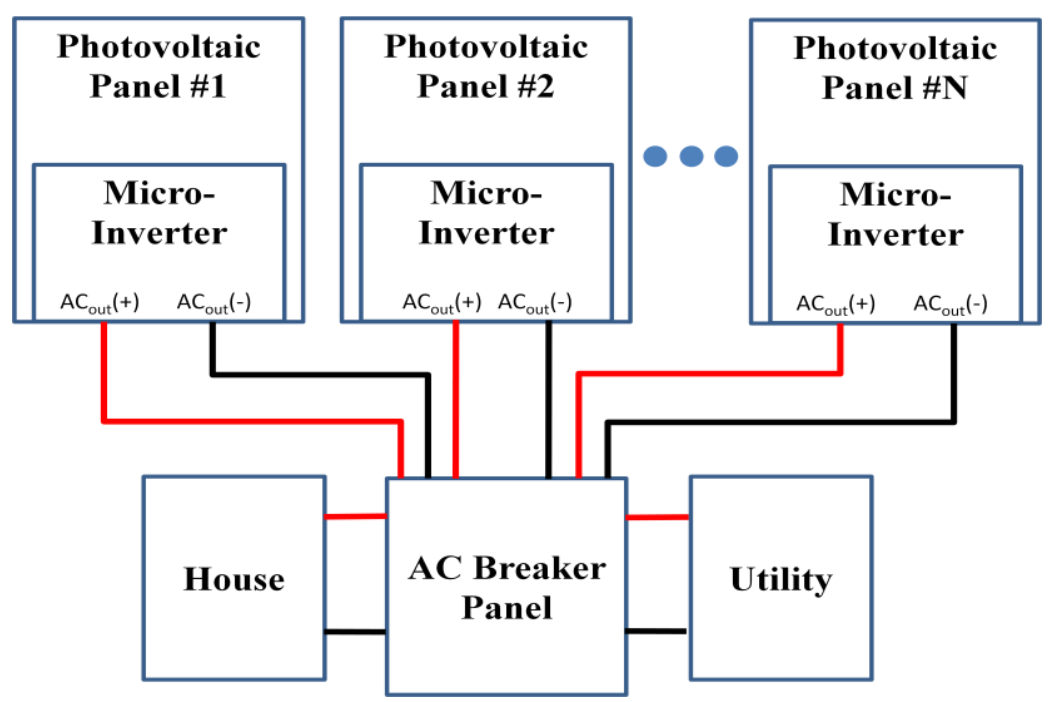

Figure 4-5: Microinverter Based Grid-Tied System Block Diagram 


\subsubsection{Component Analysis}

As with the non-battery backed grid-tied system, there is only one major system component besides the photovoltaic panels, and it is the microinverters. The proposed microinverter is an Enphase M215 Microinverter. Their recommended input power rating is a range from $190 \mathrm{~W}$ to $270 \mathrm{~W}$ while its maximum input voltage and current are $45 \mathrm{~V}$ and $10.5 \mathrm{~A}$ respectively. It has two nominal output voltage levels which are $208 \mathrm{~V}_{\mathrm{AC}}$ and $240 \mathrm{~V}_{\mathrm{AC}}$ with a frequency between $59.3 \mathrm{~Hz}$ and $60.5 \mathrm{~Hz}$. Its rated continuous output power is $215 \mathrm{~W}$. Finally, the M215 meets the following compliances:

UL1741/IEEE1547, FCC Part 15 Class B CAN/CSA-C22.2 NO. 0-M91, 0.4-04, and 107.1-01, and it is compatible with most 60 cell PV panels [26].

\subsubsection{Monitoring Analysis}

As with SMA's monitoring system, Enphase also produces a monitoring system designed especially for their products. Their monitoring system utilizes the Envoy Communications Gateway and Enlighten Software. The Envoy Communications Gateway is a hub into which all of the microinverters in a system connect. The connections from the microinverters to the Gateway are made through existing electrical lines. From there, the Gateway can connect to a standard broadband router to transmit the data. The Enlighten Software is used to display the status of the system over a webbased interface. It can display daily, weekly, monthly, or lifetime graphs of the systems

outputs. It can also send reports to the user with summary reports or error reports [27].

Figure 4-6, Figure 4-7, and Figure 4-8 show Enlighten's web-based display of a system. The system being shown is a residential system with eight total microinverters in 
San Luis Obispo, CA, with data being taken on May 31, 2013 at 8:00 a.m. One of the major benefits of this display is that in Figure 4-6, it shows the output of each microinverter. Therefore, if one of the microinverters was not working properly, it would be very easy to diagnose which microinverter was in need of repair.

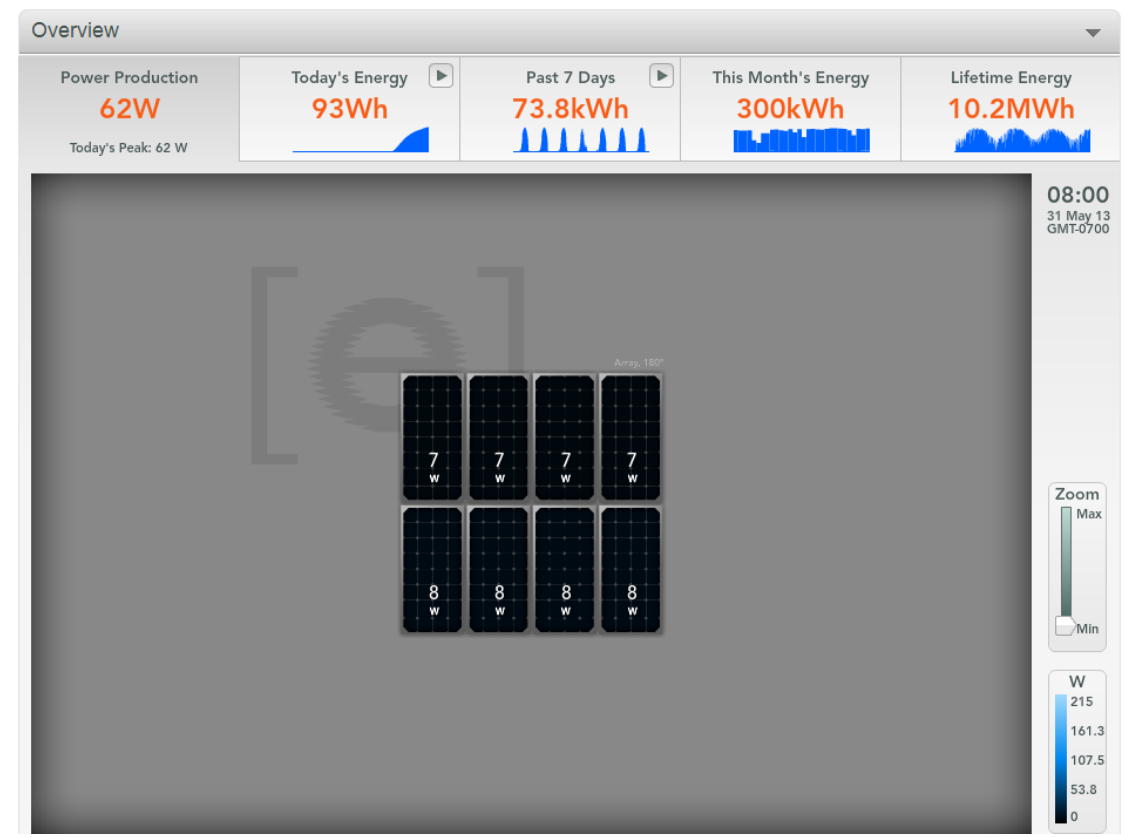

Figure 4-6: Enlighten's Overview Display

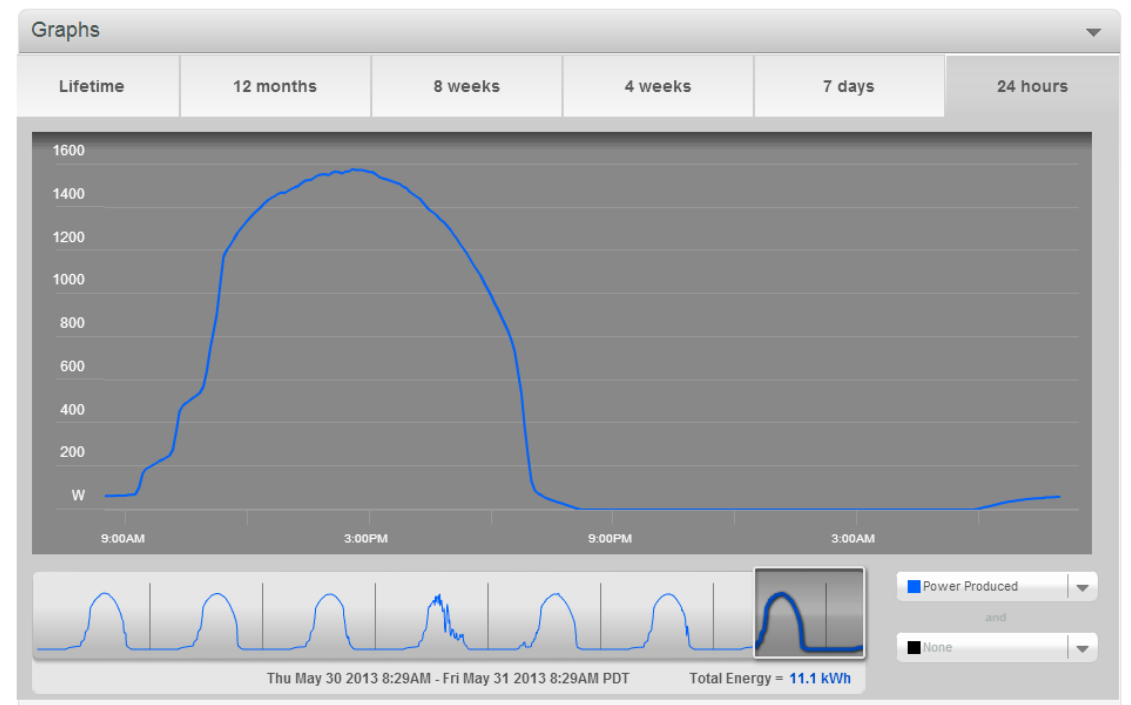

Figure 4-7: Enlighten's Graphs Display

Page 71 


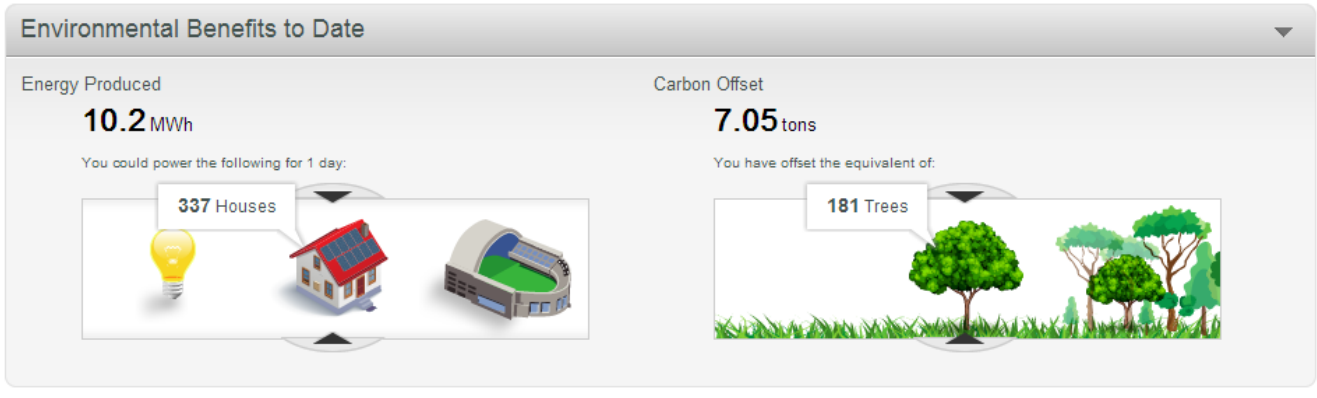

Figure 4-8: Enlighten's Environmental Benefits Display

\subsubsection{Cost Analysis}

Table 4-3 contains the cost analysis of the microinverter based system. Since the actual system has not been designed, the number of photovoltaic panels is not certain. Therefore, the number of panels is based on the number of panels within the Solar Decathlon House, which are 12 total panels.

Table 4-3: Cost Analysis for the Microinverter Based System

\begin{tabular}{|c|c|c|c|}
\hline Component & Quantity & Price/unit & Subtotal \\
\hline Enphase M215 Microinverter & 12 & $\$ 168.00$ & $\$ 2,016.00$ \\
\hline Envoy Communications Gateway & 1 & $\$ 480.90$ & $\$ 480.90$ \\
\hline & & Total & $\$ 2,496.90$ \\
\cline { 3 - 4 }
\end{tabular}

As is evident from the cost analysis table, the overall cost of the system is highly dependent on the number of photovoltaic panels in the system. The more panels, the higher the cost will be. 


\subsection{Summary}

All three systems have been widely used and provide a lot of information. In order to decide which monitoring system is best for a specific grid-tied system, a complete design of the system needs to be completed. However, from all three cost analysis sections, it is clear that grid-tied systems without batteries are much cheaper. Although battery backed grid-tied systems will reduce the likelihood of losing power during a power outage, the designer must assess if the bulkiness and cost of the batteries are worth putting them into the system. Overall, all three monitoring systems are feasible, but a detailed design of the system is needed before choosing which monitoring system is best. 


\section{Conclusion}

Because photovoltaic systems have been rapidly growing in recent years, various methods for monitoring and data-logging these systems have also been growing. After in depth research and testing, a monitoring system was installed on Cal Poly's Solar Decathlon House which is a stand-alone system. The in depth analysis of the WinVerterOB and WattPlot monitoring software showed good real-time data of the Solar Decathlon House. However, inconsistencies with power calculations and state of charge calculations were found. After analysis and programming of an Excel script to organize the raw data from the MATE2, it was found that the inconsistencies with power calculations came from the fact that the raw data only contained integer values for the currents and truncated the fractional portions of the data.

Research and design of a grid-tied system was then analyzed. System analysis, component analysis, and cost analysis were performed on a battery back grid-tied system, non-battery backed grid-tied system, and microinverter based system. It was concluded that a grid-tied system without a battery bank could be up to $\$ 17,000$ cheaper because of how expensive high quality batteries can be. However, it is impossible to state which system is the best since there are advantages and disadvantages for each depending on the overall system requirements.

Along with other projects such as Cal Poly's Sustainable Power for Electrical Resources (SuPER) project, methods for monitoring a photovoltaic system can greatly 
increase the system's health. Although the price ranges for the grid-tied systems researched in this thesis are in the thousands of dollars range, other projects have been worked on corresponding to the SuPER project which are much cheaper. A senior project entitled, "Controller Board Prototype Development for the Cal Poly SuPER Project" by Clifford Susa states that the cost of the controller board for the SuPER project which monitors and logs the system's data as well as performs other functions would be in the hundreds of dollars rather than thousands [28]. Therefore, there are multiple methods to monitor a photovoltaic system, each with its own pros and cons, so the user must determine what type of system would best fit his or her needs.

\subsection{Why this is useful?}

An immediate application of system monitoring that was discovered is monitoring the health of components. During analysis of the real-time data of the Solar Decathlon House, three of the batteries in the battery bank were found to be under nominal voltage and not performing at optimal levels. This was causing the three strings with the bad batteries to produce less current. Therefore, the other three strings in the system had to compensate for the lack of current being produced by the three bad strings. Solutions for this problem could include recharging the bad batteries to see if the strings can be balanced again or simply buying three new batteries.

Another possible application is rerouting power from the panels and battery bank depending on the incoming data from the monitoring system. For instance, by monitoring daily power output of the system, the peak power times can easily be found and a secondary power source such as an electric vehicle with bidirectional power 
capabilities can be turned on to help produce more power into the system. Also, if the state of charge of a battery bank is dangerously low, the same secondary power source can be turned on to help the system once again.

\subsection{Improvements}

One improvement that can be made to the Excel script is to turn it into a real-time data analyzer. As of now, the Excel script can only be used to organize logged data from the MATE2. However, using the Excel script in conjunction with a program such as RealTerm would allow the Excel script to analyze real-time data. RealTerm is a program that can capture data streams such as the MATE2 raw data through the serial port of a computer and can be accessed by various programs such as Microsoft Office Macros, Matlab, and more. However, if the Excel script was turned into a real-time analysis tool, it would probably need changes to the script in order for it to run properly.

Another improvement that would have to be suggested to OutBack Power Systems would be to transmit the fractional values of all the data from the MATE2. With the fractional values of all the data, more precise calculated values could be obtained and there would be less chance of an error. Unfortunately, this change would have to be made to the software of the MATE2 and would thus have to be made by OutBack Power Systems themselves. 


\section{References}

[1] R.A. Hinrichs and M. Keinbach, Energy: Its Use and the Environment $5^{\text {th }}$ Edition, Boston: Brooks/Cole, Cengage Learning, 2013.

[2] Former Governor Arnold Schwarzenegger, "Executive Order \# S-14-08," Sacramento, CA: Office of the Governor, 2008.

[3] California Polytechnic State University-San Luis Obispo, "U.S. Department of Energy Solar Decathlon," 2005. [Online]. Available:

http://www.solardecathlon.gov/past/2005/

technical_report.html. [Accessed 12 February 2013].

[4] Next Solar Systems, "NXT-20e," NXT-20e specifications sheet.

[5] Solar Power Planet Earth, "Maximum Power Point Tracking," [Online].

Available: http://solarpowerplanetearth.com/solarchargecontrollers.html. [Accessed 27 March 2013].

[6] OutBack Power Systems Staff, MX60 PV MPPT Charge Controller Installation and User's Manual, OutBack Power Systems, 2004.

[7] OutBack Power Systems Staff, FLEXnet DC User's Guide, OutBack Power Systems, 2007.

[8] Phaesun, "OutBack Power Systems," [Online]. Available:

http://www.phaesun.com/. [Accessed 27 March 2013].

[9] OutBack Power Systems Staff, MATE System Controller and Display:

Installation and User Manual for the OutBack MATE and MATE2, OutBack Power Systems, 2004.

[10] Solar Conduit, “OutBack MATE2," [Online]. Available: https://solarconduit.com/ shop/electrical/charge-controllers/outback-charge-controllers/outback-mate2-

remote-control-flush-mount.html. [Accessed 27 March 2013].

[11] OutBack Power Systems Staff, HUB Communications Manager User's Manual, OutBack Power Systems, 2008.

[12] Centennial Batteries, "CB27-AGM," [Online]. Available: http://www.centennialbatteries.com/products_specialty.html. [Accessed 27 March 2013].

[13] Samlex America Staff, Pure Sine Wave Power Inverter Owner's Manual, Samlex Power.

[14] A. Welch, WattPlot User's Guide, WattPlot, 2010.

[15] OutBack Power Systems Staff, MATE Serial Communications Guide, OutBack Power Systems, 2007.

[16] BP Solar, “BP 4175,” BP 4175 datasheet, 2004.

[17] Trojan Batter Company, "Trojan 8D-AGM," 8D-AGM specifications sheet, 2007. 
[18] Trace Engineering Company Staff, SW Series Inverter/Chargers Owner's Manual, Trace Engineering Company, Inc., 1999.

[19] U.S. Department of Energy, "Solar Decathlon Rules," 2013. [Online]. Available: http://www.solardecathlon.gov/pdfs/2013_rules.pdf. [Accessed 12 February 2013].

[20] R. A. Messenger and J. Ventre, Photovoltaic Systems Engineering $3^{\text {rd }}$ Edition, Boca Raton: CRC Press, 2010.

[21] OutBack Power Systems, "GTFX3048," GTFX3048 specifications sheet.

[22] B. Boglioli, Hawai i Operations Sales and Technical Support Manager. [Interview]. 27 May 2013.

[23] SMA Solar Technology, "Sunny Boy 5000-US," Sunny Boy 5000-US technical data.

[24] SMA Staff, Sunny WebBox User Manual, SMA, 2011.

[25] SMA, "Sunny Portal Website," [Online]. Available: www.sunnyportal.com. [Accessed 27 May 2013].

[26] Enphase, "Enphase M215," M215 datasheet.

[27] Enphase, "Enphase System Overview Brochure," [Online]. Available: http://enphase.com/wp-uploads/enphase.com/2011/08/Enphase-Brochure-SystemOverview.pdf. [Accessed 27 May 2013].

[28] C. Susa, Controller Board Prototype Development for the Cal Poly SuPER Project, Senior Project, California Polytechnic State University San Luis Obispo, Department of Electrical Engineering, 2011. 
Appendix A: Solar Decathlon House Electrical Report Images
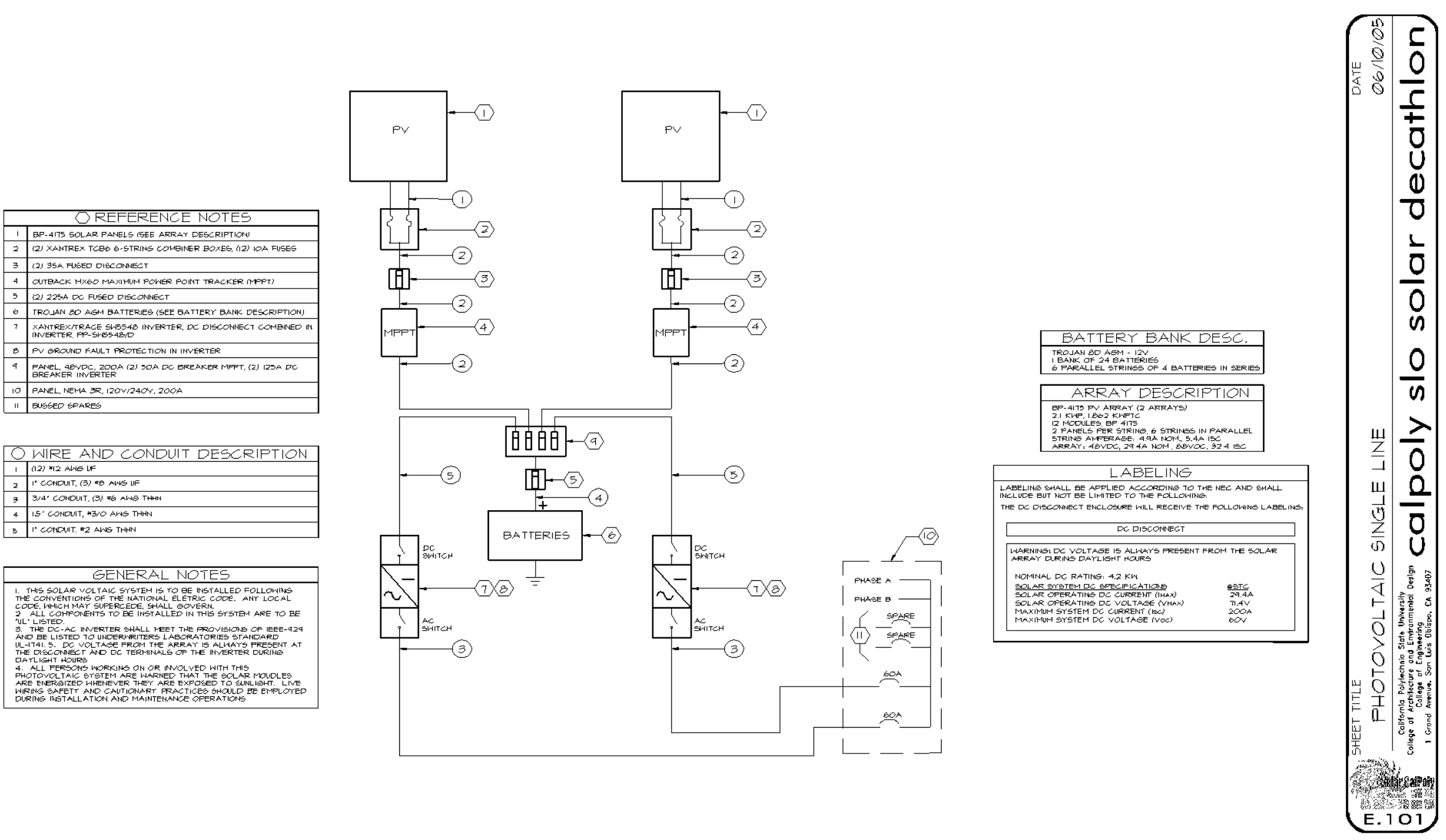

Figure A-1: Photovoltaic System Block Diagram [3] 


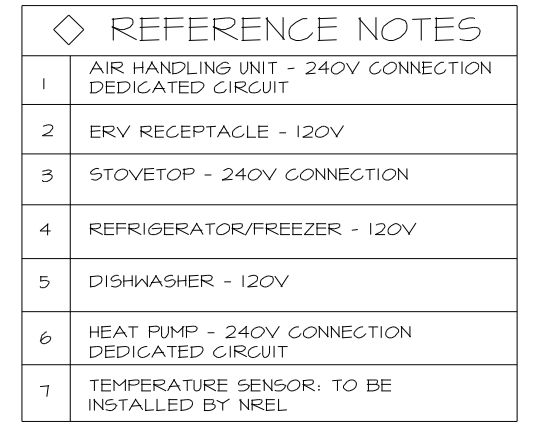

$X$ SEE LUMINARE SCHEDULE, SHT. E.2O0

\begin{tabular}{|c|c|c|c|}
\hline \multicolumn{4}{|c|}{ LEGEND } \\
\hline$\triangle$ & WALL SURFACE MOUNT LIGHT & (ग) & \lrcorner$-B O X, T Y P$. \\
\hline i) & TASK LIGHT LOCATION & (P) & PENDANT LIGHT, SEE SCHEDULE \\
\hline$\Longrightarrow$ & FLUORESCENT UPLIGHT & \# & DOUBLE DUPLEX RECEPTACLE, IN COUNTER, GFCI \\
\hline$\Longrightarrow$ & UNDER COUNTER & $\phi_{\mathrm{ev}}$ & ELECTRIC VEHICLE OUTLET \\
\hline--- & COUNTER DOOR LIGHTS & $\Phi_{240}$ & 240V CIRCUIT RECEPTACLE \\
\hline$\Phi$ & SINGLE RECEPTACLE, HT. +16", UNO & $\$$ & SWITCH \\
\hline$\$$ & DUPLEX RECEPTACLE, HT. +16", UNO & $\$$ & DIMMING SWITCH \\
\hline $\mathbb{D}_{\mathrm{ArCl}}$ & $\begin{array}{l}\text { ARC FAULT CIRCUIT INTERRUPT, HT, +16", } \\
\text { UNO }\end{array}$ & \multirow{3}{*}{\multicolumn{2}{|c|}{$\begin{array}{l}\text { FOR HEIGHTS REFER TO EXT. \& INT. ELEV'S, U.N.O. } \\
\text { SIPS HAVE CONDUIT RUNS AT +16" AND 44" HORIZ. \& } \\
\text { CENTER LINE, VERT., U.N.O. }\end{array}$}} \\
\hline$\not \mathbb{H}_{\mathrm{LFI}}$ & $\begin{array}{l}\text { GROUND FAULT CIRCUIT INTERRUPTER, } \\
\text { HT. +16", UNO }\end{array}$ & & \\
\hline$\$ \mathbb{H}_{6 \mathrm{FI}}^{240}$ & $\begin{array}{l}\text { GROUND FAULT CIRCUIT INTERRUPTER, } \\
\text { HT. +16", UNO }\end{array}$ & & \\
\hline
\end{tabular}

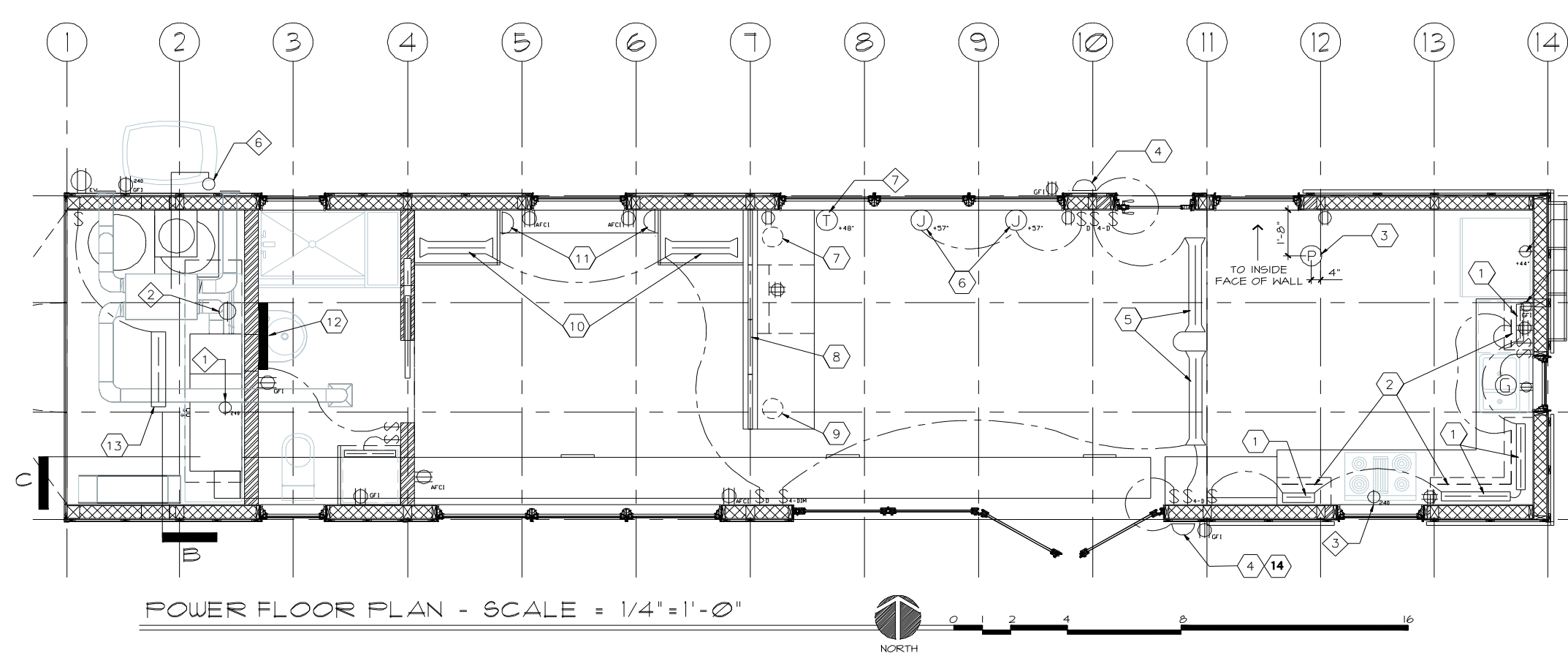



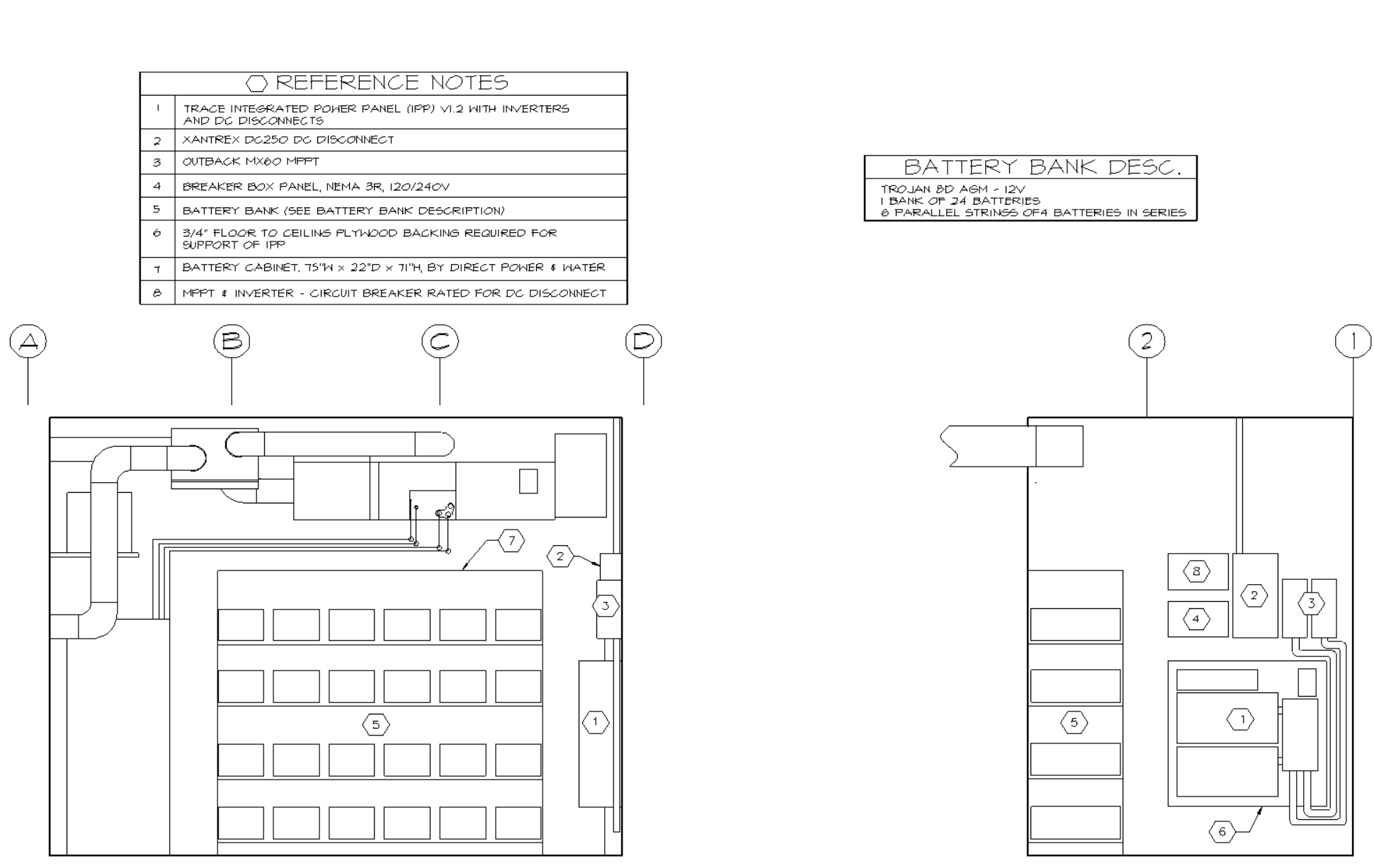

(1) INTERIOR ELEVATION - VIEW B-B

TROJAN 80 AGM - IVV
BANK OF 24 BATIREIES
BARALLL STRINES OFA BATTERIES IN SERIES
PARALEL STR

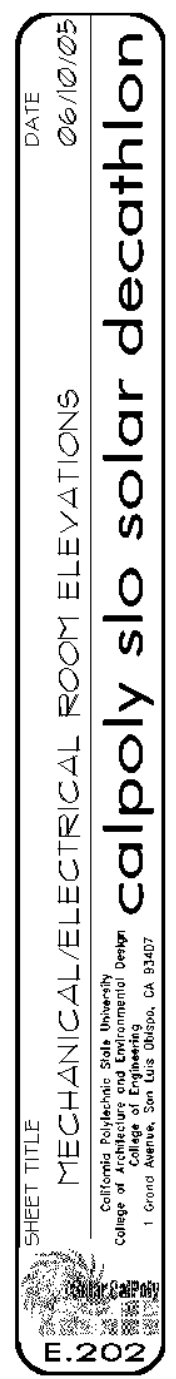

Figure A-3: Battery Bank Layout [3] 


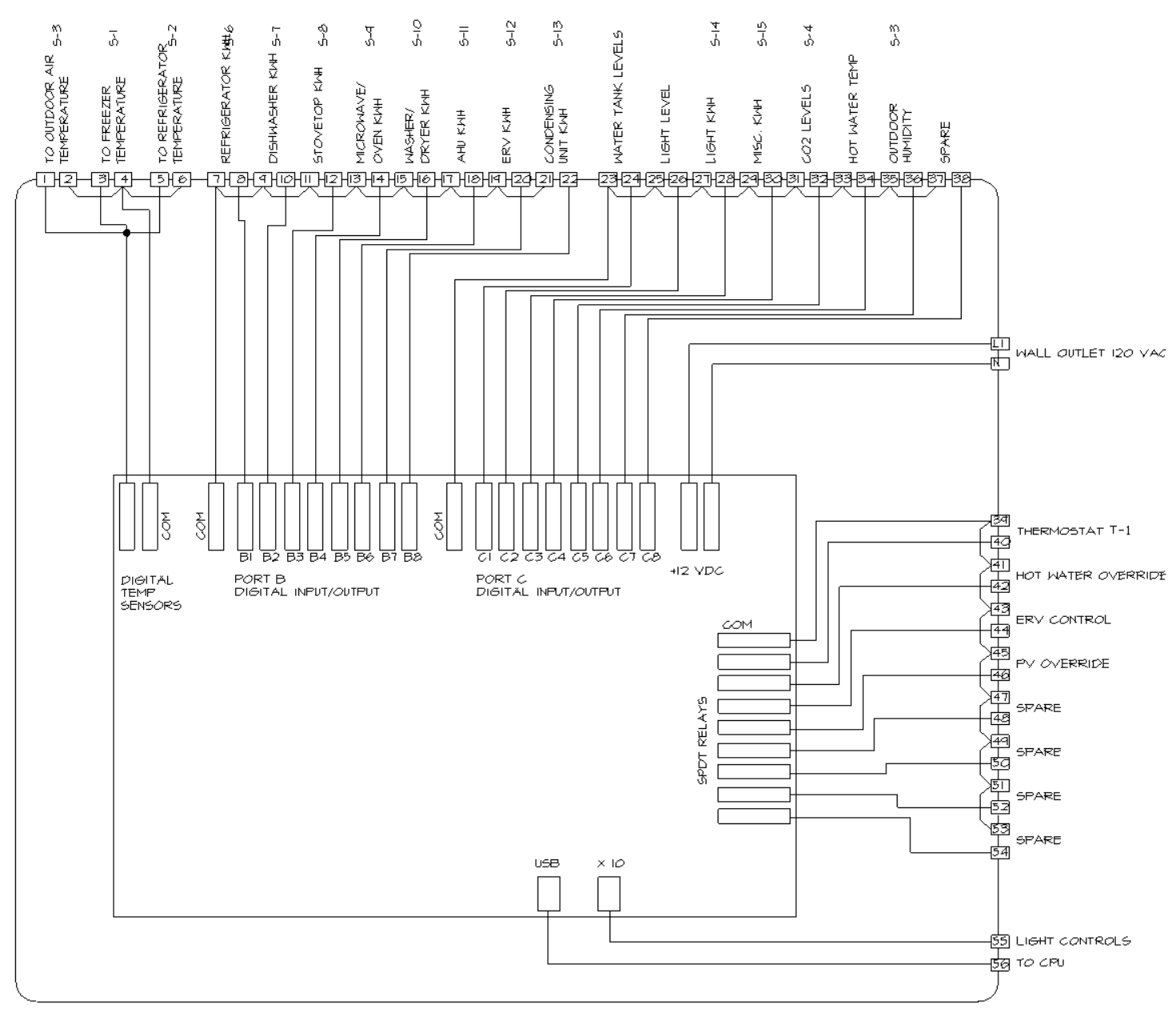

\begin{tabular}{|c|c|c|c|c|}
\hline \multicolumn{5}{|c|}{ EQUIFMENT } \\
\hline ITEM & MANUF. & QTY & MODEL\# & DESCRIPTION \\
\hline UNT-1 & $\begin{array}{l}\text { CUSTOM } \\
\text { SOLUTIONS }\end{array}$ & I & HV-PRO & CONTROLLER \\
\hline$T-1$ & RCS & I & $T \times B \mid 6$ & ROOM STAT \\
\hline $5-1,2$ & MAXIM & 2 & DS18520 & TEMP SENSOR \\
\hline $5-3$ & JOHNSON & I & $\mathrm{HE}-67 \times \times-\mathrm{ONOET}$ & OUTDOOR SENSOR \\
\hline$s-4$ & JOHNSON & I & $\angle D-W O O-O O-O$ & COZ SENSOR \\
\hline s-5 & $\begin{array}{l}\text { APPLIED } \\
\text { DISITAL }\end{array}$ & I & BOBCAT & LIEHT SENSOR \\
\hline $5-6,78$. & $O M E G A$ & 10 & OMIO & POWER SENSOR \\
\hline
\end{tabular}

CONTFOL PANEL WIFE DIAGFAM - SCALE = N.T.S.

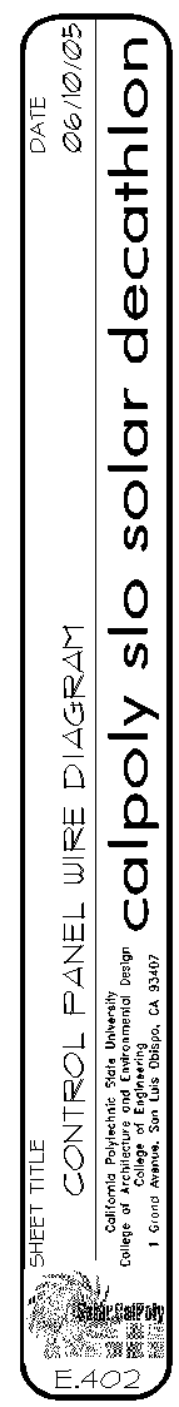

Figure A-4: Control Panel Layout [3] 


\section{Appendix B: MATE2 Raw Data}

Table B-1 contains 8 seconds of logged raw data from the MATE2 in the test setup of Chapter 2.

Table B-1: MATE2 Raw Data from Test Setup

\begin{tabular}{|l|}
\hline$\sim$ \\
\hline B $, 00,00,00,033,000,00,00,000,01,137,9999,00,072$ \\
\hline b,0002,0001,0000,09,00000,137,100,001,16,08,090 \\
\hline$\sim$ \\
\hline B, $00,01,00,033,000,00,00,000,01,137,9999,00,073$ \\
\hline b,0001,0000,0000,10,00000,137,100,001,00,08,073 \\
\hline$\sim$ \\
\hline B,00,01,00,033,000,00,00,000,01,137,9999,00,073 \\
\hline b,0001,0000,0000,11,00000,136,100,001,00,08,073 \\
\hline$\sim$ \\
\hline B, $00,01,00,033,000,00,00,000,01,137,9999,00,073$ \\
\hline b,0004,0000,0000,12,00000,137,100,001,00,08,078 \\
\hline$\sim$ \\
\hline B $, 00,01,00,033,000,00,00,000,01,137,9999,00,073$ \\
\hline b,0004,0000,0000,13,00000,137,100,001,00,08,079 \\
\hline$\sim$ \\
\hline B, $00,01,00,033,000,00,00,000,01,137,9999,00,073$ \\
\hline b,0004,0000,0000,00,00000,137,100,001,00,08,075 \\
\hline$\sim$ \\
\hline B,00,01,00,033,000,00,00,000,01,137,9999,00,073 \\
\hline b,0003,0000,0000,01,00000,137,100,001,00,08,075 \\
\hline B,00,00,00,033,000,00,00,000,01,137,9999,00,072 \\
\hline b,0002,0001,0000,02,00000,137,100,001,00,08,076 \\
\hline
\end{tabular}

Page 83 
Table B-2 contains 8 seconds of logged raw data from the MATE2 in the Solar Decathlon House of Chapter 3.

Table B-2: MATE2 Raw Data from Solar Decathlon House

\begin{tabular}{|c|}
\hline$\sim$ \\
\hline $\mathrm{B}, 00,25,24,056,007,00,00,000,02,505,9999,00,097$ \\
\hline $\mathrm{C}, 00,29,19,083,009,00,00,000,02,504,9999,00,107$ \\
\hline $\mathrm{c}, 0022,0152,0173,67,00111,505,090,000,56,32,125$ \\
\hline$\sim$ \\
\hline $\mathrm{B}, 00,24,23,056,007,00,00,000,02,504,9999,00,094$ \\
\hline $\mathrm{C}, 00,29,18,084,009,00,00,000,02,504,9999,00,107$ \\
\hline $\mathrm{c}, 0026,0169,0195,68,00011,505,090,000,56,32,141$ \\
\hline $\mathrm{B}, 00,24,23,056,007,00,00,000,02,504,9999,00,094$ \\
\hline$\sim$ \\
\hline $\mathrm{C}, 00,29,18,083,009,00,00,000,02,504,9999,00,106$ \\
\hline $\mathrm{c}, 0027,0172,0198,69,00057,505,090,000,56,32,150$ \\
\hline $\mathrm{B}, 00,23,22,056,007,00,00,000,02,505,9999,00,093$ \\
\hline $\mathrm{C}, 00,28,18,084,009,00,00,000,02,504,9999,00,106$ \\
\hline$\sim$ \\
\hline $\mathrm{c}, 0028,0176,0202,06,00000,505,090,000,56,32,120$ \\
\hline $\mathrm{B}, 00,23,22,056,007,00,00,000,02,505,9999,00,093$ \\
\hline $\mathrm{C}, 00,28,18,084,009,00,00,000,02,504,9999,00,106$ \\
\hline $\mathrm{c}, 0028,0176,0202,07,00090,505,090,000,56,32,130$ \\
\hline$\sim$ \\
\hline $\mathrm{B}, 00,23,22,057,007,00,00,000,02,504,9999,00,093$ \\
\hline $\mathrm{C}, 00,28,18,084,009,00,00,000,02,504,9999,00,106$ \\
\hline c,0030,0185,0214,08,00000,505,090,000,56,32,118 \\
\hline$\sim$ \\
\hline $\mathrm{B}, 00,23,22,057,007,00,00,000,02,504,9999,00,093$ \\
\hline $\mathrm{C}, 00,27,18,084,009,00,00,000,02,504,9999,00,105$ \\
\hline $\mathrm{c}, 0030,0187,0216,09,00038,505,090,000,56,32,134$ \\
\hline$\sim$ \\
\hline $\mathrm{B}, 00,23,21,057,007,00,00,000,02,504,9999,00,092$ \\
\hline $\mathrm{C}, 00,27,17,083,009,00,00,000,02,504,9999,00,103$ \\
\hline $\mathrm{c}, 0031,0191,0221,10,00000,505,090,000,56,32,107$ \\
\hline
\end{tabular}

Page 84 


\section{Appendix C: Excel Script for Test Setup}

The following is the Excel script that was implemented to organize the raw data

from the MATE2. Analysis of this script can be found in Section 2.3.3.2.

\section{Sub Mate_Data_Organizer()}

'Find last row used in column A

Dim lastRow As Long

lastRow $=$ ActiveSheet.Cells(Rows.Count, "A").End(xlUp).Row

'Find number of seconds through number of times "B" is seen

Dim sec As Long

Dim b As Long

$\sec =0$

For $\mathrm{b}=1$ To lastRow +1

If Left(Range("A" \& b), 1) = "B" Then

$\sec =\sec +1$

End If

Next b

'Creates a Message Box for the user to enter the start time

Dim Start_Time As String

Start_Time $=$ Application.InputBox

(Prompt:="Please Enter Data Stream Start Time" \& vbCrLf \&

"Enter in the Format: HH:MM:SS AM/PM" \& vbCrLf \&

"Ex: for 4:50:22 AM, Enter 04:50:22 AM" \& vbCrLf \& _

"Be as specific as possible" \& vbCrLf, _

Title:="Start Time", Type:=1)

'Column of time for Charge Controller \#1

Range("B2").Value = "Time"

Range("B3").Value = Start_Time

Range("B3").NumberFormat = "[\$-F400]hh:mm:ss AM/PM"

'Column of time for FLEXnet DC \#1

Range("J2").Value = "Time"

Range("J3"). Value = Start_Time

Range("J3").NumberFormat = "[\$-F400]hh:mm:ss AM/PM"

Dim c As Long

Dim g As Long

$\mathrm{g}=4$ 


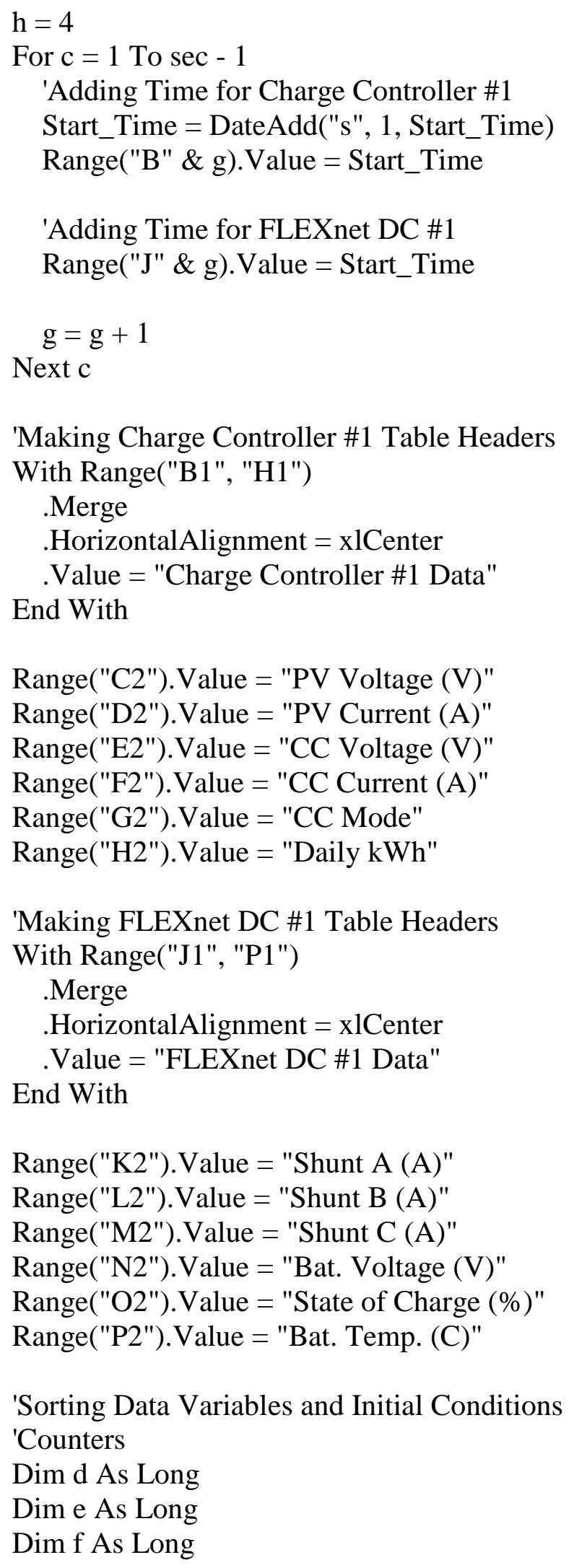

'Sorting Data Variables and Initial Conditions

'Counters

Dim d As Long

Dim e As Long

Dim f As Long 
'Charge Controller Variables

Dim Bat_Volt_a As Long

Dim Bat_Volt_b As Integer

Dim Bat_Volt As Double

Dim Mode_a As Integer

Dim Mode As String

Dim kWh_a As Long

Dim kWh_b As Integer

Dim kWh As Double

'FLEXnet DC Variables

Dim Shunt As Double

Dim Shunt_a As Long

Dim Shunt_b As Integer

Dim Temp As Integer

'Decimal to Binary Conversion Variables

Dim Bin As String

Dim Dec As String

Dim i As Long

$\mathrm{d}=0$

$\mathrm{e}=3$ 'To start in row 3

$\mathrm{f}=3$ 'To start in row 3

'Sorting Data Algorithm

For $\mathrm{d}=1$ To lastRow +1

'Sort through Charge Controller Data

If Left(Range("A" \& d), 1) = "B" Then

'PV Voltage

Range("C" \& e).Value = Mid(Range("A" \& d), InStr(10, Range("A" \& d), ",") _ $+1,3)$

'PV Current

Range("D" \& e).Value = Mid(Range("A" \& d), InStr(6, Range("A" \& d), ",") _ $+1,2)$

'Battery Voltage/Charge Controller Voltage

Bat_Volt_a = Mid(Range("A" \& d), InStr(30, Range("A" \& d), ",") + 1, 2)

Bat_Volt_b = Mid(Range("A" \& d), InStr(30, Range("A" \& d), ",") + 3, 1)

Bat_Volt = Bat_Volt_a \& "." \& Bat_Volt_b

Range("E" \& e).Value = Bat_Volt

'Charge Controller Current

Range("F" \& e).Value = Mid(Range("A" \& d), InStr(4, Range("A" \& d), ",") _ $+1,2)$ 
'Charge Controller Mode

Mode_a = Mid(Range("A" \& d), InStr(28, Range("A" \& d), ",") + 1, 2)

Select Case Mode_a

Case 0

Mode $=$ "Silent"

Case 1

Mode $=$ "Float"

Case 2

Mode $=$ "Bulk"

Case 3

Mode $=$ "Absorb"

Case 4

Mode = "EQ"

End Select

Range("G" \& e).Value = Mode

'Daily kWh

kWh_a = Mid(Range("A" \& d), InStr(14, Range("A" \& d), ",") + 1, 2)

kWh_b = Mid(Range("A" \& d), InStr(14, Range("A" \& d), ",") + 3, 1)

$\mathrm{kWh}=\mathrm{kWh} \_\mathrm{a} \&$ "." \& kWh_b

Range("H" \& e). Value = kWh

'Counter to keep correct row for data table

$\mathrm{e}=\mathrm{e}+1$

'Sort through FlexNet Data

ElseIf Left(Range("A" \& d), 1) = "b" Then

'Converting Status Flags from Decimal to Binary

Dec = Mid(Range("A" \& d), InStr(37, Range("A" \& d), ",") + 1, 2)

'Pre-setting Bin

If $\mathrm{Dec}>31$ Then

$\operatorname{Bin}=1$

Else

Bin $=0$

End If

For $\mathrm{i}=5$ To 1 Step -1

Bin = Bin \& IIf(CLng(Dec) And $2^{\wedge}$ (i - 1), "1", "0")

Next i

'Shunt A Currents

Shunt_a = Mid(Range("A" \& d), InStr(1, Range("A" \& d), ",") + 1, 3)

Shunt_b = Mid(Range("A" \& d), InStr(1, Range("A" \& d), ",") + 4, 1)

Page 88 
Shunt = Shunt_a \& "." \& Shunt_b

'Is it Negative

If $\operatorname{Mid}(\operatorname{Bin}, 3,1)=1$ Then

Range("K" \& f).Value $=-1 *$ Shunt

Else

Range("K" \& f).Value = Shunt

End If

'Shunt B Currents

Shunt_a = Mid(Range("A" \& d), InStr(4, Range("A" \& d), ",") + 1, 3)

Shunt_b = Mid(Range("A" \& d), InStr(4, Range("A" \& d), ",") + 4, 1)

Shunt = Shunt_a \& "." \& Shunt_b

'Is it Negative

If $\operatorname{Mid}(\operatorname{Bin}, 2,1)=1$ Then

Range("L" \& f).Value $=-1 *$ Shunt

Else

Range("L" \& f).Value = Shunt

End If

'Shunt C Currents

Shunt_a = Mid(Range("A" \& d), InStr(9, Range("A" \& d), ",") + 1, 3)

Shunt_b = Mid(Range("A" \& d), InStr(9, Range("A" \& d), ",") + 4, 1)

Shunt = Shunt_a \& "." \& Shunt_b

'Is it Negative

If $\operatorname{Mid}(\operatorname{Bin}, 1,1)=1$ Then

Range("M" \& f). Value $=-1 *$ Shunt

Else

Range("M" \& f). Value = Shunt

End If

'Battery Voltage

Bat_Volt_a = Mid(Range("A" \& d), InStr(24, Range("A" \& d), ",") + 1, 2)

Bat_Volt_b = Mid(Range("A" \& d), InStr(24, Range("A" \& d), ",") + 3, 1)

Bat_Volt = Bat_Volt_a \& "." \& Bat_Volt_b

Range("N" \& f). Value = Bat_Volt

'Battery State of Charge

Range("O" \& f).Value = Mid(Range("A" \& d), InStr(29, Range("A" \& d), ",") _ $+1,3)$

'Battery Temperature

Range("P" \& f).Value = Mid(Range("A" \& d), InStr(40, Range("A" \& d), ",") _ $+1,2)-10$

$f=f+1$ 
End If

Next d

'Information for User if Graphs are wanted

With Range("R1", "S1")

.Merge

.HorizontalAlignment $=$ xlCenter

.Value = "Information for Graphs"

End With

Range("R2").Value = "First Row of Data"

Range("S2").Value = "Last Row of Data"

Range("R3").Value = 3

Range("S3"). Value = f - 1

With Range("R4", "S10")

.Merge

.HorizontalAlignment $=$ xlLeft

.Value $=$ "Instructions: 1)Insert New Graph " \&

"2)Use column of Time Values as X Values " \&

"starting from 'First Row of Data' to 'Last Row of Data' " \& vbCrLf \&

"3)Select any other column for Y Values " \&

"starting from 'First Row of Data' to 'Last Row of Data'"

End With

'AutoFit all the columns

Columns("A").AutoFit

Columns("B").AutoFit

Columns("C").AutoFit

Columns("D").AutoFit

Columns("E").AutoFit

Columns("F").AutoFit

Columns("G").AutoFit

Columns("H").AutoFit

Columns("J").AutoFit

Columns("K").AutoFit

Columns("L").AutoFit

Columns("M").AutoFit

Columns("N").AutoFit

Columns("O").AutoFit

Columns("P").AutoFit

Columns("R").AutoFit

Columns("S").AutoFit

End Sub 


\section{Appendix D: Excel Script for Solar Decathlon House}

The following is the Excel script that was implemented in the Solar Decathlon

House to organize the raw data from the MATE2. It is nearly identical to that in

Appendix $\mathrm{C}$ except for the addition of an extra charge controller analyzer and small

changes to variables.

Sub Solar_House_Data_Organizer()

'Find last row used in column A

Dim lastRow As Long

lastRow = ActiveSheet.Cells(Rows.Count, "A").End(xlUp).Row

'Find number of seconds through number of times "B" is seen

Dim sec As Long

Dim a As Long

$\sec =0$

For $\mathrm{a}=1$ To lastRow +1

If Left(Range("A" \& a), 1) = "B" Then

$\sec =\sec +1$

End If

Next a

'Creates a Message Box for the user to enter the start time

Dim Start_Time As String

Start_Time $=$ Application.InputBox

(Prompt:="Please Enter Data Stream Start Time" \& vbCrLf \&

"Enter in the Format: HH:MM:SS AM/PM" \& vbCrLf \&

"Ex: for 4:50:22 AM, Enter 04:50:22 AM" \& vbCrLf \& _

"Be as specific as possible" \& vbCrLf, _

Title:="Start Time", Type:=1)

'Column of time for Charge Controller \#1

Range("B2").Value = "Time"

Range("B3").Value = Start_Time

Range("B3").NumberFormat = "[\$-F400]hh:mm:ss AM/PM"

'Column of time for Charge Controller \#2

Range("J2").Value = "Time"

Range("J3").Value = Start_Time

Range("J3").NumberFormat = "[\$-F400]hh:mm:ss AM/PM"

Page 91 


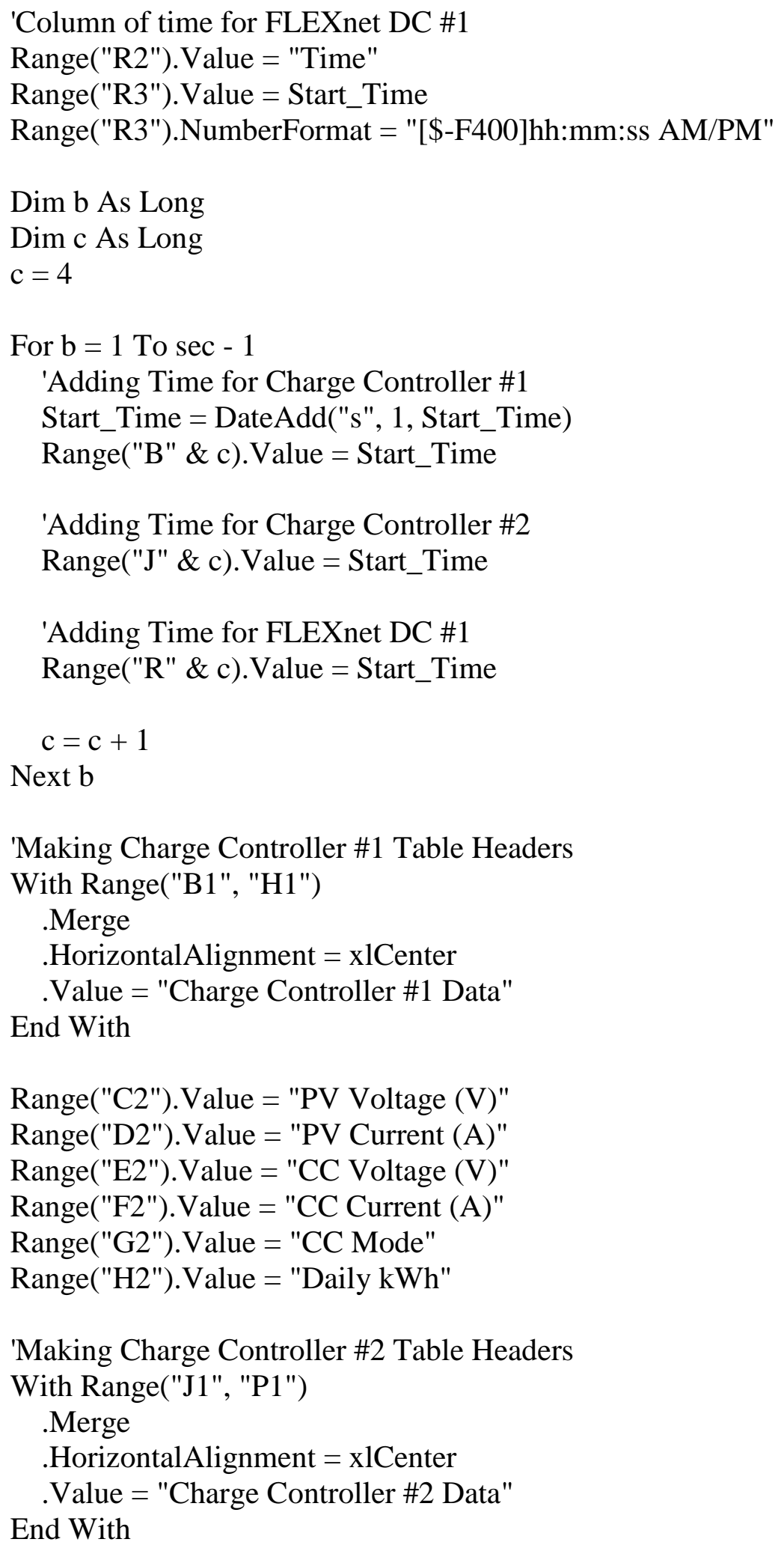




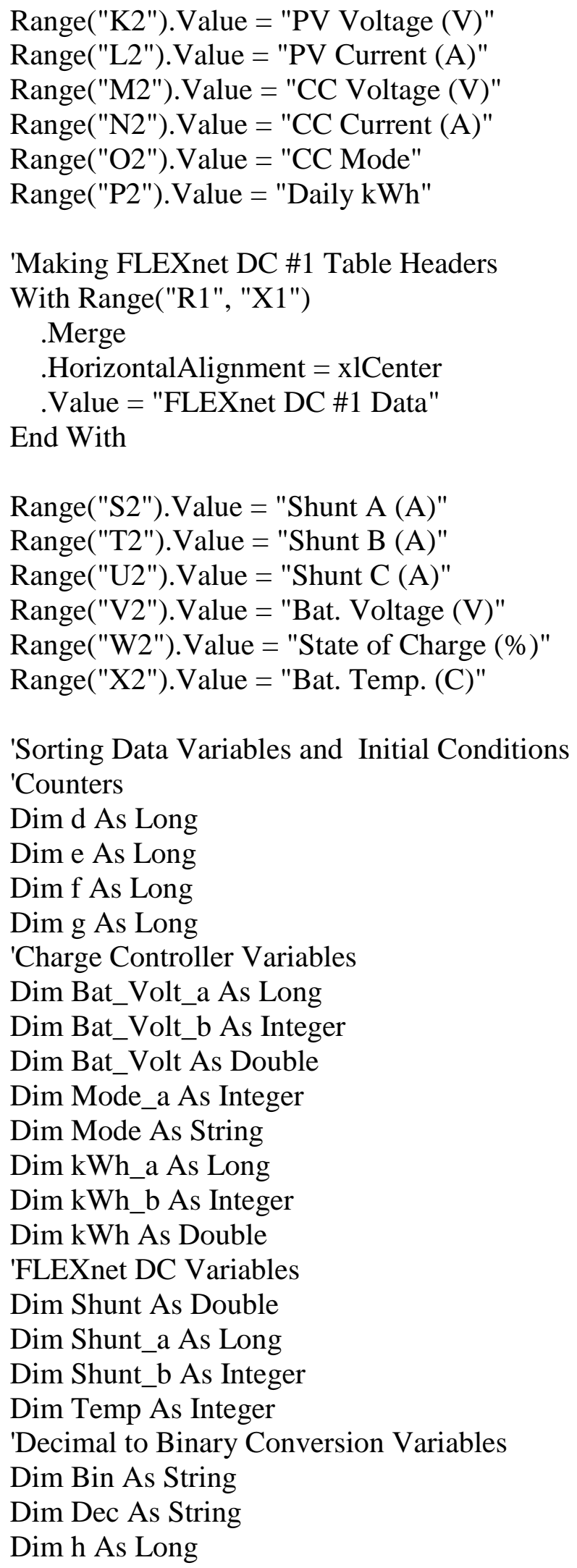


$\mathrm{d}=0$

$\mathrm{e}=3$ 'To start in row 3

$\mathrm{f}=3$ 'To start in row 3

$\mathrm{g}=3$ 'To start in row 3

'Sorting Data Algorithm

For $\mathrm{d}=1$ To lastRow +1

'Sort through Charge Controller \#1 Data

If Left(Range("A" \& d), 1) = "B" Then

'PV Voltage

Range("C" \& e).Value = Mid(Range("A" \& d), InStr(10, Range("A" \& d), ",") _ $+1,3)$

'PV Current

Range("D" \& e).Value = Mid(Range("A" \& d), InStr(6, Range("A" \& d), ",") _ $+1,2)$

'Battery Voltage/Charge Controller Voltage

Bat_Volt_a = Mid(Range("A" \& d), InStr(30, Range("A" \& d), ",") + 1, 2)

Bat_Volt_b = Mid(Range("A" \& d), InStr(30, Range("A" \& d), ",") + 3, 1)

Bat_Volt = Bat_Volt_a \& "." \& Bat_Volt_b

Range("E" \& e).Value = Bat_Volt

'Charge Controller Current

Range("F" \& e).Value = Mid(Range("A" \& d), InStr(4, Range("A" \& d), ",") _ $+1,2)$

'Charge Controller Mode

Mode_a = Mid(Range("A" \& d), InStr(28, Range("A" \& d), ",") + 1, 2)

Select Case Mode_a

Case 0

Mode = "Silent"

Case 1

Mode $=$ "Float"

Case 2

Mode = "Bulk"

Case 3

Mode $=$ "Absorb"

Case 4

Mode = "EQ"

End Select

Range ("G" \& e). Value = Mode

Page 94 
'Daily kWh

kWh_a = Mid(Range("A" \& d), InStr(14, Range("A" \& d), ",") + 1, 2)

kWh_b = Mid(Range("A" \& d), InStr(14, Range("A" \& d), ",") + 3, 1)

kWh = kWh_a \& "." \& kWh_b

Range("H" \& e).Value = kWh

'Counter to keep correct row for data table

$\mathrm{e}=\mathrm{e}+1$

'Sort through Charge Controller \#2 Data

ElseIf Left(Range("A" \& d), 1) = "C" Then

'PV Voltage

Range("K" \& f).Value = Mid(Range("A" \& d), InStr(10, Range("A" \& d), ",") _ $+1,3)$

'PV Current

Range("L" \& f).Value = Mid(Range("A" \& d), InStr(6, Range("A" \& d), ",") _ $+1,2)$

'Battery Voltage/Charge Controller Voltage

Bat_Volt_a = Mid(Range("A" \& d), InStr(30, Range("A" \& d), ",") + 1, 2)

Bat_Volt_b = Mid(Range("A" \& d), InStr(30, Range("A" \& d), ",") + 3, 1)

Bat_Volt = Bat_Volt_a \& "." \& Bat_Volt_b

Range("M" \& f).Value = Bat_Volt

'Charge Controller Current

Range("N" \& f).Value = Mid(Range("A" \& d), InStr(4, Range("A" \& d), ",") _ $+1,2)$

'Charge Controller Mode

Mode_a = Mid(Range("A" \& d), InStr(28, Range("A" \& d), ",") + 1, 2)

Select Case Mode_a

Case 0

Mode $=$ "Silent"

Case 1

Mode $=$ "Float"

Case 2

Mode $=$ "Bulk"

Case 3

Mode = "Absorb"

Case 4

Mode = "EQ"

End Select

Page 95 
Range("O" \& f). Value = Mode

'Daily kWh

kWh_a = Mid(Range("A" \& d), InStr(14, Range("A" \& d), ",") + 1, 2)

kWh_b = Mid(Range("A" \& d), InStr(14, Range("A" \& d), ",") + 3, 1)

$\mathrm{kWh}=\mathrm{kWh} \_\mathrm{a} \& \mathrm{*}$." \& kWh_b

Range("P" \& f). Value $=\mathrm{kWh}$

'Counter to keep correct row for data table

$\mathrm{f}=\mathrm{f}+1$

'Sort through FlexNet Data \#1

ElseIf Left(Range("A" \& d), 1) = "c" Then

'Converting Status Flags from Decimal to Binary

Dec = Mid(Range("A" \& d), InStr(37, Range("A" \& d), ",") + 1, 2)

'Pre-setting Bin

If $\mathrm{Dec}>31$ Then

$\operatorname{Bin}=1$

Else

Bin $=0$

End If

'Finding other 5 bit values

For $\mathrm{h}=5$ To 1 Step -1

Bin $=$ Bin \& IIf(CLng(Dec) And $2^{\wedge}(\mathrm{h}-1), " 1 "$, "0")

Next h

'Shunt A Currents

Shunt_a = Mid(Range("A" \& d), InStr(1, Range("A" \& d), ",") + 1, 3)

Shunt_b = Mid(Range("A" \& d), InStr(1, Range("A" \& d), ",") + 4, 1)

Shunt = Shunt_a \& "." \& Shunt_b

'Check Corresponding Bit Value to see if Negative

If $\operatorname{Mid}(\operatorname{Bin}, 3,1)=1$ Then

Range("S" \& g). Value = - $1 *$ Shunt

Else

Range("S" \& g). Value = Shunt

End If

'Shunt B Currents

Shunt_a = Mid(Range("A" \& d), InStr(4, Range("A" \& d), ",") + 1, 3)

Shunt_b = Mid(Range("A" \& d), InStr(4, Range("A" \& d), ",") + 4, 1)

Shunt = Shunt_a \& "." \& Shunt_b

'Check Corresponding Bit Value to see if Negative

If $\operatorname{Mid}(\operatorname{Bin}, 2,1)=1$ Then

Range("T" \& g).Value $=-1 *$ Shunt

Page 96 
Else

Range("T" \& g).Value = Shunt

End If

'Shunt C Currents

Shunt_a = Mid(Range("A" \& d), InStr(9, Range("A" \& d), ",") + 1, 3)

Shunt_b = Mid(Range("A" \& d), InStr(9, Range("A" \& d), ",") + 4, 1)

Shunt $=$ Shunt_a \& "." \& Shunt_b

'Check Corresponding Bit Value to see if Negative

If $\operatorname{Mid}(\operatorname{Bin}, 1,1)=1$ Then

Else

Range("U" \& g).Value = -1* Shunt

Range("U" \& g). Value = Shunt

End If

'Battery Voltage

Bat_Volt_a = Mid(Range("A" \& d), InStr(24, Range("A" \& d), ",") + 1, 2)

Bat_Volt_b = Mid(Range("A" \& d), InStr(24, Range("A" \& d), ",") + 3, 1)

Bat_Volt = Bat_Volt_a \& "." \& Bat_Volt_b

Range("V" \& g). Value = Bat_Volt

'Battery State of Charge

Range("W" \& g).Value = Mid(Range("A" \& d), InStr(29, Range("A" \& d), ",") _ $+1,3)$

'Battery Temperature

Range("X" \& g). Value = Mid(Range("A" \& d), InStr(40, Range("A" \& d), ",") _ $+1,2)-10$

$\mathrm{g}=\mathrm{g}+1$

End If

Next d

'Information for User if Graphs are wanted

With Range("Z1", "AA1")

.Merge

.HorizontalAlignment $=$ xlCenter

.Value $=$ "Information for Graphs"

End With

Range("Z2").Value = "First Row of Data"

Range("AA2").Value = "Last Row of Data"

Range("Z3").Value = 3

Range("AA3").Value = f - 1 
With Range("Z4", "AA10")

.Merge

.HorizontalAlignment $=$ xlLeft

.Value $=$ "Instructions: 1)Insert New Graph " \&

"2)Use column of Time Values as X Values " \&

"starting from 'First Row of Data' to 'Last Row of Data' " \& vbCrLf \&

"3)Select any other column for Y Values " \&

"starting from 'First Row of Data' to 'Last Row of Data'"

End With

'AutoFit all the columns

Columns("A").AutoFit

Columns("B").AutoFit

Columns("C").AutoFit

Columns("D").AutoFit

Columns("E").AutoFit

Columns("F").AutoFit

Columns("G").AutoFit

Columns("H").AutoFit

Columns("J").AutoFit

Columns("K").AutoFit

Columns("L").AutoFit

Columns("M").AutoFit

Columns("N").AutoFit

Columns("O").AutoFit

Columns("P").AutoFit

Columns("R").AutoFit

Columns("S").AutoFit

Columns("T").AutoFit

Columns("U").AutoFit

Columns("V").AutoFit

Columns("W").AutoFit

Columns("X").AutoFit

Columns("Z").AutoFit

Columns("AA").AutoFit

End Sub 


\section{Appendix E: Download and Setup Instructions for WattPlot Monitor}

The following is a comprehensive list of instructions to download and setup a free viewer version of WattPlot Monitor. This will allow a user to remotely monitor the Solar Decathlon House by piggybacking onto the primary computer from a secondary computer.

\section{Download Instructions for WattPlot Monitor (Viewer Functionality Only)}

Step 1) Go to: http://wattplot.com/wattplot.htm\#download

Step 2) Click on selection corresponding to the Windows version of your computer.

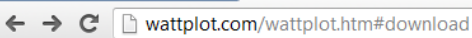
SOFTWARE Available for DOWNLOAD: (or click here for free updates to existing copies.)

2. Remote program to capture inverter performance data for a remote Monitor program with access to shared files. Free!

3. Test/Data Capture program to confirm MATE connections, show raw data, and capture data for simulations. Free!

Click your operating system below to go to the DOWNLOAD PAGE:

Windows XP downloads

Windows Vista downloads

Windows 7 downloads

Windows NT downloads (now OBSOLETE)

Windows 98 downloads (now OBSOLETE)

Windows 2000 downloads (now OBSOLETE

Windows Server 2003 downloads

Windows ME downloads
} 
Step 3) Click on the first selection: "Monitor program."

Note: Although it says that you need an activation key to run the software, you do NOT need an activation key if you just want to use the "Viewer program functionality."

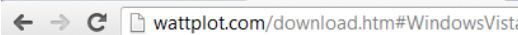

Possible WattPlot Downloads for Windows Vista and Windows 7:

Windows Vista and Windows 7 are supported operating systems for the WattPlot programs, assuming the following: The PC must be running Vista Service Pack 2 or later, the install must be performed in Administrator mode, and WattPlot should be run in XP-compatible mode.

1. Monitor program to capture, display, plot, and log inverter performance data from an Outback MATE. The Monitor download is the same for both WattPlot and WattPlot PRO, and is all you need for a typical installation!

NOTE: You need an activation key from us to run this software. The key is based on a unique PC ID (derived from your specific computer and Mate) that will be displayed to you when the software is first run. Email us that unique ID, and we will send you an evaluation key (usually within 24-48 hours), good for a fully functional trial of 15 days or more.

Download Monitor program (for Vista or 7) (includes Viewer program functionality)

2. Test/Data Capture program to confirm MATE connections, show raw data, and capture data for simulations.

Download Test/Data Capture program (for Vista or 7) (FREE and included with above Monitor download)

3. VisualMATE program to give a unique animated view of production and power flow. WattPlot VisualMATE is Careware, with no fee or activation required.

Download VisualMATE program (for Vista or 7) (FREE - donation suggested)

4. Remote program to capture inverter performance data for a remote Monitor program.

Download Remote program (for Vista) (FREE)

Step 4) Follow instructions to start the download process for your personal computer.

Step 5) Follow the images below to complete the downloading process.

Note: Any changes to Directory or Program Group can be made at the user's discretion.

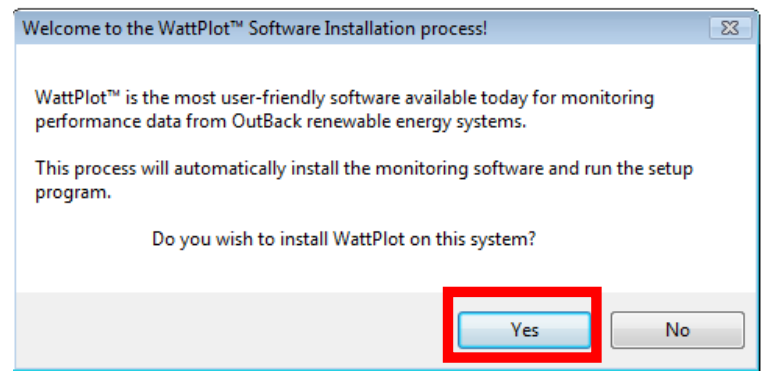

Page 100 


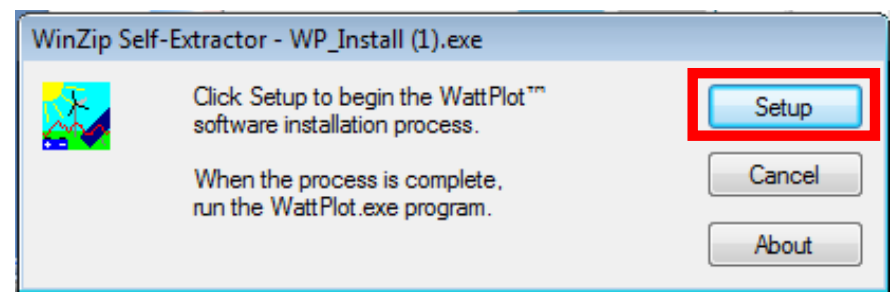

WattPlot Monitor Setup

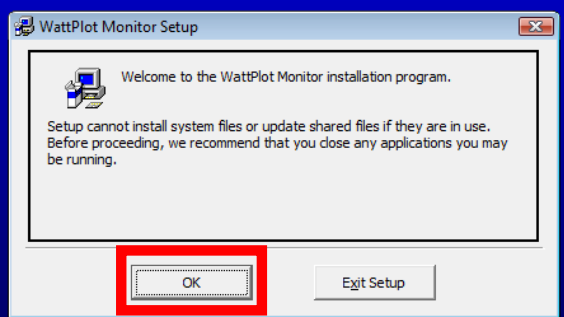

Page 101 


\section{WattPlot Monitor Setup}

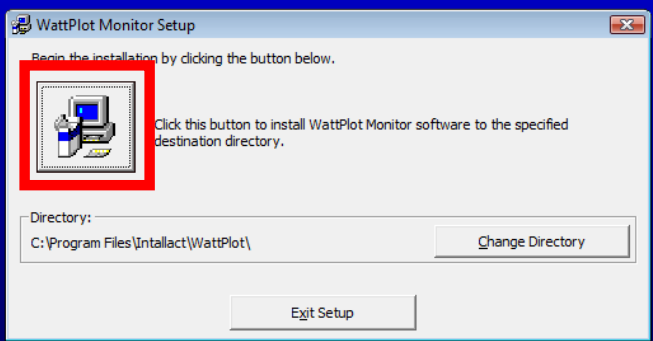

\section{WattPlot Monitor Setup}

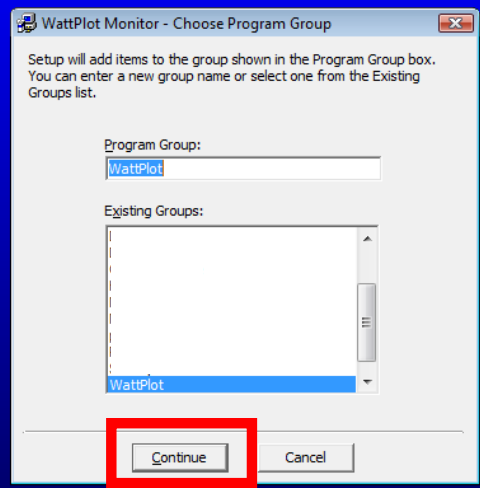

Page 102 


\section{WattPlot Monitor Setup}

WattPlot Monitor Setup

WattPlot Monitor Setup was completed successfully.

Page 103 


\section{Setup Instructions for WattPlot Monitor (Viewer Functionality Only)}

Step 1) Open WattPlot Monitor through the Start Menu

Step 2) Accept Terms of Use

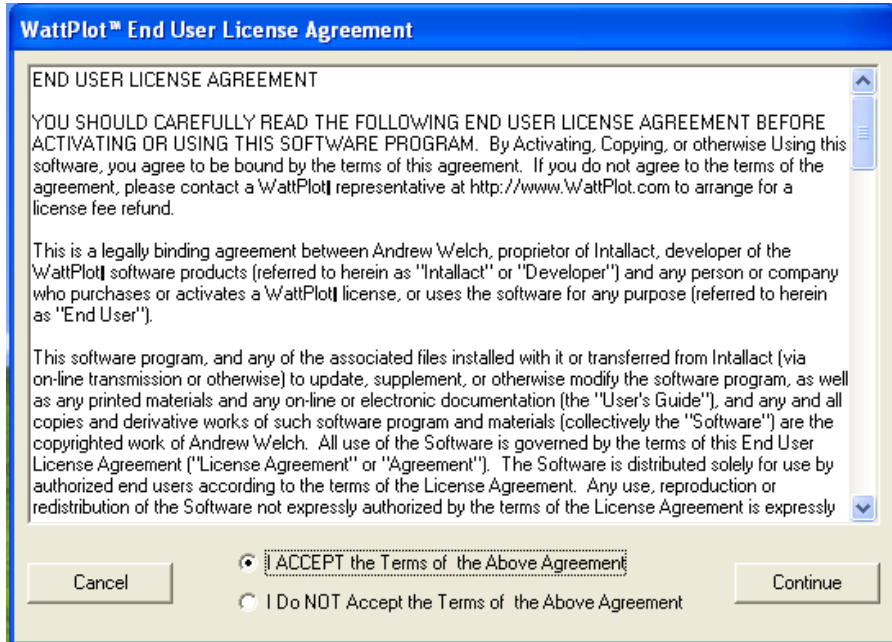

Step 3) It is up to the user whether or not to open the WattPlot User's Guide for more assistance with setup.

Welcome to WattPlot!

? This is the installation and licensing process for the WattPlot Monitor program.

We strongly recommend that you refer to the setup instructions in the User's Guide that was installed with this product.

You should find a copy of the WattPlot User's Guide at

C:',Program Files'Intallacti'WattPlot'Users_Guide.pdf

Would you like WattPlot to attempt to open the User's Guide for you now?

(** NOTE ** that the installation process will continue but may be hidden by the User's Guide!)

Yes No


Step 4) When asked for the OutBack MATE serial number, press the CANCEL button. This will run WattPlot Monitor in the FirstMATE Viewer Mode.

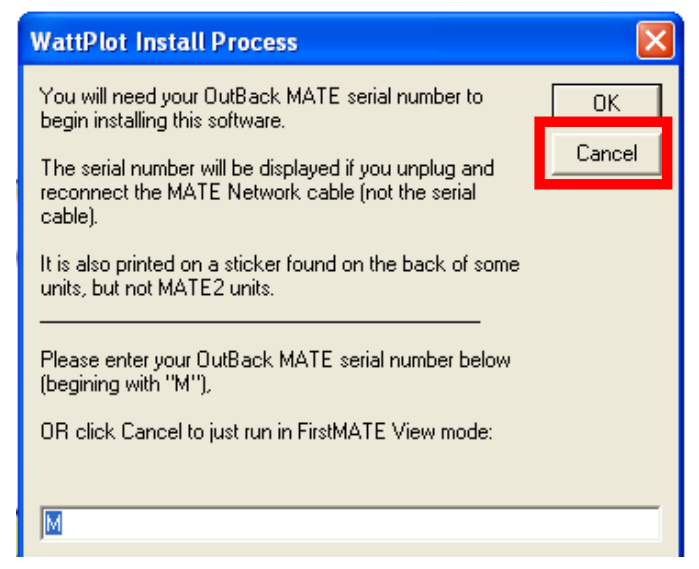

Step 5) The next windows will ask if you have internet and email capabilities in order to setup WattPlot's email application. It is up to the user's discretion whether to install it or not. If the user will only be using WattPlot Monitor on a secondary computer in FirstMATE Viewer Mode to monitor a primary computer, then I would suggest to not install WattPlot's email application.

Step 6) Finally, WattPlot Monitor will open up. Go to File $\rightarrow$ Monitor by Piggy-Back...

Step 7) In the Add New System window, enter a System Name then press Add. I would suggest a name such as "Cal Poly Solar House."

Note: A new window will appear that says, "You can now copy the client's Configuration file (solrwind.ini) and other data files to this computer." It is not necessary to add these files unless you have a licensed version because this is used for data logging.

Step 8) Go to Options $\rightarrow$ MATE Data Source...

Step 9) Select TCP/IP. The user must enter the IP Name/Address, IP Port, and password given by the primary computer. For this information, please contact Dr. Dale Dolan. 
Once this information is entered, click Test. If a data stream appears in the white box, then a connection has been made, so press OK. If not, see note below.

Note: If you are not able to make a connection, then you should check your internet connection first and then make sure you have the correct IP Name/Address and IP Port second. If internet connection is lost and reestablished on the primary computer (the computer connected directly to the MATE2 at the system site), then the IP Name/Address or IP Port could have changed.

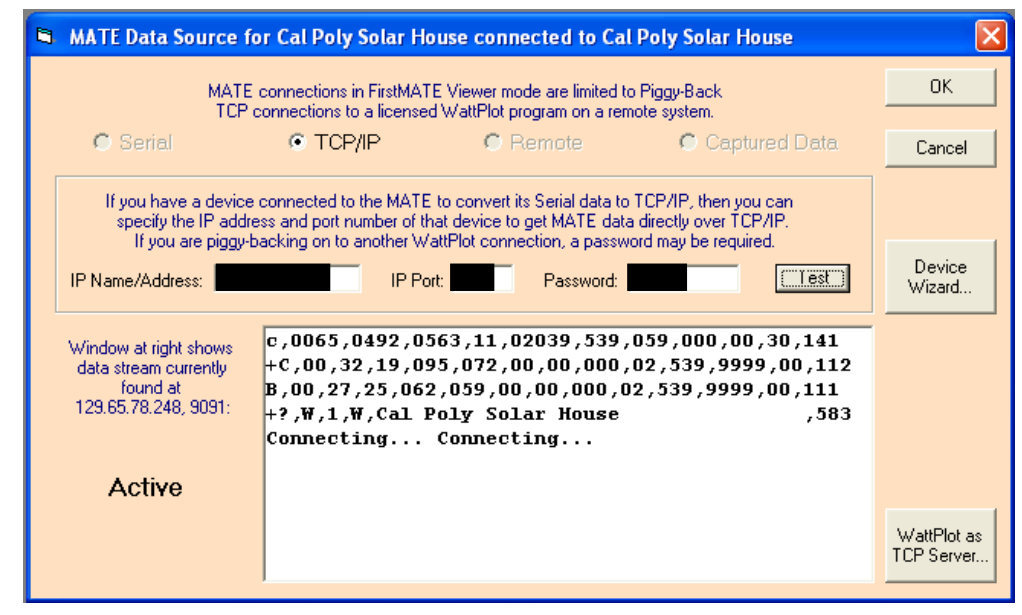

Step 10) Next, a window with the WattPlot Device Wizard Results will appear and give a summary of the devices in the system you just connected to. Click Next.

Step 11) Next, a window stating that WattPlot has received the system configuration will appear. Click Finish.

Step 12) Then, a window displaying the components and their specifications will appear. The user can flip through the components to see their information. However, since this is just a "piggy-backed" system, the user will not be able to make changes from the secondary computer.

Note: Once Close is selected, the entire program will close then reopen. 
Step 13) Finally, go to File $\rightarrow$ Begin Receiving MATE Data from TCP/IP. Real-time data of the Cal Poly Solar Decathlon House will begin to be displayed. For any desired changes to pen-plot scales, window selection, or anything else, please see the WattPlot User's Guide which can be found at http://wattplot.com/Users_Guide.pdf. 